1618. Colon. fol. In Bibliotheca Magna veterum Patrum 14 voll. T. III.

1624. Paris. fol. In Bibl. M. Patrum. 10 voll.

1644. Paris. fol. In Bibl. Magna Patrum. 17 voll. T. V. 1654. Paris. fol. In eadem. T. V.

*1671. Cantabrig. 8. In Opuseulis mythologicis, ethicis et physicis Graece et Latine [ed. Tho. Gale] sub titulo: Sexti Pythagorei Sententiae e Graeco in Latinum a Ruffino Versae et Xysto Romanae Ecclesiae Episcopo Falsò attributae. Cant. ex off. J. Hayes. 1670. pp. 12.

*1677. Lugd. fol. In Maxima Bibl. Patrum. 27 voll. T. III. p. $335-339$.

*1688. Amst. 8. In Opusculis myth. cet. [iterum ed. Tho. Gale]. Ap. Henr. Wetstenium p. $645-646$.

1693. Amst. 12. THEOLOGIAE | CHRISTIANAE | juxta Principia | Iacobi Bohemii | Teutonici | Idea brevis \& methodica. Accedunt Sextii Pythagorei Sententiae. Ex typogr. Boetemanni-s. a. pp. 66. Annum sumo e Fabricii Bibl. Gr. ed. Harles I 874.

*1725. Lps. 4. Ed. Urb. Gdfr. Siberus. v. s. p. XIV.

*1819. Lps. 8. In Opusculis Graecor. veterum sententiosis et moralibus Gr. et lat. coll. Io. Conr. Orellius. T. I. p. 247-268.

*1843. Paris. 8. Sentences de Sextius, philosophe Pythagoricien; Traduites en français pour la première fois, accompagnées de notes, précédées de la doctrine de Pythagore, de celle de Sextius, Et suivies de la vie d'Hypathie. Par le $\mathrm{C}^{\text {te }}$ C.-P. de Lasteyrie. Pagnerre éditeur. pp. 304. v. s. p. IX.

*1860. Paris. 8. In Fragmentis philosophorum Graecorum coll. F. G. A. Mullach. A. F. Didot. I 523-531.

\title{
Veterum testimonia.
}

Origenes c. Cels. VIII p. 397 Spenc. 、 (versus a. 250.)

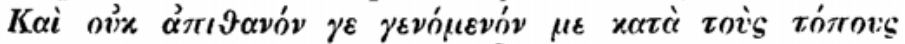

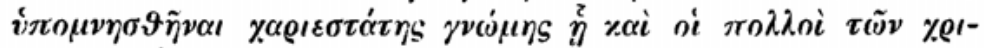

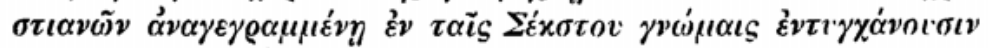

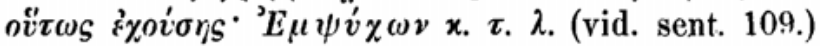

Idem, in Matth. 19, 3.

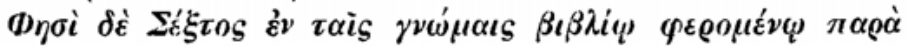

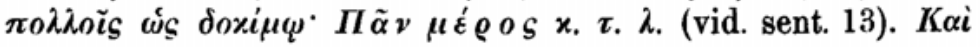




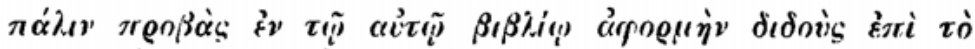

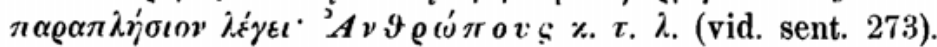

Rufini prologus.

Scio quia, sicut grex ad vocem pastoris accurrit, ita ct religiosus auditor vernaculi doctoris commonitionibus gaudet. Quia ergo karissime fili Aproniana religiosa filia mea, soror tua in Christo, poposcerat me, ut ei aliquid quod legeret tale • componerem, ubi neque laboraret in intellegendo et tamen s proficeret in legendo, aperto et satis plano sermone: Sextum in Latinum verti, quem Sextum ipsum esse tradunt, qui apud vos id est in urbe Roma Xystus vocatur, episcopi et martyris gloria decoratus. Hunc ergo cum legerit, inveniet tam brevem ut videat singulis versiculis ingentes explicare sensus, tam in vehementem ut unius versus sententia ad totius possit perfectionem vitae sufficere, tam manifestum ut ne absens quidem legenti puella expertem se intellectus esse causetur. Omne autem opus ita breve est, ut de manu eius nunquam possit

Prologum (ta vocant QUer, praefationem rell.) omittunt AWw. Rufinus Prb. Minisio P: Rufinus presbiter Th coo C: Rufinus Aproniano filio S. P. D. c: Rufinus Aproniano suo s. p. d. r: nilil praemittunt QLOVBJSMAU.

1 quoniam grex Je: grex sicut $\mathbf{A} \mid$ pastoris QP: proprii pastoris LOVBJSCMGUer | libenter accurrit OVGr: libenter occurrit U || 2 pastoris BMJe | almonitiombus LBMJer || 3 Aproniana LOPBJSCG: Aproniane $\mathbf{Q}$ ? MUer et $\mathbf{L}$ a sec. manu | religiosa filia mea om. Je: religiosa om. LOPSBCM | soror iam in Christo tua LOPVBJSGUMr: soror iam tua in Christo C: om. C || 4 poposceras B | me Q: a me rell. | ei om. CGU || 5 laboret J | intellegendo LOPVBJC | tam V || 6 profiteret QP in om. OPBSC | et tamen proficeret in legendo om. er: laboraret in legendo et (tamen $\mathbf{U}$ ) proficeret intellegendo $\mathbf{G U} \mid$ aperte $\mathbf{V} \mid$ et aperto et satis U | satis om. PSe | ae B || 7 Sixtum Gr: Sixtum Pythagoricum C | converti P | Sixtum Ger: Syxtum P | ipsum om. OPSC: episcopum c | esse om. GU | apud nos MJe || 8 id est QLVBU: idem OJSGr: om. PCMe | Romana LOPBMJer | Xystus Q0: Syxtus LPVBJSM: Sixtus CGUer | episcopus $\boldsymbol{G}$ : et episcopus $\mathbf{U} \| \mathbf{9}$ decorus $\boldsymbol{G}$ | Hunc vero $\mathbf{L J M G e r}$ invenit S: tam br. inven et C || 10 versibus LOPBJSCMer | explicari JSCUMer $\| 11$ vehementer 0 i unius Q: ut (sic) C: om. rell. | totius hominis $\mathbf{U}|| 12$ vitae om. GU | man.] maximum $\mathbf{c}$ | ne absens $\mathbf{Q}$ : ne assistens LOPSCGU: ne assis (sic) JM: nec assistens VBr: om. e | quidam OB: quid M: orn. C || 13 puella QG: puellae rell. | expertae $0 \| 14$ enim U tam br.- GU | est om. PVBGr | de om. G: a $\mathbf{U}$ | nuuq. sit necesse rec. SC 
recedere totus liber, unius pristini alicuius pretiosi anuli optinens locum. Et revera aequum videtur, ut, cui pro verbo dei terrena ornamenta sorduerunt, nunc a nobis ad vicem verbi et sapientiae monilibus adornetur. Nune ergo interim habea5 tur in manibus pro anulo liber, paulo post vero in thesaurum proficiens totius servetur disciplinae bonorum actuum commonitiones de intimo suggesturus arcano. Addidi praeterea et electa quaedam religiosi parentis ad filium, sed breve totum, ut merito onne opusculum vel enchiridion si Graece vel antso lus si Latine appelletur.

1 liber Q: hic liber rell.| unius pristini Q: ibı pristim $\mathbf{V r}$ : unıus B : utramque vocem om. LOPJSCMGUe | pretiosi anuli optinens l. QLVBM : pretiosi optinens auuli 1. Oer: pretiosı anuli optinet l. PSCJ : anuli optineus 1. G: anull l. optinet $\mathbf{U}\|\mathbf{2} \mathrm{cum} \mathbf{L B}\| 3$ sorduerunt Q: -rant rell.: -rint a sec. manu (propter cum) L | vobis $\mathbf{L} \mid$ ad invicem JSU $\| 4$ et om. SC adornentur $\mathbf{Q}$ | ergo om. J | habetur $\mathbf{S}|| \mathbf{5}$ liber iste $\mathbf{C}$ | post om. $\mathbf{C}$ : thesauris SC || 6 proficiscens $a$ sec. manu $\mathbf{V}$ : proficens $\mathbf{C}$ | totius QLOPBSCU: totis MJe: totus VGr | serv. in corde omnes praeter $\mathbf{Q}$ | disciplinae bouorum actuun commonitiones $\mathbf{Q}$ : disciplinis et bonorum actuum communiones MJe: sermo disciplinae et bonorum actuum- communio PSC | sermonis disciplinae et bonorum actuum communionis LOB et $\mathbf{V}$ a prima manu, sed a sec. sermones eṭ communiones; in $\mathbf{L}$ sec. m. voluit communiones: ita, sed sermones et comnunionis $\mathbf{r} \| \mathbf{7}$ de - arc. om. $\mathbf{S}$. suggessurus OPB | Post arcano Q: Explicit prologus feliciter. | Addidi praeterea et electa (elata S) OVBSU: haec omnia. Addidi praeterea telata (sic) P: haec omnia reddidi. praeterea et electa C: Addidi et elceta LMJr: Addidi et $\mathbf{e} \| 8$ totum] id tamen $\mathbf{U} \| 9$ vel om. $\mathbf{U}$ | vel anulus si latine P: vel sı lative anulus MJe: vel latine anulus LOVBGUr: vel anulus vocetur si latine app. SC || 10 vocetur $\mathbf{U} \mid$ Vale in fine addunt praescriptione respondens $\mathbf{P C r}$ Vall.)

Hieronymus adv. Iovimian. I in fin. (IV, 192 Mart. II 318

Unde et Sextus ${ }^{1}$ ) (v. I. Xystus) in sententiis, adulter est, inquit, in suam uxorem amator ardentior.

Jdem in Ezech. VI, 18 (III 821 Mart. V, 206 Vall.) a. 414.

Pulchre in Xysti Pythagorici sententiolis dicitur: adulter est uxoris propriae amator ardentior. Quem librum quidam in latinam linguam transferens martyris Xysti nomine voluit illustrare, non considerans in toto volumine, guod in duas partes Prustra divisit, III 434.

1) Male Hatsius e coniectura 'Sextius' edidit in Senecue operibus 
Christi nomen et apostolorum omnino reticeri. Nec mirum, si gentilem philosophum in martyrem et Romanae urbis episcopum transtulerit, cum Eusebii quoque Caesariensis primum pro Origene librum Pamphili martyris vocabulo commutavit, ut facilius tali laudatore libros impiissimos regi cuyyiù Romanis conciliaret auribus.

Idem in lerem. IV, 22 (III 632 Mart. IV, 993 Vall.) a. 415.

Miserabilis Grunnius. qui ad calumniandos sanctos viros aperuit os suum linguamque suam docuit mendacium, Sexti Pythagorei hominis gentilissimi. unum librum interpretatus est in latinum divisitque eum in duo volumina et sub nomine sancti martyris Xysti urbis Romanae episcopi ausus est edere: in quibus nulla Christi, nulla spiritus sancti, nulla Dei patris, nulla patriarcharum prophetarum et apostolorum fit mentio et hunc librum solita temeritate et insania Anulum nominavit, qui per multas provincias legitur et maxime ab his qui $\dot{a} \pi \alpha \dot{y} y \varepsilon u \nu$ et impeccantiam praedicant. Quomodo igitur dominus Iechoniam instar anuli de manu sua et digito se proiecturum comminatur, ita lectorem obsecro ut nefarium librum abiiciat legatque, si voluerit, ut ceteros philosophorum libros, non ut volumen ecclesiasticum.

Idem epist. ad Ctesiphontem (n. 43. IV 476 f. Mart. n. 133. I J 030 Vall.)

a. 415 .

Illam autem temeritatem, immo insaniam eius quis digno possit explicare sermone, quod librum Sexti (v. l. Syxti, Xysti, Xesti) Pythagorei hominis absque Christo atque ethnici immutato nomine Sixti (v. 1. Xysti) martyris et Romanae ecclesiae episcopi praenotavit: in quo iuxta dogma Pythagoricorum, qui hominem exaequant deo, et de eius dicunt. esse substantia, multa de perfectione dicuntur, ut qui volumen philosophi nesciunt sub martyris nornine bibant de aureo calice Babylonis: Denique in ipso volumine nulla prophetarum, nulla patriarcharum, nulla apostolorum, nulla Christi fit mentio, ut episcopum et martyrem sine Christi fide fuisse contendat. Unde et vos plurima contra ecclesiam usurpatis testimonia. Fecerat, hoc et in sancti Pamphili martyris nomine, ut librum primum sex librorum defensionis Origenis Eusebii Caesariensis, quem fuisse Arianum nemo est qui nesciat, nomine Pamphili martyris praenotaret, quo scilicet egregia illa quatuor Origenis negi ćoycìv volumina latinis infunderet auribus.

Augustinus de natura et gratia e. 64 (77). $\quad$ a. 415 .

Quis item Christianus ignorat, quod beatissimum Sixtum (v. l. Xystum), Romanae ecclesiae episcopum et domini martyrem dixisse commemorat [Pelagius]-quia libertatem arbitrii sui permisit hominibus deus ut pure et sine peccato viventes similes fiant deo [s. 36]. Sed ad ipsum arbitrium pertinet vocantem audire et credere et $\mathbf{a b}$ eo in quem credit non peccandi adiutorium postulare. Nam utique cum dicit, similes fiant deo per caritatem dei futuri sunt similes deo quae diffusa est in cordibus nostris non naturae possibilitate nec libero arbitrio quod est in nobis sed per spiritum sanctum, qui dutus est nobis [Rom. 5,5]. Et quod dicit idem martyr: templum 
sanctum est deo mens pura et altare optimum est ei cor mundum et sine peccato [s. 46]: quis nescit ad istam perfectionem perducendum cor mundum, dum interior homo renovatur de die in diem, non tamen sine gratia dei per Iesum Christum dominum nostrum. Item quod ait ipse: vir castus et sine peccato potestutem accepit a deo esse filius dei [s. 60]: utique admonuit, ne cum quisquem factus fuerit ita castus et sine peccato (quod ubi et quando in eo perficiatur nonnulla quaestio est, sed inter pios bene quaeritur, inter quos tamen constat fieri posse et sine mediatore dei et hominum homine (hristo Iesu fieri non posse) tamen ut dicere coeperam, prudenter Sixtus admonuit, ne cum fuerit quisquam talis factus et per hoc recte inter filios dei deputatus putetur ipsius.fuisse potestalis, quam per gratiam accepit [s. 60] a deo, cum eam non haberet in natura iam vitiata atque depravata, sicut in evangelio legitur: quotquot autem receperunt eum dedit eis potestatem filıos dei fieri [1o. 1, 12] quod utique non erant per naturam nec omnino essent nisi eum recipiendo accepissent per eius gratiam huiusmodi potestatem. Haec est potestas quam sibi vindicat fortitudo caritatis, quae non est in nobis, nisi per spiritum sanctum qui datus est nobis.

liem Retractat. 1. II c. 42 .

a. 427 .

Venit etiam- tunc in manus meas quidam Pelagii liber, ubi hominis naturam contra dei gratiam qua iustificatur impius et qua ('hrıstiani sumus quanta potuit argumentatione defendit. Librum ergo quo huic respondi, defendens gratiam non contra naturam, sed per quam natura liberatur et regitur, de natura et gratia nuncupavi. In quo verba quaedam quae velut Sixti (v. l. Xysti) Romani episcopi et martyris Pelagius posuit ita defendi, tanquam revera eiusdem Sixti essent, id enim putaveram, sed postea legi Sexti philosophi esse, non Xysti christiani.

Gelasii decretum VII 24 (Credner Zur Gesch. d. Kanons. 1847 p. 218).

a. 492 .

Liber proverbiorum, qui ab haereticis conscriptus et sancti Xysti nomine praenotatus est, apocryphus.

139 Arev.).

Isidorus, qui perhibetur, de viris illustribus c. I (VII

Xystus episcopus Romanae urbis et martyr composuit ad instar Salomonis librum proverbiorum tam brevi eloquio ut in singulis versibus singulae explicentur sententiae. Cui quiden opusculo haeretici quaedam contra ecclesiasticam fidem inseruerunt, quo facilius sub nomine tanti martyris perversorum dogmatum reciperetur assertio. Sed is qui catholicum sese meminit, probando legat et ea quae, veritati contraria non sunt recipiat. Quidam autem putant eundem librum ab haereticis, non a Xysto, fuisse dictatum. Refellit autem hanc opinionem beatissimus Augustinus, qui in quodam opere suo ab eodem martyre hoc opus compositum esse fatetur. 
1 (1) *Fidelis homo electus homo est.

2 (2) *Electus homo homo dei est.

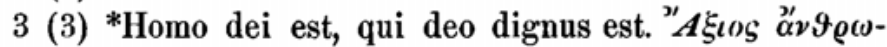

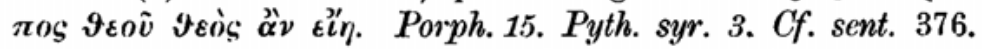

4 (4) *Deo dignus est, qui dignum deo agit.

5 *Studens fidelis esse nihil, quod deo indignum est, agas.

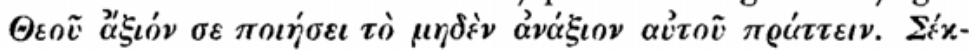
бזกv Georg. 43. Porph. 15. Max. 1. Agapet. 3.

$6(5)$ *Dubius in fide infidelis.

2 dei est homo $\mathbf{G} \mid$ Alterum homo om. WW $\| 3$ homo deus secundum Porplyrium legere voluit Boiss. Anecd. I 155 || 4 dignum deo A : nihil indignum deo Qc: nihil inđigne WOPVGwr || 5 studens fidelis esse AQ: deo studens fidelis esse WOVBGewr: deo studens dignus esse $\mathbf{P}$ | nihil quod] qui $\mathbf{A} \| \mathbf{6}$ infidelis $\mathbf{A Q}$ : infidelis est WOPVBGwr| in fide male in sent. 7 transfert A | infidelis. 7 Infidelis homo om e.| quia dubius in fide infidelis est Pseudo-Isid. Sixti f ep. 1, 3 (p. 107.) Iul. ep. 12 (p. 468). Capit. Angilr. 3.

1-3. Syr. II 10, 23 consone. Syr. I 2, 2 pro sententiis prima et secunda praebet: Deus propter dignitatem operum ereditur verus deus esse et homo propter praestantiam operum ereditur esse sincere fidelis. Tertiam mox post vigesimam exhibet: Qui renuntiat mundo et affectibus et per fidem suam sapiens est, deus inter homines est, magis igitur sententiae 376 et Porphyrio respondentem.

4. II 18, 24: Dignus deo est, qui nil facit quod deo non placet.

5. II 10, 25: Si igitur animus tuus fidelis esse studet, nil facias quod deo dignum non sit.

6. II 10, 26: Quicunque modicae fidei (Mt. 6, 30 etc.) est, fidelis non est. I 2, 5: Qui modicae fidei (prorsus ut Pesh. et Nitr.) est, in hac sua fide infidelis est. 
7 (6) *Infidelis homo mortuus in corpore uiuenti.

8 (7) *Uere fidelis est qui non peccat.

9 (7) *Etiam in minimis caute age.

10 (8) *Non est minimum in uita hominis neglegere mi-

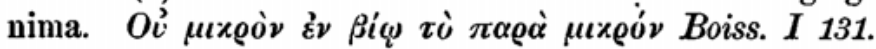

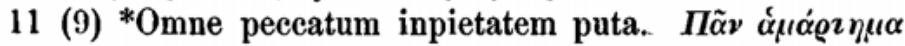

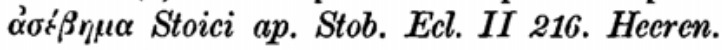

$12(9)$ *Non manus aut oculus peccat aut aliquod huiusmodi membrum, sed male uti manu uel oculo.

7 Infidelis in fide $\mathbf{A}(c f . s .6) \mid$ in corpore viventi AQ: est in corpore vivente W(-ti) POVB(-ti) Gewr cum Pseudo-Isid. (var. -ti) Calist. ep. 1,4 (p. 136) Melch. 1, 5 (p. 249) \| 9 age AWOVBB' $\mathbf{A W}^{2}$ : agas $\mathbf{w}$ : agit QPre | minimis]imis Q || 10 in vita homini $\mathbf{A}$ et ut vill. $\mathbf{G}$ : in vita hominis $\mathbf{e}$ : in vita hominum WPVBB'rw: in humana vita $\mathbf{Q}$ (?) O (?) | minima]anima A: animam e || 12 Non AQ: non enim WOPVBre:

7. II 10, 27: Fidelis autem, qui etiam in fide sua probatus est, is deus est habitans in humano corpore vivo ( $c$. similem locum post sent. 82), et qui in fide sua certus non est, homo est mortuus, in corpore vivo habitans. I 2, 6: Mortuus est homo, qui cum damno suo in corpore vivit.

8. II 10, 30: Vere autem fidelis est homo peccatorum expers. I 2, 4 (ante sent. 6): Vere fidelis non is est, qui tantum non peccat, sed is qui etiam peccatoribus causa est, ut iusti fiant.

9. II 11, 1: et usque ad minimas vitae res prudenter agit. I 2, 7: Etiam usque ad minima caute age in vita tua, quia ex pauca palea ignis exardescit (Sirac. 11, 32 Syr.; in

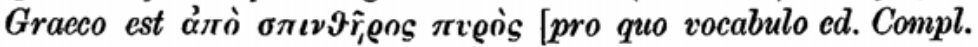
praebet $\mu \varkappa \varrho \dot{\alpha}\rfloor] \pi \lambda \eta \vartheta \hat{v} v \varepsilon \tau \alpha \iota \stackrel{\alpha}{\alpha} \vartheta \varrho \alpha x i \alpha)$. Et spiritalis omnia

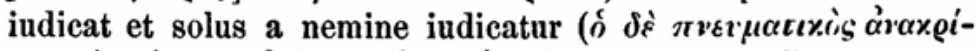

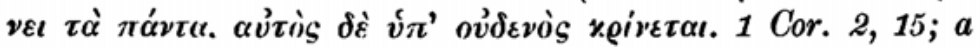
Simplice paulum recedit), sed ne a deo quidem arguitur.

10. II 11, 1: Fidelis enim neque parva neque magna vilipendit, sed omnes vitae suae res ad perfectionem adducit.

11. II postquam sententiam 283 eamque auctam inseruit, quam vide suo loco, 11, 8: Omne enim peccatum contrarium

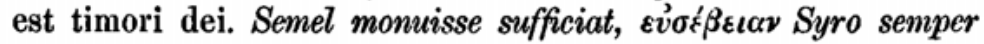
esse timorem dei.

12. II 11, 8: Non oculus peceat, neque manus, nec ullum 
13 (10) *Omne membrum corporis, quod suadet te contra pudicitiam agere, abiciendum. melius est enim sine uno membro

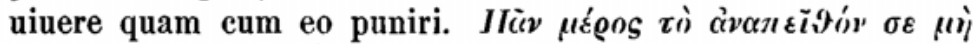

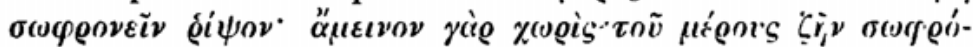

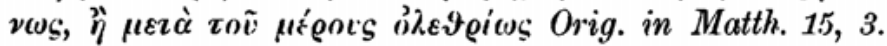

14 (11) *Inmortales tibi crede manere in iudicio et honores et poenas.

15 (12) *Quicquid saeculi habes, etiam auferat tibi quis, non indigneris.

16 (13) *Te ipsum reprehensibilem mundo non praebeas.

quum $\mathbf{W}$ | aut AQ: vel rell. | aliquod AWGVer: aliquid Q0PB | uti rell. utens $\mathbf{C} \mid$ peccatum est in fine add. Vr | male on. Of | sed male - corporis om. W \| 13 corporis om WB ! abiciendum AGr: abiciendum est QWOPVBew | sine AQG(: sine membro vivere uno) w: cum WOPVBer eo AQWO(in quo ante e et ipsam in rasura collocatam erasa videtur d) PVBGw: dnobus er, quod e Mt. 18, 8 sumpserunt. I In fine $\mathbf{G}$ habet: perire vel puniri, in quo vera lectio Graeco et Syro consentanea servata aut coniectando restituta videtur; puniri e loco Mt. 18.8 ortum esse potest. If 14 tibi crede AQer: crede tibi WOPVB(xw | manere A: permanere rell. (in iudicio permanere $\mathbf{P}) \mid$ et - et AWVB(ter: aut - et 0: aut - aut $\mathbf{P}$ : primum et om. $\mathbf{Q}($ ?) | in iudicio et om. $\mathbf{W} \| 15$ tibi om. V | auferet $\mathbf{O}$ | quis tibi auferat $\mathbf{G}$ || 16 Sic AQGVe: inreprehensibilem

membrum aliud, sed id, quod contra legem per haec membra patratur, peccatum est.

13. II 11, 10: Propterea quodvis membrum corporis, quod a castitate abstrahere te vult, abiice abs te. Melius est caste (acopeóvcus, ut Origenes) sine uno menbro vivere, quam totum cum illo membro abire in interitum sempiternum.

- 14. II 11, 13 Scias autem et videas, rationen tibi in iudicio reddendam esse ( $c f . E c c l .11,9)$; propterea ne libidine corporis te contamines, et scias, tum eos, qui cruciantur, sine morte esse in cruciatu, tum consilia, quae apud deum asservata sunt, aeterna esse; nam dona illius diei aeterna sunt- et decretum iudicii eius aeternum est.

15. II 11, 17: Tota mundi huius transeuntis possessio si abs te aufertur, ne aegre feras. Repetit idem post s. 91 p. 13, 20: Quod ex hoc mundo abstulisti, si aufert a te mundus, ne aegre feras.

16. II 11, 19: Vide autem cave, ne ipse tu irretiaris 
17 (14) * Omnia auferenti abs te cede praeter libertatem.

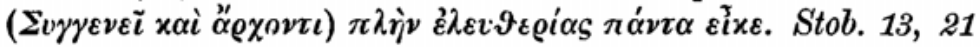
(Pyth). Demoph. 42. Pyth. syr. 75.

18 (15) *Sapiens vir et contemptor pecuniae similis deo

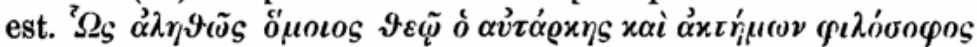
Boiss. III 470 ( $\alpha_{\nu}^{\prime}$ †

19 (16) *Rebus saeculi in causis tantum necessariis utere.

20 (17) *Quae saeculi sunt, saeculo, et quae dei sunt, deo.

21 (18) *Certus esto, quia animam tuam depositum fidele acceperis a deo.

mundo praebeas B: inreprehensibilem mundo non praebeas WOPw, quod P illustrat superscriptis verbis: -i. non te laudes illi | mundo om. $\mathbf{r}||$ 17 Omnia AQOPewr: omni WVBG | abs te AQ: a te rell. | quid abs te $\mathbf{Q}$; voluit igitur omui | o. tibi auferenti ante (sic) $\mathbf{e} \mid$ per libertatem $\mathbf{A} \|$ 18 deo est AQVG: est deo WOPBewr il 19 necessariis tantum Q: necessariis om. G ||. 20 saeculo relinque, quae dei sunt, deo redde $\mathbf{w}$ | deo] reddantur deo $\mathbf{r}|| 21$ quia $\mathbf{A}$ : quod rell. | tuam depositum AQVGr: tuam id est depositum WOPew: tuam in depositum $\mathbf{B}$ | a deo acceperis $\mathbf{w}$

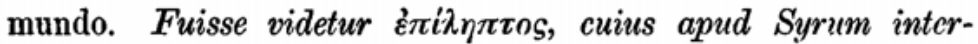
pretatio ad sent. 15 et 17 magis accommodata est.

17. II 11, 20: Si omne, quod extra te est, abs te aufertur, ne aegre feras, praeter solam libertatem tuam, quam ne reddas servitutem.

17a . Addit II 11, 21: Coram quovis, qui dux tibi esse vult, humilia te. Habuit ergo similem sententiam: Nó $\mu \omega^{\prime}$ xai

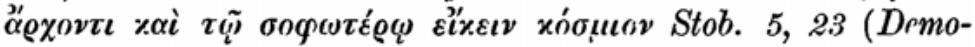
criti). Democrat. 13. Max. 49. 58. Ant. I 67. I1 73 (qui eum ad Isocratis, Epicteti et Democr. collectionem retulerunt). Flor. Mon. 37.

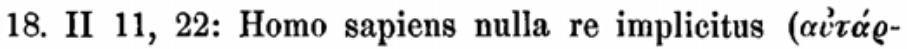
$x \eta s)$ deo similis est.

19. II 11, 22: Magis quam omnibus rebus tuis utere iis, quae coram deo magni aestimatae et pretiosae sunt. I 2, 9: Rebus huitus mundi non utere nisi pro necessitate tua.

20. II 11, 23: Per ea, quae huius mundi sunt, mundo servi et per ea, quae dei sunt, prudenter deo servi. I 2, 10: et redde mundo sua et deo sua.

$20^{2}$. Addit II 11, 25: Sed scias eius quod concupiscis te

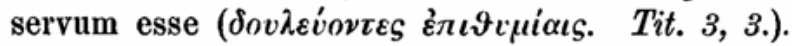

21. II 11, 26: Ne animum tuum propter corporis libidinem 
22 (19) *Cum loqueris de deo, scito, quia indiceris a deo.

23 (20) *optimam purificationem putato nocere nemini.

$24(21)$ *Anima purificatur in uerbo dei per sapientiam.

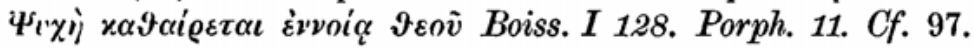

25 (22) *Numquam putes dei substantiam insensibile esse.

26 (23) *Déus sicut mens est, quae sponte mouetur, secundum hoc et subsistit.

27 (24) *Magnitudinem dei non inuenies, etiamsi pennis volare possis.

$28(25) *$ Nomen dei non quaeras, quia nec inueniès, quia

22 de deo] deo $\mathbf{G}$ | quia $\mathbf{A}$ : quod rell. | a deo] ab co e || 23 putato OVGer: putat A: puto WPB: putes $\mathbf{w} \mid$ nemini nocere 0 Pw: nemini noceri WB \| 24 in om. Q \| 25 putas 0 : coniectabis $\mathbf{w}$ | substantiam AQWOPBGw: sapientiam Ver | insensilbile A : insensibilem rell.| esse om. WOPBW | esse insensibilem $\boldsymbol{G} \| \mathbf{2 6}$ sponte movetur AQ: movetur sponte WOPVB(wwr: modo sponte $(s i c)$ e | haec er | subsistet Q\|

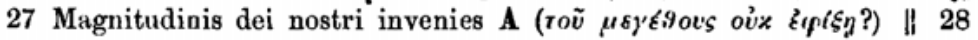
Non AWPVBGer: ne Q0w | nec AWPVBewr: non OG | quia nee invenies om. Q | omne om. G | nomine AVBGewr: nomen QW: nōm OP\| compellatur A: compellitur Q: appellatur rell. | meliori $\mathbf{W} \mid$ accepit AQWOPVBW : accipit Ger | alius alius AQer: aliud aliud WOPVBGw| vocetur B | audiatur c | qui om. Q | posuit AQ: imposuit WOPVBewr|

probro afficias, (cf. quae habuit 14), sed scias animum tuum esse depositum tibi a deo datum.

22. Nil apud Syros.

23. II 11, 27: Mens pura, quae omni rei praeferenda est, ea est, quae neminem malo afficit.

24. II 11, 29: Animus autem purificatur per verbum dei, quod sapientes effantur,

25. II 11, 30: Substantiam (síoí $\alpha$ ) ullam, quae careat sensu intellectus discernentis, ne quis tibi persuadeat a deo esse.

26. II 12, 1: Nam deus intellectus est per se ipsum liber

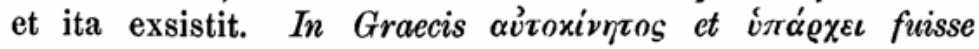
videtur.

26a . Addit II 12, 2: Deo divina conveniunt iisque gaudet et contentus fit.

27. II 12, 3: Magnitudinem divinitatis assequi nequis, etiamsi pennis velocibus volares.

28. II 12, 3: Nomen divinitatis ne quaeras, non enim 
omne .quod nomine compellatur a meliore nomen accepit, ut alius quidem vocet, alius autem audiat. Quis ergo est, qui nomen posuit deo? Deus non nomen est deo, sed inclicium

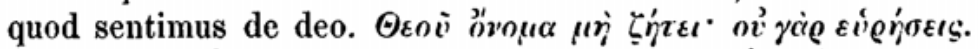

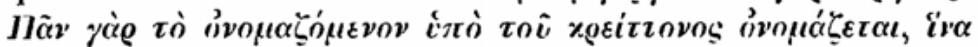

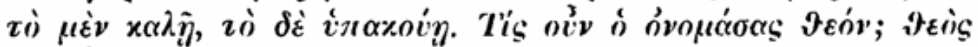

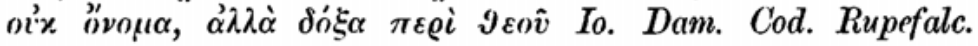
o, 1. II 785 e martyrio Babylac, cui hace tribuuntur.

29 (26) *Nihil ergo in deo quod non licet quaeras.

30 (27) *Deus sapiens lux est incapax contrarii.

deus non nomen est deo $\mathbf{A G}$ : d. autem non n. est deo WOPVwr: deus nomen est dei $\mathbf{Q}$ : d. autem non n. est dei Be | indietum $\mathbf{A}$ : iudicium $\mathbf{G}$ Abstemins. sed indicium e $\| 29$ in deo AQw: in denm WOPVBGer| quod libet V: quae licet $\mathbf{A} \| 30$ Deus AQer: om. WOPVBGw

invenis, nam omne, quod pronuntiatur, nominatur et appellatur, a deo qui omnibus praestantior est appellatur et nominatur, ut cognoseatur nominans et nominatus et qui imperat et qui obedit. Quis igitur est, qui ineffabili nomen ponat? Hoc autem nomen, quod deus appellatur, nequaquam verum dei nomen est, sed nomen hoc hominibus pro signo datum est laudandi nominis divini occulti causa, ut per hoc nomen, quod pronuntiatur, laudetur nomen dei occultum, quod non pronuntiatur. In actis S. Babylae, quae sccundo loco posucrunt Bollandi sodales AA. SS. Ian. II 57.4, hacc ita leguntur: Si te ad caelum perferret innumerus ordo pennarum et volatu ad astra pertingeres, tamen nomen dei scire non posses, nec enim vocatus a quoquam est aut appellatus aut visus, nisi quibus se ita prodidit, ut mortales oculi poterant sustinere. Nec enim deus nomen, sed virtutis (?) est gloria. Deus prudentiae via est, quae ducit ad vitam. Nihil ergo de eo quaerendum est, a quo omnia constant effecta. In Graccis igitur, unde hacc translata sunt, aderant etiam sententia 27 et 29. Priorem habet $\mathrm{Me}$ taphrastes in vita Babylae T. I p. 971 A. ed. Migne 1864 hac

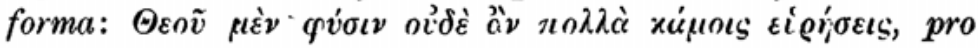
reliquis alia praebet.

29. II 12, 12: Quod igitur in deo non est, non quaeras in eo.

30. II 12, 12: Deus enim ortus est lucis sapientiae novae, quam nemo assequitur, nec naturam contrariam assumit. 
31 (28) *Quaecumque autem fecit deus, pro hominibus ea fecit.

32 (29. 30) *Angelus minister est dei ad hominem; non enim ministrat ad nullum; tam pretiosus est homo apud deum.

33 (31) *Primus beneficus deus; secundus est is qui beneficii eius fit particeps homo. Cf. 176.

34 (31) Uiue igitur tamquam qui sis post deum secundus et electus ab eo.

$35(32) *$ Habes in te aliquid simili dei ct ideo utere te ipso velut templo dei propter illud, quod in te simile dei.

$36 *$ Libertatem arbitrii sui permisit hominibus deus sine dubio, ut pure et sine peccato uiuentes similes fiant deo.

37 (33) *Reuereatur uitam tuam mundus.

38 (33) *Nihil admittas, quod tibi inurat notam.

39 (34) *Male uiuentes cum e corpore excesserint cruciabit malus daemon usque quo exigat ab eis etiam nouis-

31 autem om. G | ea om. G || 32 Ita AQ (Q: ministrat deus ad) | est om. WOPV: dei est BW | non enim ministrat ad nullum om. WOP VB(tewr | In fine addunt quam angelus WOPVBGer: quoniam angelus w || 33 beneficius $\mathbf{A}$ et a prima manu $\mathbf{Q}$ | est deus or $\mid$ beneficiis $\mathbf{Q}$ | sit $\mathbf{O}$ | particeps est e || $\mathbf{3 4}$ ita tamquam $\mathbf{W}$ | qui] quam $\mathbf{V}$ om. $\mathbf{G}$ | secundus om. WVBw || 35 Habes inquit $\mathbf{B}$ : habes inquam er | veluti $\mathbf{w} \mid$ templum Q | quod om. Q | simile est dei Qcr: est simile dei WOPB(iw : est in te simile dei $\mathbf{V} \| \mathbf{3 6}$ promisit Abstemius | hominibus deus AQ: deus hominibus rell. Laudat Augustinus De nat. et grat.c. 64, qui loabet hominibus deus \| 38 admittas] sit $\mathbf{w}$ | inferat $\mathbf{V}$ : ingerit $\mathbf{G}$ : invehat cr || 39 cxicrint Q: idem, sed supra scripto excesserint $\mathbf{P}$ | usque quod

31. II 12, 14: Consone.

32. Il 12, 15: Etiam angeli coeli ministri sunt dei, qui ab eo propter vitam hominum mittuntur, nec propter aliud quid creati sunt angeli, sed ut ministrent deo et hominibus; maioris igitur homo bonus.a deo aestimatur quam angeli.

33. II 12, 18: Primus adiutor deus est et secundus, qui adiuvatur, homo est.

34. II 12, 19: Ita igitur in tota tua vita age, pure et caste, ac si secundus sis post deum. Ultima vocabula ad sententiam sequentem traxit.

35. II 12, 20: Si electus dei es, per ipsam tuam electionem natura quaedam [addendum videtur tibi] est, quae deo similis est; ita igitur utere corpore tuo tanquam templo dei. 


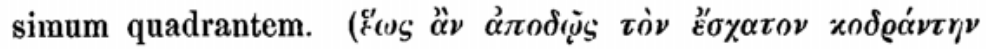
Mt. 5, 26).

$40(35)$ *Beatus vir, cuius animam nemo reprehendit ad deum pergentem.

41 (37) *Quicquid supra omnia honoraneris, hoc tibi dominabitur.

$42(36) *$ Deum ergo honora super omnia, ut ipse tibi dominetur.

$43(37)$ *Si autem dominatum tui gerit deus, ita demum tu dominaberis omnibus.

44 (38) *Honor summus deo seire eum et imitari.

45 (39) *Simile quidem deo per omnia nihil est, grata tamen ei est inferioris, prout possibile est, imitatio.

$46(40) *$ Templum sanctum est deo mens pii et altare

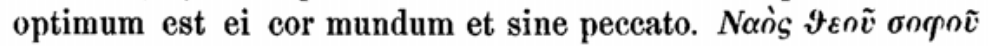

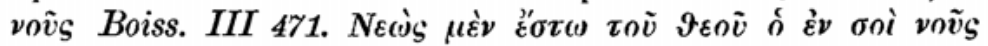

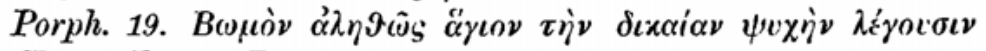
Clem. Al. 849 Pott.

47 (41) *Hostia deo sola et acceptabilis bene facere hominibus pro deo.

A: quousque G | etiam nov. A: nov. Q: etiam ultimum VG: ultimum etiam WOPBw: etiam nov. q. ex. ab eis er. Rufinum probabule est scripsisse ultimum; nam librariss famliare fuit novissimum, quod in codicibus et apud patres (uno excepto libello De laude martyrii c. 13 apud Cyprian. III 36 Hartel) in Itala et Vulgat ( constanter legitur \| 40 reprehendat c || 41 supra AWVB: super rell. | donabitur Q | (supra -43 autem om. (X) || 42 supra WVB (A: siper) | tibi om OP | dominetur tibi w || 43 gesserit $Q$ | tu demum er | omnia Q || 44 imitari eum e || 45 per omnia om. $\mathbf{G} \mid$ possibile] pollere e $\| 46$ dei $\mathbf{Q}$ | deo est $\mathbf{e}$ | est om. w | ei om. WOPBew | pii om. e | est optimum er | Laudat Augustinus De nat. et grat. c. 64, pro pii praebens pura \| 47 deo sola AQ: sola deo WOPVBw: soli deo er | est acc. $\mathbf{G}$ | et om. $\mathbf{e}$

42. 43. II 12, 23: Sic enim homini fideli dominatus datus est, ut dominatus dei; homini enim, cui pura conscientia est, innocenti omnis dominatus a deo datus est.

44. Conferendum est III 31, 1: Honor dei summus est oceulta

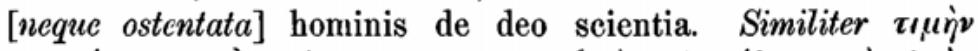

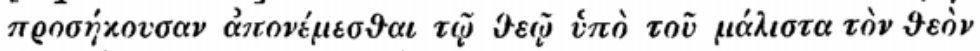

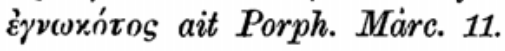

47. II in appendice 26, 11: Primarium facinus insigne, 
$48(42)^{*}$ Deo gratiam praestat homo, qui in quantum possibile est uiuit secundum deum. Cf. 381 .

49 (43) *Deus quidem nullius eget, fidelis autem dei solius.

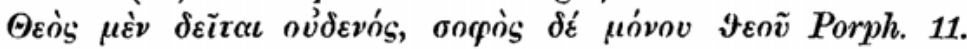
Boiss. I 127. Georg. 45. Fl. Mon. 7. Cf. Stob. 5, 34 (Socr.).

50 (43) *Aemulatur ergo illum, qui nullius eget, is qui

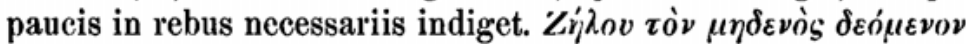
Boiss. I 128.

51 (44) *Satis age m̀agnus quidem esse apud deum, apud homines uero inuidiam effugere.

$52(45) * \mathrm{Si}$ benignus es apud indigentes, magnus eris apud deum.

53 (46) *Sapiens uir, cuius uiuentis quidem parva est apud homines opinio, defuncti vero gloria praedicatur. Sorpo v

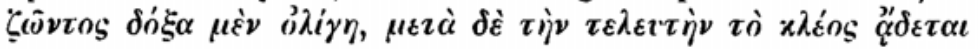
Boiss. I 134.

$54(47) *$ Omne tempus in quo non de deo cogitas, hoc te computa perdidisse.

48 homo pracstat $G$.| qui] quum $G \mid$ in quantum AQW0Ber: quantum PVGw || 49 quidem] autem $\mathbf{c}$ | indiget $\mathbf{P}$ | dei solıus AQVr: solius dei WOPBGew || 50 ergo om. $\mathrm{e}$ | illum| deum $\mathbf{G}$ | nec ullius eget $\mathbf{e} \mid$ qui in pancis necessariis indiget $\mathbf{G} \| 51$ Satage $\mathbf{G w} \mid$ quidem om. QVe | esse] fieri $\mathbf{V}$ | vero om. G: vero homines $\mathbf{c}$ | effugere $\mathbf{A Q}$ : fuge WOPVBGewr \| 52 apud AWPGewr: erga Q0VB | es A: sis rell. \| 53 Saplens vir cuius] Saprentis viri $\mathbf{w} \mid$ apud hom. parva est $\mathbf{G} \| \mathbf{5 4}$ in quo AQWVBewr: quo OP: quod $G$ | non de deo AQ0Pw: de deo non VB(ter: non deo W/ hoc om. | te computa AQWOPVBW: te puta G: puta te er

quod homo facit, est hominibus dei bona facere, eis qui se deo dedicarunt $(28,9:)$ et hoc est sacrificium deo magis gratum, quam omnes hostiae et splendida sacrificia.

49. I 2, 12: Dominus omnium nullius rei indiget, et qui ei fidem habet, eius solius indiget. Cf. quae dicentur ad s. 382 .

50. I 2, 14: Eum igitur, qui nullius rei indiget, imitatur, ut similis fiat, is qui pancis tantum sibi -necessariis indiget.

51. Fortasse, cum sent. 44 praecedat et 56. 57. 58. scqui videantur, huc referendum est III 31,2 : Omnis qui dei similis esse vult, fugiat quaecunque deo opposita sunt, et sicut te pudet dei, ita te pudeat tui ipsius.

54. I 2, 15: Omnia tempora, quibus deus in cogitationem 
$55(48) *$ Corpus quidem tuum incedat in terra, anima

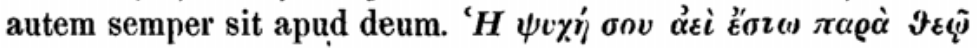
Boiss. $I$ 127. = 144. 418.

56 (49) *Intellege quae sint bona, ut bene agas. ( $C f$. 344.)

$57(50) *$ Cogitatio hominis deum non latet et ideo cogi-

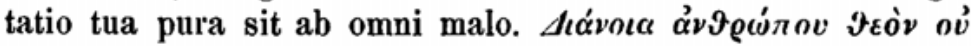
$\lambda \alpha \nu^{\prime}{ }^{\prime}{ }^{\prime} \nu \varepsilon \iota$ Boiss. I 128.

58 (51) *Dignus esto eo, qui dignatus est te filium dicere, et age omnia quasi filius dei. $C f$. 221.

$59(52) * Q u i$ deum patrem vocas, hoc in actibus tuis memor esto. $=222$.

$60(53) *$ Uir castus et sine peccato potestatem accipiet a deo esse filius dei.

61 (54) *Bona mens chorus est deî.

62 (55) *Mala mens chorus est daemonum malorum. Xív-

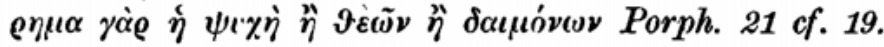

63 (56) Iniustum si inhibeas agere iniuste, hoc est secundum deum punire.

$64(57)$ *Satis age non nideri, sed esse iustus. certum est enim uere non esse eum qui uideri vult. $C f .189$.

55 tuum quidem $\mathbf{e} \mid$ autem tua $\mathbf{G} \mid$ ad deum $\mathbf{Q} \| \mathbf{5 6}$ sunt $\mathbf{P G} \mid$ sint ut et bene agas bona $Q \| 57$ Cogitatio $\mathbf{A}$, et $\mathbf{Q}$ post sent. $67, u b i$ hanc repetit: Bona cog. $\mathbf{Q}$ (hoc loco. sed litteris minoribus) WOPVB Gewr | sit] sit apud deum G || 58 eo AWOPBGewr: deo Q: ei $\mathbf{V}$ dign. est te AQ: te dign. est rell.| age QWOPVBGw: agere Aer | dei in fine om. w || 59 Qui Ac: quod QWOPVBGwr (cf. sent. 222) | hoc] huius cr | esto memor Q \| 60 accipiet Q: accipit $G$ : accepit WOPVBewr. Laudat Augustinus De nat. et grat. c. 64, apud quem hodie legitur accepit || 61. 62 corus A: thorus Q || 62 malorum om. A \| 64 Satage G | sed $\tilde{\theta}$ est $\mathbf{A} \mid$ iustus sed esse $\mathbf{G} \mid$ certum enim est G: enim ont. $\mathbf{c} \mid$ vere A: om. rell | eum non esse $\mathbf{C} \mid$ vult videri $\mathbf{G} \mid$ esse in fine addunt omnes praeter $\mathbf{A}$

non venit, non solum perdita a te reputentur, sed tibi etiam ipsi noxia habeantur.

56. Vix respondet ( $c f .51$ ) III 31, 4: Et assiduus semper esto in cultu dei.

57. Vix III 31, 5: quia in cogitationem iusti deus imperium habet. Sed ef. 145 .

64. I 2, 17: Stude, mi fili, ut iustus sis neque simules 
$65(58) *$ Honora quod iustum est propter hoc ipsum, quia iustum est.

66 (59) Nequaquam latebis deum agens iniuste, sed nec

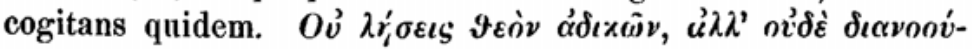

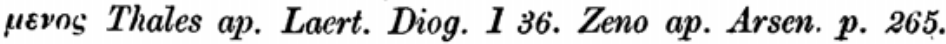

67 (60) Uir sapiens castus erit deo.

68 (61) Omnem spurcitiam fuge.

69 (62) *Semper de bonis loqui stude.

$70(63) *$ Libidinem nince.

$71(63){ }^{*}$ Contine corpus in omnibus, quia ex deliciis et uoluptatibus non effugies spurcitiam.

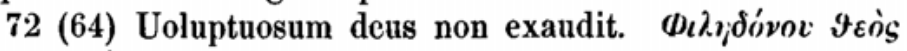

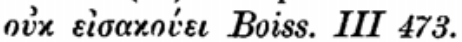

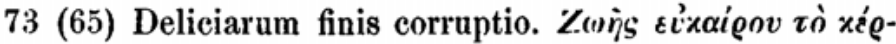

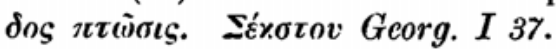

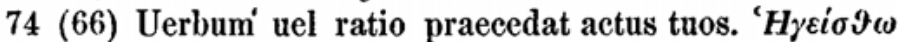

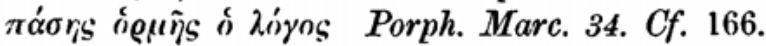

$75(67)$ *Perniciosum est seruire uitiis. quanta uitia habet

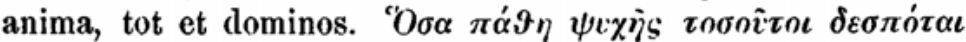
Boiss. I 131 (Porph. Marc. 34. Demoph 31. 'Pyth. Syr. 53: xai (ưuni $\delta \varepsilon \sigma \pi n ́ \tau \alpha \iota)$.

65 qui iustum est A | ipsud Q: iustum (sic) c | quia AQ: quod rell | est in fine om. $\mathbf{w} \| 66$ latebit WBew | deum]eum $Q \mid$ ne WPw 71 Contineas Qer $\mid$ et del. Q | non om. c || 74 Verbum vel ratio QW0 PVBGw: non verbum sed ratio er \|| 75 Quanta AQG: quot V: quia quot WOPBewr

esse; nam fallaci simulatione inveterata fraudaris quin vere iustus sis.

65. Fortasse (cf. 51) III 31, 6: Et sicut tu deum honoras, honora eos, qui apud deum honorati sunt.

71. Ultima tantum verba servata sunt I 2,19 : et si voluptates amas, lasciviam fugere nequis.

73. I 2, 20: Propinquus est enim interitus deliciis.

74. I 2, 20: Praecedat cogitatio actum tuum et linguam quoque nec unquam facto delinque neque verbo transgredere. Num duplex illa verbi hóyos interpretatio latina et prior quidem satis absurda revera a Rufino originem habuerit, ex nostris fontibus effici non potest.

75. I 5, 11: Perquam difficile est actionibus mundi sub- 
$76(68)$ *Amor pecuniae anorem carnalium indicat. Cf.

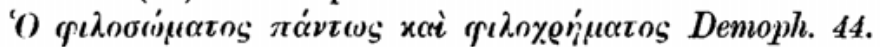

77 (69) *Adquire possessionem firmam animae, virtutem.

78 (70) Renuntia rebus corporis, dum adhuc potes et quantum potes.

79 (71) Hoc solum tibi proprium dicito, quod bonum est.

80 (72) *Qualis uis esse, cum oras deum, semper talis esto.

81 (73) Cum optima quaeque abieceris praedam, tunc velut, purificatus pete quod vis a deo.

77 Ita $\mathbf{A}$ (sed is animam) $\mathbf{Q}$ (sed is animi) VG: Contra Adquire possessionem firmam. Quid est firma possessio nisi virtus animae WOPBw. Insuper er praebent virtus aut vis, et $\mathbf{r}$ post firmam addit animae virtutem \|| 78 corporeis $Q$ | potest bis $W$ \| 79 tibi proprium dicito Q: tibi ducito WOPVB(iew: tuum ducito $\mathbf{r} \| 80$ Qualis] Qualem te V: In $\mathbf{P}$ super vocem qualis scriptum est: est pro quale | cum AG: dum QWOPBewr: on. (orans?) V deum oras Ger $\{$ semper talis AQWBGw: talis semper OPVer \| 81 Cum codd.: dum edd. I pracdam Q: pracdia rell. | tunc codd.: tum edd. | velut Q: om. rell. | a deo WOPBewr: a domino Q: ab co $\mathbf{V}$ a deo quod vis $\mathbf{w}$

iectum esse, quot enim vincula animi, tot eius duri (couni) domini. Legitur ibi post sent. 262, unde intelligitur cur $\pi \dot{\alpha} \vartheta \eta$ in vineula mutari potucrint.

76. I 3, 2: Amor pecuniae filius est defectus fidei, qui oritur, si de deo dubitatur.

77. I 3, 3: Ea quae animi sunt acquire, quia firma sunt. Apud Latinum etiam vocabulum virtutem additicium consendum videtur.

7S. I 3, 4: et quae corporis sunt mitte, quia vel vi se ab eis expedire oportet. II 12, 25: Quantum omnibus viribus potes, fuge et abstine ab eis, quae corporis sunt.

79. II 12, 26: Et corroborare legibus veris, quae sunt bonum perfectum.

80. II 12, 27: Sicut eo tempore, quo coram deo precans stas, sic semper coram oculis tuis stabilita et fixa sit dei recordatio.

81. Il 12, 29: $\mathrm{Si}$ in oculis tuis omnes res corporis tui pro stercore et luto habentur, tune cor purum acquirere potes, et quando cor purum acquisivisti, omne quod a deo petis tibi conceditur. Praediis lic locus non est; melius quadrat 
82 Qualis uis esse apud deum, iam nunc esto talis, cum distribuis ea quae mundi sunt; et ea despice tamquam qui te scias esse post deum.

$83(74) *$ Lingua maleloquax indicium mentis est malae.

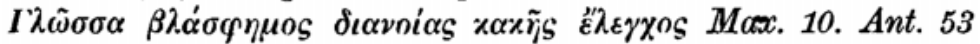
(Plutarchi). Arsen. p. 165.

$84(75)$ *Insuesce linguam tuam bene proloqui, et maxime cum de deo sermo fit.

85 (76. 77) Male quidem facere deo nemo potest; inpius autem est qui blasphemat; hoc enim solum quod potuit fecit.

82 Sententiam om. $\mathbf{Q} \mid$ talis esto $\mathbf{P} \mid$ cum distribuis WOPVB : cum distribueris Gw: dum distribueris er | qui.te scias WOPVBw: te scias G: sciens er | praeter deum er | Codices post sunt interpungunt, editiones a voce Dum vel Cum novam sententiam incipiunt \| 83 maleloquax A: maliloquax Q ita etiam Publit. Syr.: lingua est maliloquax mentis indicium malae 187 in app. Wolffini, 624 Ribbeck: maliloqua rell. | mentis est malae AQV : est malae mentis WOPBew: est mentis malae Gr: mentis malae $\mathbf{B}^{2} \|$ || 84 loqui e | fit AQW0BG: sit PVewr| In hac sententia desinit cod. Q $\| 85$ est WVBGewr: et P: om. $\mathbf{0}$, quod praeferendum esset, nisi obstaret enim | deo facere Gr | solum om. e

praedam, etsi durius dictum. Syrus si confertur, de permutatis inter se $\sigma \times v \beta \alpha^{\prime} \lambda \omega$ et $\sigma \times v^{\prime} \lambda(\varphi)$ cogitari potest; $c f . \sigma \times v \beta \alpha \lambda i \zeta \varepsilon \iota v$ Sir. 26, 28.

82. II 13, 2: Qualem mens tua te apud deum esse cupit, talis ut semper sis stude; possessionem mundanam contemne et sine parsimonia inde distribue et pauperibus da; et si ita feceris, scias te esse secundum a deo.

$82^{\mathrm{a}}$. Addit II 13, 5: Animus iusti est deus, quia (sic, sed uno vocabulo deleto legendum erit qui) commoratur in corpore mortali (cf. eundem Syrum 7). Qui igitur in vita male agit, affligit deum in se ( $v e l$ in eo) habitantem eique contumeliam imponit (cf. 429).

83. II 13, 7: Lingua contumeliosa indicium est mentis internae: quomodo corrupta (et) a deo (aversa) sit et quid semper sit eius studium.

84. II 13, 8: Lingua igitur laudans et benedicens sit tibi, imprimis erga deum.

85. II 13, 10: Homo dẹo contumeliis male facere non potest; in impii autem, qui contumeliis utitur, potestate si fuisset aliud quid facere, fecisset. 
86 (78) *Fundamentum pietatis continentia, culmen autem

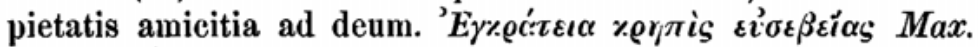
12. Ant. 31 (Clitarchi).

87 (79) Pium hominem habeto tamquam te ipsum.

$88(80)$ *0pta tibi euenire non quod uis sed quod ex-

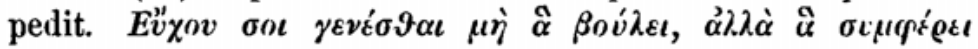
Boiss. I 122.

89 (81) Qualem uis esse tibi proximum tuum, talis et tu esto proximis tuis.

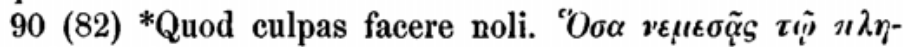

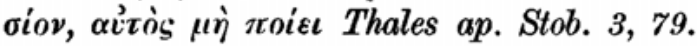

91 (83) Nulli suadenti adquiescas petere quod non est

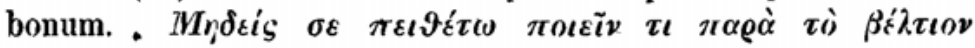
Boiss. I 122.

86 pietatis AP: pietatis est WOVBGewr | amicitia] institia e: est amicitia W | a deo A || 88 Optat tibi et venire non qui vis sed qui expedit $\mathbf{A}$ | expediat $\mathbf{Q} \| 89$ tibi vis pr. t. esse, talis tu esto $\mathbf{G |}$ proximum tuum tibi er | proximis tuis WVBGew: tuis proximis OPr\| 90 quod culpas A: quae culpas VG: quae culpes er: quae culpae est WOPB: quae culpa est $\mathbf{w} \| 91$ Noli (sic) $\mathbf{G} \mid$ ut petas $\mathbf{w} \mid$ non om $\boldsymbol{G}$

86. II 13, 12: Continentia autem ita animum a peccatis tuetur, ut crepida pedem tegit; perfectus vero dei timor est hominis erga deum amor. Melius vocem xoljtís intellexit Pyth. syr. 44.

87. II 13, 14: Ita autem homine deum timente uti ne dubites, ut te ipso.

88. II 13, 15: Ne ores ut tibi fiat, quod cogitas, sed quod vitae tuae utile esse debet.

89. II 13, 17: Quale vis tibi homines facere, tale eis tu quoque fac. Repetit idem 18, 9 post sent. 210: Ut vis tibi facere socios tuos tibi coniunctos, ita eis tu quoque fac. Similia:

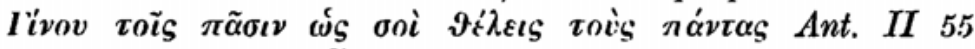

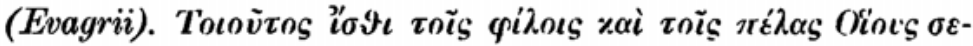

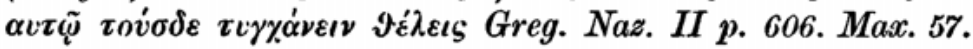
Ant. II 83. Cf. Mt. 7, 11.

90. II 13, 18: Nihil cuius tandem te poenitebit facias.

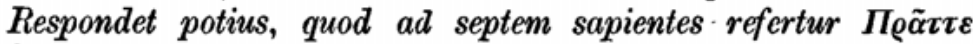

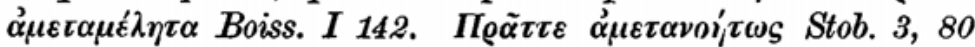
(p. 91, 15 Mein.).

91. II 13, 19: neve unquam tibi quis persuadeat facere 


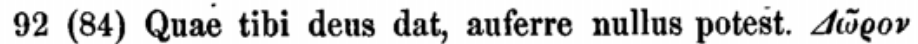

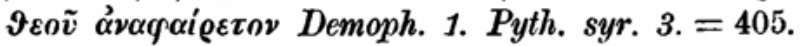

93 (85) *Delibera priuscuam agas, et antequam agas

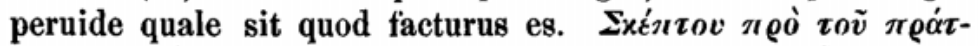

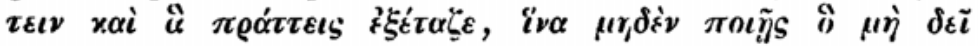
Boiss. I 128. cogites.

94 (86) Si quid non uis scire deum, hoc ne agas nec

95 (87) Priusquam agas quodeumque agis, cogita deum, ut lux eius praecedat actus tuos.

96 (88) Grandis inpietas in deum hominem affligere.

97 (89) *Anima inluminatur recordatione dei. $C f .24$.

92 Quod VGer | nullus auferre BGer || 93 Delibera AVr: libra WOP (is supra scripta glossa: estima) BGew | priusque $\mathbf{A}$ | antequam facies $\mathbf{A}$ I pervide $\mathbf{A} \mathbf{W}$ (: fervide) $\mathbf{P}$ (: fer:Vide) $\mathbf{w}$ : provideVBcr: praevide G|quod] que A quale sit q. f. e. Aer: q. f. e. quale est WOPVBGw (sed Gw: sit) | scire non vis $\mathbf{A} \mid$ istud $\mathbf{r} \mid$ ne-ne WOP: ne-nec B: nec-nec VGer: ne agas sed ne cogites quidem $\mathbf{w}$. Scripsi nec cogites, nam quod praebet W necogites ex antiqua scripturae ratione hoc significare potest. \| 95 ut om. $c \mid \| 6$ in] apud, sed supra scripto in $\mathbf{P}$ | hom. affl. WOPVBw: affl. hom. er: hominem om. $\mathbf{A} \| \mathbf{9 7}$ inluminatur $\mathbf{A}$ (:-netur) WOPVBGw : illustratur er | cogitatione sed supra scripto vel recordatione $\mathbf{P}$

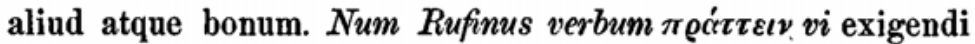
accepit, an legendum est patrare? neutrum placet. Cf. Carm.

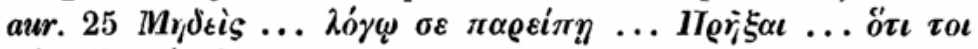

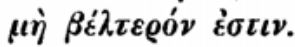

Sequitur sent. 15 quam v. supra p. 3.

92. II 13, 21: Consone.

93. II 13, 22: Primum meditare et tune fac negotium tuum; consulta et tune age, ne iterum facere debeas.

94. II 13, 24: Nihil quod deo non placere scis facias.

95. II 13, 25: Ante omnia opera tua dei memor sis et initio omnium verborum tuorum (memor sis) observandorum eius praeceptorum. I 3, 5: Ante omnes actus tuos dei memento et is efficiet, ut illucescat tibi cognitio omnium, quae te facere oportet.

96. II 13, 26: Impietas enim erga deum magna est hominem homini male facere.

97. II 13, 27: Omnis enim animus, qui hominem magni 
$98(90) *$ Contentus esse mediocribus stude.

99 (91) *Noli omnia concupiscere.

100 (92) Occasiones bonorum perquire etiam cum labore.

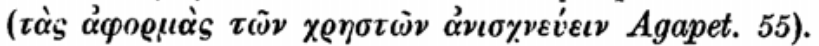

101 (93) Noli diligere ea, quae corporis sunt.

102 (94) Inmundum hominem facit actus turpis.

103 (95) Purgatur anima insipientis, cum arguitur intrinsecus latens sensus eius.

$104(96) *$ Deus in bonis actibus hominibus dux est.

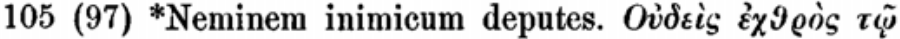

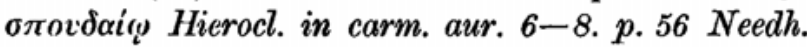

$106(98)$ *Dilige omnem, qui eiusdem tecum naturae est, deum uero etiam plus quam animam tuam dilige.

98 Itá A, si colligere licet e silentio collatoris | esse de minimis G: esse de mediocribus cw: esto. De mediocribus WOPVBr. Sed Syrus unam tantum sententiam esse confirmat. || 106 omnem qui A: hominem aestimat, divino intellectu collustratus est. I 3, 6 (post 95): illuminata enim est mens, cum deum cogitat.

98. II 13, 28: Omne, quod satis est, sufficiat tibi. I 3, 7: Insuesce te, ut pauca tibi sufficiant.

99. II 13, 28: neve concupiscas ea, quae remota abs te sunt. I 3, 8: neve cupias quae usum tibi necessarium excedunt.

100. II 13, 29: Et e bonis elige tibi meliora et e melioribus perfecta.

101. II 13, 30: Ne diligas, quod appetit corpus, sed appete opera animi.

102. II 14, 1: Homo impurus, ut nomine impuro appelletur, actus mali efficiunt. I 3, 8: Immundum enim reddit hominem etiam vana cogitatio.

103. II 14, 2: Omnis anima scientia carens amat laudem vanam.

104. II 14, 3: Deus bonis [sic lege e cod. B; editum est bonorum] hominum operibus praeest et is solus dux est omnis boni. I (postquam inter 102 et hanc inseruit sententiam 113) 3, 10: dux enim [deus, quod e sent. 113 supplendum] bonorum actuum eis est, qui eum implorant.

105. II 14, 4: Nemo in hoc mundo tibi inimicus sit.

106. II 14, 5: sed omnes homines dilige tanquam filios tuos, deum magis dilige, quam te ipsum. 
107 (99) Pessimum est peçcatoribus in unum conuenire, cum peccant.

108 (100) Multi cibi inpediunt castitatem et incontinentia ciborum inmundum facit hominem.

109 (101) Animantium omnium usus quidem in cibis in-

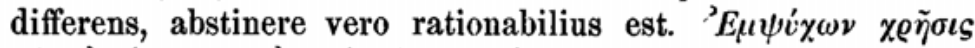

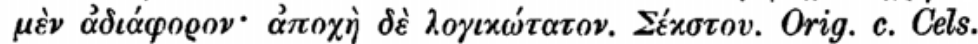
VIII, 30 p. 397 Spenser.

110 (102) Non cibi, qui per os inferuntur, polluunt hominem, sed ea quae ex malis actibus proferuntur.

qui e: omne quod WOPVBwr | eiusd. tec. nat. AWOPVr: eiusd. nat. tec. $\mathbf{B G}$ : tec. eiusd. nat. $\mathbf{w}$ : eadem tec. natura $\mathbf{e} \mid$ deum et quae sequuntur A non exhibet | vero etiam plus WOPVer: vero et amplius B: vero plus GW || 108 Cibi multi V | castitati WOP(: sed supra scripto vel tem) B : impedimento sunt castitati $\mathbf{w}$. dativus hic veram lectionem fuisse castitate indicat | hominem facit VG || 109 Animantium quidem esus indifferens est $\mathbf{c}$ | indiff. est $\mathbf{G} \| \mathbf{1 1 0}$ animam $\mathbf{c}$

107. II 14, 6: Haud indecorum peccatoribus est convenire in unum, quando resipiscere volunt a peccatis.

108. II 14, 7: Multi eibi animum a puritate apud deum impediunt et delabitur (leg. الم (م) a sublimi altitudine, in qua positus erat; quicunque se a multis cibis non continet, animum immundum reddit.

109. II 14, 10: Multo enim praestantius est hominem carne non vesci. Mire cum Sexto concinit Manus 5, 56: na mânsabhakshane dosho ... pravrittir eshâ bhûtânâm, nivrittis tu mahâphalâ: Non contrahitur carnium esu culpa; naturale hoc est hominibus; abstinendo autem magnopere merentur.

110. II 14, 11: At vero non quod os intrat polluit hominem, sed cogitationes malae, quae ex corde malo egrediuntur. Haec

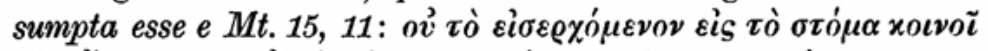

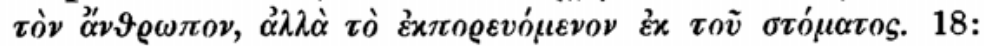

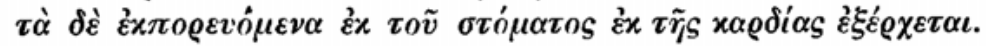

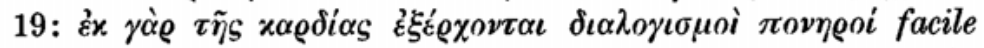
apparet eisdemque verbis utuntur. Simplex et Nitriensis. An etiam sententia qualem Rufinus habuit inde originem duxerit, addubitandum est; nam rei cardo positus est in sent. 111, quae cum in sacris Christianorum libris non legatur inde sumi non poterat. 
111 (103) Quicquid cupiditate victus acceperis polluit te.

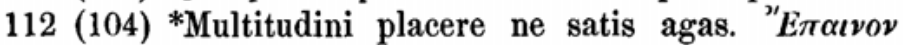

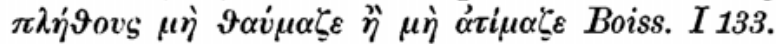

113 (105) In omni quod bene agis auctorem esse deputa

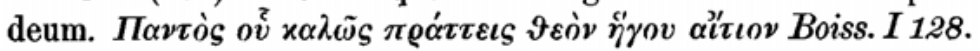

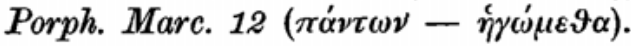

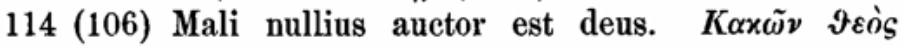

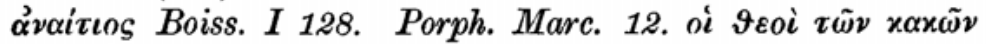

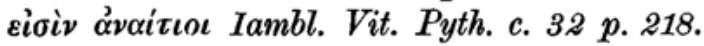
poscit.

115 (107) Non amplius possideas, quam usus corporis

116 (108) Aurum animam non eripit de malis.

117 (109) In deliciis posilus corporis certum est, quia ignoras illa, quae praeparata sunt a deo.

111 polluet G || 112 satagas GW || 113 In omne PVB ${ }^{2} \mathbf{G}$ | agas $\mathbf{P}$ | deum deputa esse $\mathbf{G}$ : esse om. $\mathbf{c}$ | adiutorem deputa esse $\mathbf{B}^{2} \| 114$ deus anctor est $G$ || 116 non eripit animam er | a malis V || 117 corporis positus Ger | certum est quia ignoras WOVBG: c. e. quod ignoras w: c. e. quia ignores er: ignoras certum est $\mathbf{P}$ | sunt WOPVBGw : sunt tibi e: sint tibi $\mathbf{r}$

111. II 14, 13: Omnis cibus, cuius cupiditate vinceris, si eum edis, corpus tuum immundum reddit.

$111^{\mathrm{a}}$. Addit II 14, 14: Numquam consentiat animus tuus libidinem corporis tui satiare. Contra omittit sent. 112.

113. II 14, 15: Omne bonum quod facis scias deum in te efficere; is enim omnis boni causa est. I 3, 9: Omnis honesti quod agis crede deum tibi esse causam (dux enim bonorum actuum est eis qui eum implorant). Ultima verba exhibent sent. 104 ( $v$. supra), quam cum II suo loco habuerit,

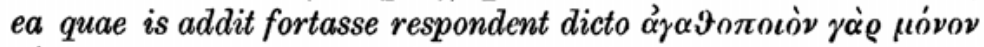

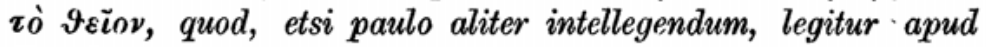
Porph. Marc. 17 (p. 203, 7 Nauck).

114. II 14, 16: Deus enim insons est omnis mali, quod faciunt homines.

115. II 14, 17: Ne avidus sis eius, quod corpus tuum concupiseit.

116. II 14, 18: quia aurum et argentum a malo non redimunt.

117. II 14, 19: Scito igitur deum, si corpus libidinibus 
118 (110) Ea posside, quae nullus possit auferre a te.

119 (111) Fer quod necesse est, sicut necesse est.

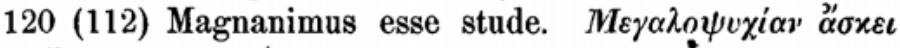
Boiss. I 128.

121 (113) Ea, quae si contemnas recte laudaris, ne retineas; in quibus probabiliter magnificus eris, haec optine.

122 (114) *Haec posce de deo, quae dignum est praestare

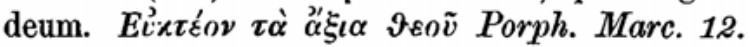

123 (115) Ratio, quae in te est, uitae tuae ipsa sit lex.

118 Haec e | auferri OPB | auferre possit $\mathbf{G}$ | a te om. $\mathbf{c} 119$ Ferre a prima manu $\mathbf{W} \mid$ ut $\mathbf{W} \mid$ in fine sit c || 120 magnanimis 0 121 quasi $\mathbf{P}$ | contemnes $\mathbf{r}$ : condempnas (vocabulorum serie prorsus turbata) $\mathbf{G}$ : quae condemnas si recte $\mathbf{W} \| 122$ de (rcọ̀) deo AWOP: a deo VBewr et $\mathbf{P}$ a sec. manu: $\operatorname{deum} \mathbf{G} \mid \operatorname{deum}] \operatorname{deo} \boldsymbol{G} \| 123$ Ratio] Non $\mathbf{G} \mid \operatorname{lex}] \operatorname{lux} \mathbf{G}$

permulceas, a te procul abesse. Ad Rufinum conf. 1 Cor. 2, 9:

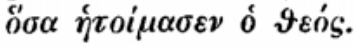

118. II 14, 20: Acquire autem tibi possessionem, quam totus mundus abs te auferre non potest.

119. II 14, 23: Caute serva magna et parva, quae tibi a deo concredita sunt. I 3, 10: Sine murmure fer difficultates, quae tibi accidunt omni modo; si a natura: propter ipsam naturam; si ab adversario: quia remissus te non cinxisti; si a domino tuo: aut ut castigeris si peccaveris, aut ut probatus fueris quia viceris.

120. II 14, 22: Et cor tuum magnum redde neve metuas, thesaurum tuum spiritalem custodire, sed acquire magnitudinem cordis.

121. II 14, 23: Neve ulla re menti tuae contemnenda tenearis, etiamsi inter homines de ea lauderis, sed quae praestantia esse scis obtine.

121 $1^{\mathrm{a}}$. Addit II 14, 25: Quodeunque enim iuste acquiris, abs te non aufertur. $C f$. 77. 118.

122. II 14, 26: Precare a deo, ut ab eo accipias quod deo dignum est.

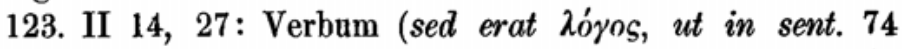
huic simili), quod in mente tua occulte habitat, lex vera in hoc mundo tibi sit. Vulgaris editionis lectio lux referri possit

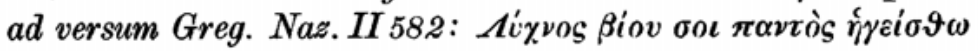


124 (116) Ea pete de deo, quae accipere ab homine non

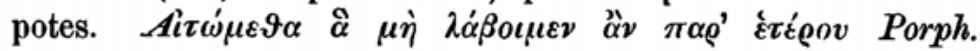
Marc. 12.

125 (117) In quibus praecedere debet labor, haec tibi

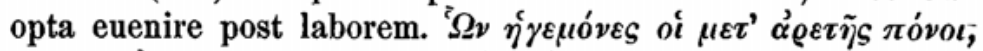

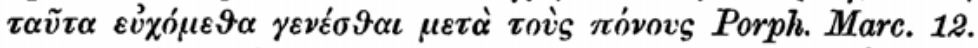

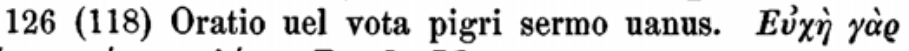

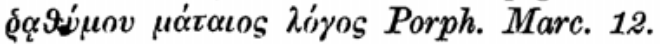

127 (119) Non oportet contemni ea, quibus etiam post

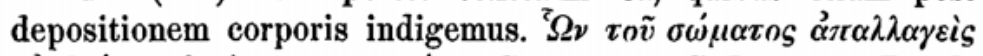

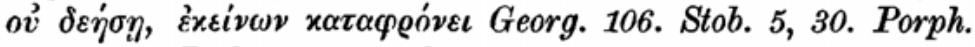
Marc. 12. Pyth. syr. 96. al.

128 (120) Non petas a deo id, quod cum habueris non

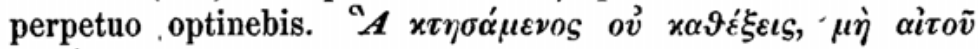

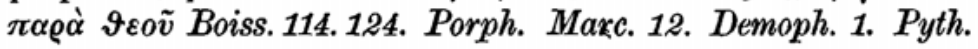
syr. 3.

124 ab homine accipere $G \| 125$ deb. praec - ev. opta $\theta \mid$ debet et opta om. c| hoc c \| 126 vel vota] tota G || 127 contemnere ( || 128 nisi id quod $\mathrm{e}$ | non] in $\mathrm{A}$

$\lambda$ ójos, nisi ab omni codicum et Syri auctoritate destituta pro mendo habenda esset. Eo minus Orellii ad h. l. coniectura dux ferri potest.

124. II 14, 28: Pete et posce a deo id quod homines tibi demere non possunt.

125. II 14,. 29: Quodcunque opera et labore acquisivisti, id pete ut penes te sit.

126. II 14, 30: Preces hominis ingenii torpidi preces inanes et vanae sunt. I 3, 13: Preces levis alicuius non solum sunt sermo vanus, sed etiam maledictio in deum per vilitatem suam.

127. II 15, 1: Quodeunque si corpore egrederis te non sequitur, contemne et loco suo relinque neve aspice. I 3, 15: Quo post mortem non indiges, id etiam in vita contemne et conculca. Rufinus vix aliter legit, sed minus accurate quam Syri Graeca verba transtulit.

128. II 15, 3: Quodeunque, postquam acquisivisti, aufertur nec tibi adhaeret neque te sequitur, ne petas a deo. I 3, 19 (post 131): Quod, si acquiris, non in perpetuum adipisceris, id nec ama neque a deo pete. 
129 (121) Insuesce animam magnum aliquid de se sentire post deum.

130 (122) Nihil pretiosum ducas, quod potest a te auferre homo malus.

131 (123) Hoc solum bonum putato, quod deo dignum est.

132 (124) Quod deo dignum est, hoc et viro bono.

133 (125) Quicquid non conuenit ad beatitudinem dei, nec conueniat họmini dei.

134 (126) *Haec debes uelle, quae uult et deus. Taṽ

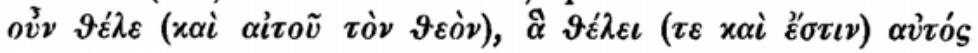
Porph. Marc. 13.

$135(127)$ *Filius dei est, qui haec sola pretiosa ducit, quae et deus.

129 animam WOPBw : animam tuam VGer | magn. al. de se sent. WVBG (qui om. de se): magn. de se sent. al. P: al. magn. de se sent. 0cwr \| 130 potest a te a. WVB: potest a. a te $\mathbf{P G}$ : possit a. a te er: a. a te possit $\mathbf{0}$ : a te malus homo a. potest $\mathbf{w} \| 132$ etiam $\boldsymbol{G} \| 133$ non om. e | nec conveniat WOPw : non conveniat VBr: non convenit e | ad - conveniat om. G \| $134 \mathrm{Ea}$ er | et deus vult $\mathbf{r}|| 135$ est qui om. $\mathbf{e}$ haec] et $\mathbf{A} \mid$ sola om. $\mathbf{G}$

129. II 15, 5: Mentem consuetudinibus bonis et honestis assuefac. III 31, 8: Et post fidem in deum fidem etiam in te ipsum habeas.

130. II 15, 5: Quodeunque abs te aufert homo malus ne 'quaeras. I 3, 16: Quodcunque homo malus tibi adimere potest, sit tibi nihili neve pretiosum id ducas.

131. II 15, 6: Sed illud a te opus bonum putetur, quidquid (or legendum videtur pro ого et alterum oor cum praecedentibus iungendum) deo gratum est; [id] fac (Verba aliquantum turbata sunt). I 3, 17: Unum tantum a te bonum putetur, id quod etiam deo convenit: eum diligere et proximum tuum amare.

132. II 15, 7: Quod deo dignum est etiam bono homine. 133. Deest.

134. II 15, 8: Ne velis aliud quid atque quod deus vult. I 3, 20. (post 128 posita et cum ea coniuncta): sed velis ab eo petere ea, quae et ipse tibi dare vult.

135. II 15, 9: Quicunque magni aestimat id, quod a deo magni aestimatur, filius dei est. 
136 (128) Donec in desideriis est caro, anima ignorat

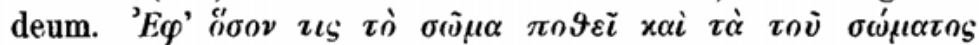

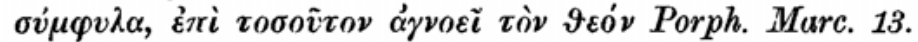

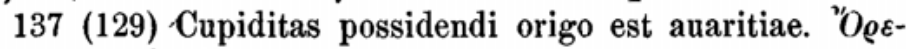

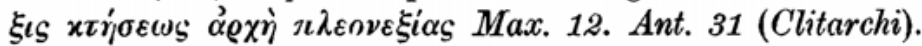

138 (130) Cum semet ipsum quis amplius diligit, inde in-

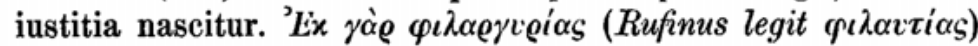

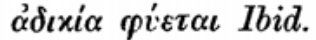

139 (131) Naturaliter parum quid corpus molestum est animae, luxuria vero facit corpus intolerabile.

140 (132) Omne quod plus est homini, quam necesse sit, inimicum est ei.

141 (133) *Qui amat quod non expedit non amabit quod

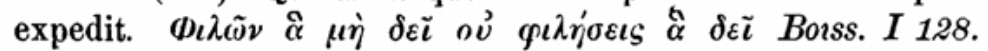
Max. 3 (Clitarchi).

138 Dum WGewr | quis semetipsum $\mathbf{w}$ | amplius om e: plus $\boldsymbol{A}$ | unde B || 139 parvum e | quid WOPVB: quidem Gewr | vero om. 140 homini plus est $\mathrm{e}$ | necesse sit WPBGewr: necesse est OV \| 141 quae - quae A : quod - quod rell. | amabit] amat $\mathbf{B}^{2} \mathbf{e}$ : habebit $\mathbf{G}$

136. II 15, 10: Quoad homo in affectibus libidinis est, deus ex animo eius amotus est.

137. II 15, 11: Cupiditas opum initium est viae avaritiae.

$137^{\mathrm{a}}$. Pergit: et ex amore pecuniae nascitur porro insolentia, quae sunt verba in ipso Clitarchi dicto sequentia: ¿̀x yà

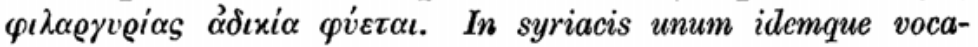
bulum est (proprie studium praevalendi), quod uti hic, ita etiam in Simplici utrique et $\pi \lambda \varepsilon \rho \nu \varepsilon \xi i \alpha$ et ádixía respondet. Contra tertiam eiusdem dicti partem, quam Rufinus 138 exhibet, Syrus non habet, at addit; is est radix omnium malorum, quae verba

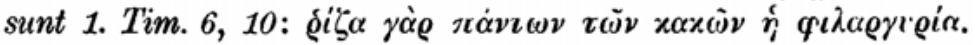

139. II 15, 13: Cogitationes autem paucae sunt in animo, quae ei molestae sunt: quae sunt avaritia et $\pi \lambda \varepsilon \sigma \nu \varepsilon \xi^{\prime} c^{\prime}$; amor vero libidinum corporis (hoc, nec animi, e $B^{2}$ contra reliquos codices omnes legendum sententia flagitat) voluptuosum corpus constituunt insatiabile.

140. II 15, 15: Omne enim supervacaneum, quod homo ad necessarium addit, ei inimicum est.

141. II 15, 16: Qui enim cupit quod cupere eum non decet, inimicum is sibi cupit. 
142 (134) Qui studium habet erga ea, quae non sunt bona, latebunt ei, quae bona sunt.

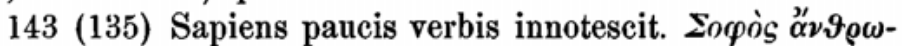

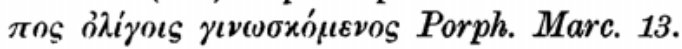

144 (136) *Sapientis mens semper apud deum est. $\Psi v \chi \dot{\eta}$

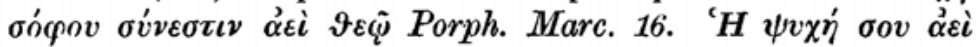

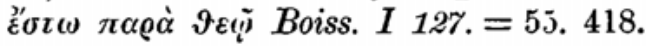

145 (137) Sapientis mentem deus inhabitat.

$146^{-}(138)$ *Inexplebilis est omnis cupiditas, propterea et

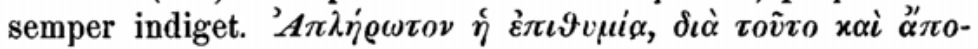
øov Max. 3 (Clitarchi).

142 Qui studet his $\mathbf{r}$ : qui studet iis $\mathbf{C}$ | bona non sunt $\mathbf{G}$ | ei $\mathbf{W}$ OPB : eum VGW : ea $\mathbf{B}^{2}$ : om. cr | bona quae sunt $\mathbf{G}$ : ea quae bona sunt w || 143 Ante 142 ponunt Oer | verbis inn. paucis $\mathbf{r}$ | Sapiens vir in paucis innotescit e | Regula Benedicti c. VII: Sapiens verbis innotescit paucis. Verbis comparatis Graeco et Syro additicium videtur || 144 Sapientıs WOPVBG: sapienti A: sapiens w | Semper apud deum mens est sapientis or || 145 mentis e || 146 Inexplebilis AGewr : inexplicabilis WOP(sed $\mathbf{P}$ superposito vel inexplebilis) VB

142. I 3, 22: Si studes eis, quae te discere non oportet, etiam quae scire et facere debes te latent. Fusius II 15, 17: Quatenus bona in te vigilant, eatenus dormiunt mala et quatenus, studium mentis tuae in mala spectat, eatenus in te exstincta et deminuta sunt bona.

143. II 15, 21: Sapiens autem etiam paucis cognoscitur sapiens esse.

144. II 15, 19: Cogitatio iusti semper apud deum est. Huc referendum est, quod I inter 134 et 143 praebet I 3, 21: Mens iusti deo perpetuo studet; propterea ei non opus est res mundanas curare.

145. II 15, 20: quia cogitationes iusti deus inhabitat.

146. II 15, 21: Cupiditatis insatiabilis finis est corruptio:

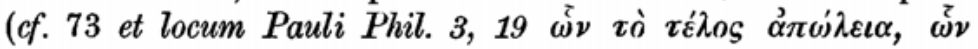

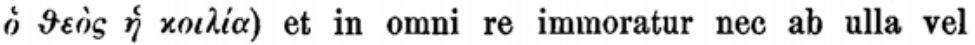
maxime inani recedit (Verba sana non sunt; verti ac si esset ij of (30:م). I 3, 24: Non finis cupiditatum est in earum servis; propterea neque hi plene eis saturantur. Addit: ad silentium autem et intermissionem rediguntur ab eis, qui, si corpus emortuum ( $c f$. Rom. 4, 19) est, in animo odium in eas conceperunt. 
147 (139) Sapiens semper sibi similis est. imitatio.

148 (140) Sufficit ad beatitudinem agnitio dei solius et

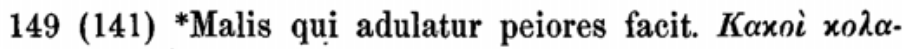

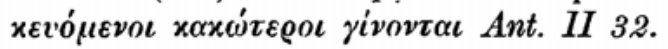

150 (142) *Intolerabilis fit malitia eum laudatur. 'Aqó-

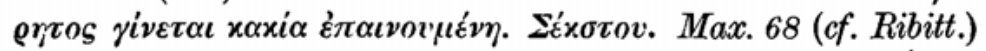
Ant. 1, 68. Democr. fr. spur. 10. Arsen. p. 88.

151 (143) *Lingua tua sensum tuum sequatur. 'H $\gamma \lambda \tilde{\omega} \sigma \sigma \alpha \dot{\alpha}$

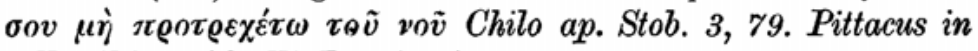
coll. Aldina (Orelli I 148). Arsen. p. 480.

$152(144) *$ Melius est lapidem frustra iactare quam uanum

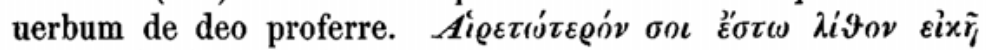

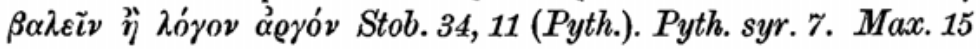
Ribitt. Ant. 1, 48.

147 similis est sibi Ger \| 149 eos facit er \| 150 fit AVer: fiet WOPBGw || 152 iactare A(: lactare)WPBGewr: iacere?? OV | vanum verbum de deo proferre A : verbum WOPVBewr | lapidem iactare quam verbum frustra $\mathbf{G} \mid$ Regula Magistri, c. $\mathrm{XI}$ : Melius est lapidem in vanum iactare quam verbum

147. II 15, 23: Sapiens semper sui similis est, stultus autem in omnes animalium formas mutatur.

148. II 15, 24: Sicut cibus ad vitam et corpus alendum sufficit, ita etiam cognitio et dei timor (leg. ad animi vitam.

149. II 15, 26: Improborum quando quis eos adulatur improbitas augetur et bonorum si humiliantur bonitas augetur. I 3 27: Stultus si quis eum adulatur magis insanit.

150. II 15, 28: Haud modus (num forte áógıбros legit aut legere sibi visus, est?) est malo quod laudatur. I 3, 28: Et (hominem) malum si laudatur nemo ferre potest.

151. II 15, 28: Semper lingua tua rationem comitetur et sequatur.

152. II 15, 29: Facilius est lapidem in hominem coniicere, quam verbum stultum in virum prudentem. Habuit igitur saltem

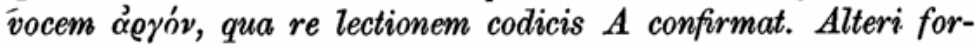
mae, in qua ảeyóv deest (Boiss. I 128, qui locus ex ipso Graeco Sexto petitus cst, Porph. Marc. 14, Flor. Mon. 66, Io. Dam. *, 
153 (144) *Delibera antequam dicas; ne quae non expedit

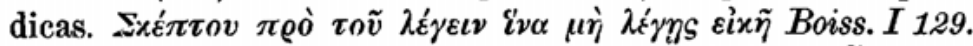

154 (144) Uerba sine sensu obprobria. 'P'

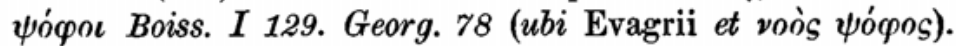

155 (145) Uerbositas non effugiet peccatum. 'Ex $\pi \circ \lambda_{v} \lambda_{0}$ -

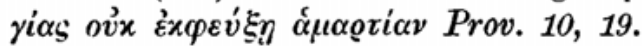

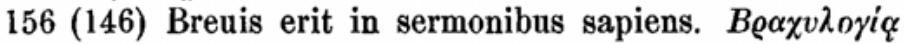

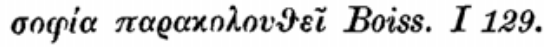

157 (147) Indicium inperitiae longa narratio. $\Sigma_{\eta \varkappa \varepsilon} \iota \tilde{o \nu}$

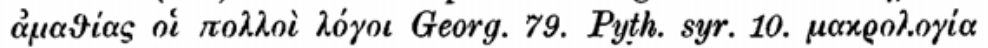

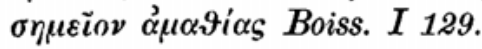

158 (148) Ueritatem ama.

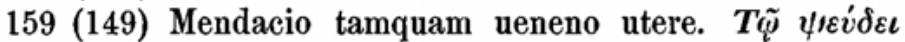

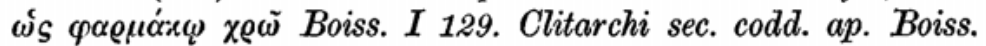
laudatos.

153 ante quem AW contra Graecum: antequam rell. I nec quae W0: ne quod G \| 154 sunt in fine add. W \| 156 erit WOV'Bw: est PGer: || 157 Indicium est $\mathbb{G}$ | est longa WOBewr || 158 arna WOP VBGw :dilige cr \| 159 tanq. ven. mend. c

3, Nil. 2), respondet reliquorum testium lectio, unde difficile dictu est, utra Rufini fuerit.

153. II 15,30 : Delibera et tunc loquere, ne loquaris quod non decet.

154. II 16, 1: quia omnia verba, quae originem non habent e sana ratione, voces inanes et vanae sunt.

155. II 16, 2: quia nemo multa loquens a vitiis liber esse potest. I 4, 2 (post 157): quia multitudine verborum homo difficulter peccatum evitat.

156. II 16, 3: Eum qui pauca loquitur sequitur sapientia. I 3, 30: Qui pauca verba facit sapiens est.

156 ${ }^{\mathrm{a}}$. Addit I 4, 1: silentium autem fructus est sapientiae.

157. II 16, 4 : Et multum loquentem neque doctrina neque disciplina sequitur. I 4, 1: Et qui multa verba facit, defectum mentis prodit,

158. II 16, 5: Veritatem dilige. I, 3, 28: Semper in corde, sermone et opere tuo verus esto.

159. II 16, 5: Et a mendacio fuge, velut a veneno letali. I 3, 29: Mendacio autem si oportet tanquarn medicamento (ita intellegi voluit, cum non ut alter adderet حمص|) utere. 
$160^{-(150)}$ Ante omnia tempus uerbis tuis requirito.

161 (151) Tune loquere, quando tacere non expedit.

$162(152) *$ De quibus ignoras tace, de quibus autem certus

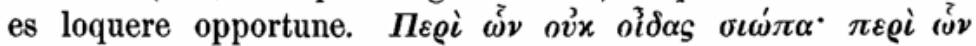
ởं $\alpha$ S o $\delta \varepsilon \tilde{\imath} \lambda \dot{\varepsilon} \gamma \varepsilon$ Boiss. I 129.

163 (153) *Sermo extra tempus indicium malitiosae mentis.

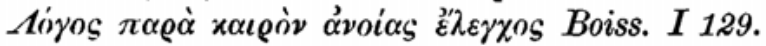

164 (154) In conuentu ne satis agas primus dicere. 'Ev

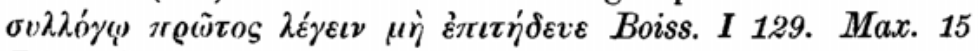
Rib. (Clitarchi). Ant I 48 (eiusd.).

161 Tunc W0VBrw: Tum PGe | expediat G \| 162 A quatuor tantum priora vocabula praebet \| 163 Summo (sic) A | extra tempus] importunus G | est post indicium addunt VG, post mentis ew \| 164 satagas er | primus WOBGw : primum PVer

160. II 16, 6: Verbis tuis tempus certum constitutum sit. $160^{\mathrm{a}}$. Addit II 16, 6: et vero intellectu instructa sint omnia verba tua.

161. II 16, 8 (post 162): De eo, quod dicere necessarium est, loquere et quando silere decet sile. Cf. Flor. Mon. 269:

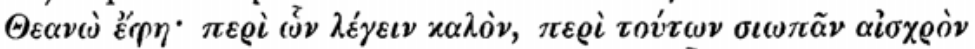

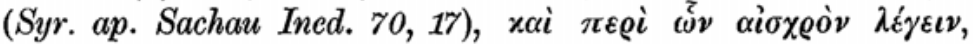

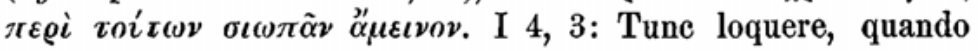
non oportet silere.

$161^{\mathrm{a}}$. Addit I 4, 3: et tempore, quod actionem postulat,

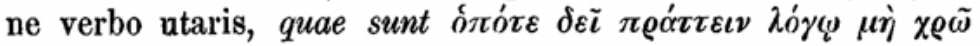
Boiss. I 129.

162. If praemissa 16,7 nova $\left(162^{\mathrm{a}}\right)$ sententia: Quando loqui decet, loquere neve tace pergit 16, 8: et de omni, quod nescis, tace neve loquere. I 4, 4 pro his habet: hoc enim est: cum ea sit sapientia, ut homo scienter loquatur et rursus prudenter taceat.

163. II 16, 9: Verbum intempestivum ei, qui dixit, opprobrium est, sin autem necesse est verbo uti, utere convenienter.

164. II 16, 11: In consilio conventus multorum ne primus loquaris, sed audias verba eorum. Graeci tres pergunt: $\mu \varepsilon \tau \grave{\alpha}$

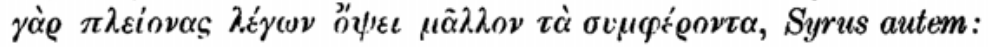
Et postea quasi ex dei dono responsum da plenum (verti ac si esset معدم vel quod consuetudo Syriaca requirere videtur

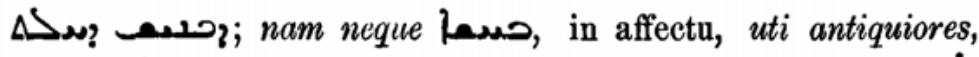


165 (155) Melius uinci uera dicentem, quam uincere men-

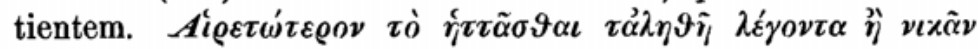

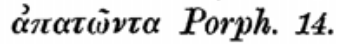

165 Melius WB : melius est rell.

neque مدص, in finem, uti recentiores codices legunt, ferri potest) timoris dei.

164 ${ }^{\mathrm{a}}$. Addit II 16, 13: Hominem enim scire, quando loquendum et quando tacendum sit, magna sapientia est. Haec est sententia ante praecedentem posita apud Boiss. $\dot{I}$ 129: $\grave{\eta}$

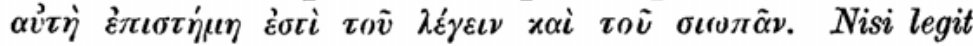

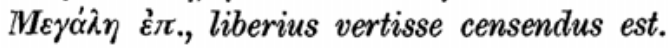

165. II 16, 14: Melius est hominem iure vinci, quam per nefas vincere. His potius respondent Gregorii Naz. apud Ant.

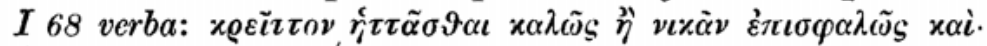

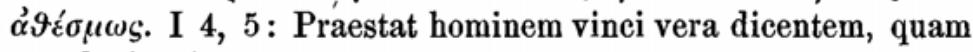
mendacio vincere.

165a . Addunt II 16, 15: Homo qui vincit ita, ut alios fallat, revera vincitur, et homo, qui veritati victoriam concedit, victoriam nanciscitur per veritatem. I 4,6: Nam qui vincit

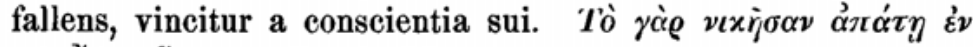

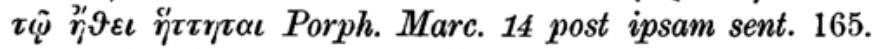

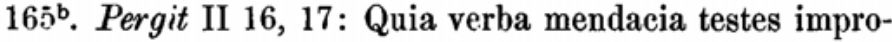

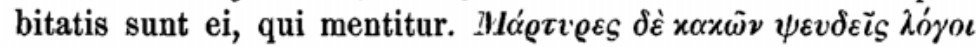

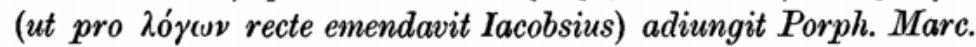
14 sententiae $165^{\mathrm{a}}$.

$165^{\mathrm{c}}$. Pergit II 16, 18: Perturbationi et angustiis mendacium non decorum est, si autem dei causa mentiris, ut malum impedias et multis prosis, non peccas iurando, quia mendacio tuo veritas inest, quae saluti hominum studet. Est sententia

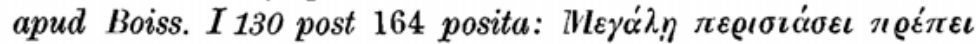
$\psi \varepsilon \dot{v} \delta \circ \mathrm{s}$, quam explicare et exclusa privata utilitate mitigare conatus est Syrus. Ceterum of. Diphilum apud Stob. 12, 12:

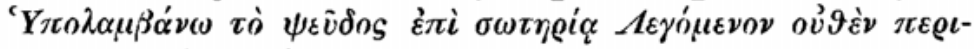

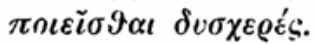

165. Tum II 16, 21: Neminem fallas, maxime qui a te bonum consilium petit. I 4, 7: Nunquam fallas aliquem, ma-

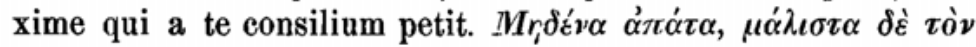

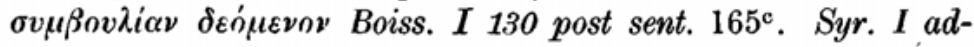
iungit 4, 8: Nam maledictus qui coecum in via fallit, quae sunt e Deuter. 27, 18. 
166 (156) *Fides omnes actus tuos praecedat. $C f .74$.

167 (157) *Sapientia animam perducit ad deum.

$168(158)$ *Nihil autem tam uernaculum sapientiae, quam

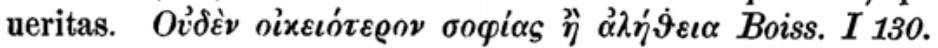

169 (159) *Numquam potest bona effici anima mendacium

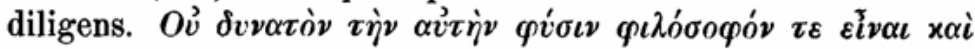
$\varphi \iota \lambda \circ \psi \varepsilon v \delta \tilde{r}$ Boiss. I 130.

170 (160). Pravo et pessimo ingenio fides aliena est.

171 (161) Fidelis homo audire quae oportet amat magis quam dicere quae non oportet.

166 omnes om. OPG. Pseudo-Isid. Fides omnes actus hominis praecedere debet Sixt. ep. 1, 3 (p. 107). Iul. ep. 12 (p. 468). Capit. Angilr. 3. || 167 animam Aer: animas WOPVBGw | perd. anim. G || 168 tabernaculum A: tam vernaculum or | nihil autem decet (deo et P: convenit w) sapientiae magis quam veritas WOPVBw: nil tam decet animam sapientem quam veritas $\mathbf{G}$ || 169 Numquid $\mathbf{A}$ | anima effici $\mathbf{G}$ | potest anima bona mendacium diligere er \| 170 Pseudo-Isidorus: malo enim et pravo ingenio fides aliena est Alex. ep. 3, $18(p .105) \| 171$ audire

165. Pergit II 16, 22: A consilio multorum oriundum

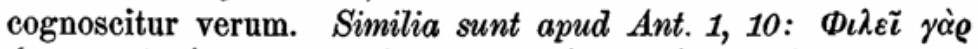

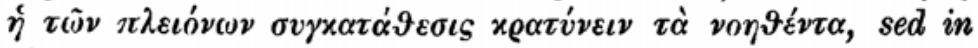
Graecis sine dubio fuit $\sigma v \mu \beta o v \lambda i \alpha$, quod adiungendae sententiae ansam dedit.

165 ${ }^{\text {}}$. Pergit I 4, 9: Homo terrificus (sive timidus, quod vocabulum cum hic non quadret, duce Isocrate ad Dem. c. 30

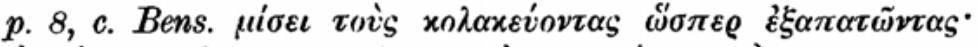

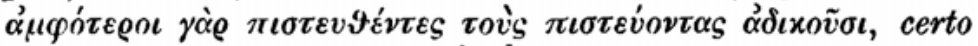
substituendum est perfidus, $1 \Delta \Delta \backslash$ ? aut similis forma) aut adulator ut verax sit nunquam fieri potest.

166. II 16, 22: Fides autem dux est omnium bonorum.

167. II 16, 23: Sapientia autem ad deum ducit.

168. II 16, 24: Nihil sapientiae tam acceptum quam verum.

169. II 16, 24 : Non enim veritatis ea natura est, ut ei adhaerere possit mendacium, neque ex eadem natura verum et mendacium proficisci possunt, quia natura veritatis libertas est nec naturam servitutis induit quae mendacium est. I 4, 10: Nam fieri non potest, ut eadem mens et verax et mendax sit. 170. deest.

171. II 16, 27: Si fidelis es, non tam loqui quam audire 
172 (162) Uir libidinosus ad omnia inutilis.

173 (163) Inreprehensibilis autem in uerbis utitur de deo.

174 (164) Peccata discentium obprobria sunt doctorum.

175 (165) Mortui sunt apud deum, per quos nomen dei maledicitur.

176 (166) Sapiens homo beneficus post deum. $C f$. 33. 34.

177 (167) Sermones tui uitam custodiant auditoribus. Tov̀s

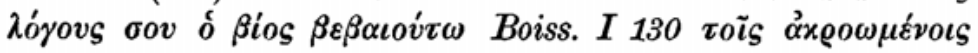
Porph. 8.

amat quae oportet G|Pseudo-Isid. fid. h. magis diligit (v. $l$. amat) audire quae oportet quam cet. Pont. ep. 2,6 (p. 148) \| 172 est inut. G: inut. est er || 173 Irreprehensibilibus $G$ : reprehensibilibus $\mathbf{w}$ | in om. $\mathbf{G W}$ | utitur de deo WOVBw: utitur deo? P: deo utitur G: unitur deo $\operatorname{cr} \|$ 174 dicentium $e \mid$ doctoris $w \mid$ doctorum sunt $G|| 177$ viam $0 P \mid$ tuam add. post vitam VGer, non WOPBW / commendent er

velis; sed audire maioris pro veritate pretii est, quam loqui; nam in conventu fidelium utilius tibi est audire, quam loqui.

172. II 16, 30: Quicunque amat libidines apparentes, etiam eis qui non apparent corruptus est. I 4, 11: Et is qui libidines amat, osor sui ipsius est, et qui se odit, omnes homines aversatur, et qui fratrem suum odit, oceisor hominum est.

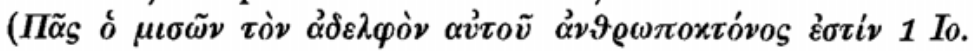
$3,15)$; etiam qui. se ipsum aversatur, sui occisor est per affectus libidinum.

173. II 17, 1: Si non dignus es, ne loquaris de deo; quandocunque autem a reprehensione abes, tunc utere verbis divinis.

174. II 17, 2: Peccata eorum, qui per inscitiam peccant, opprobrium doctorum sunt.

175. II 17, 3: Mortui autem, qui deo mortui sunt, ei sunt, quorum causa nomini dei maledicitur.

176. II 17, 5: Sapiens vir autem adiutor est post deum.

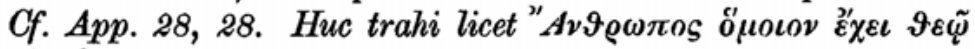

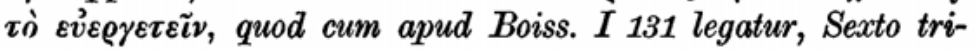
buendum videtur, nulli tamen alii sententiae melius respondet. Paulo variatum et amplificatum exstat tum Exc. Vind. $7=$ Arsen. 189 (Demosth.) Max. 8 Rib. Ant.1, 29. (eiusd.) tum Max. 8 (sine lemmate apud Gesnerum et Ribittum) = Arsen. 193 (Democr.).

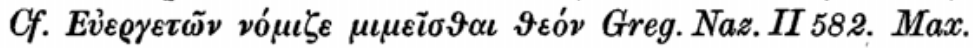
8. Ant. 1, 29.

177. II 17, 6: Opera tua confirment verba tua in auribus 
178 (168) Quod fieri non debet, nec in suspitionem venias

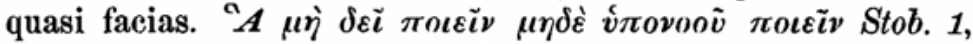
20 (Pyth.). Pyth. syr. 6. Thales ap. Laert. Diog. I 36. Max. 59 (Epict.). Ant. I 64.

179 (169) Ea quae pati non uis neque facias. $O$ peíyeıs

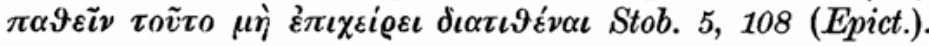

178 debet WOVBw: decet Per: quae - decent G | veniat Vr| facias WPBG: facies Ow: id feceris er / veniat; quae enim cogitas facere, quasi facis V || $179 \mathrm{Ea}$ quae WOPVBG: quod ewr|vis ab alio er | ne ipsa facias $\mathbf{P}$ : neque id feceris $\mathbf{c w r}$

auditorum. Melius igitur quam Rufinus, apud quem fortasse tuam $e$ codicibus inferioris notae addendum est, verba reddidit Syrus.

177ª I 4, 13: Oportet ut mores tui verbis tuis respondeant coram auditoribus eorum (Haec potius est sententia, quae

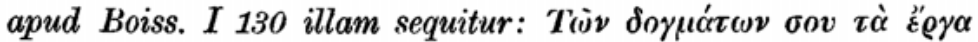

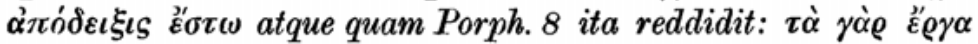

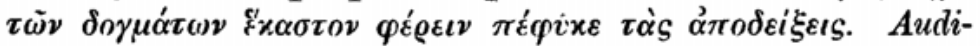
torum mentionem praebet Porphyrius in iis, quae adiungit: $\alpha \alpha i$

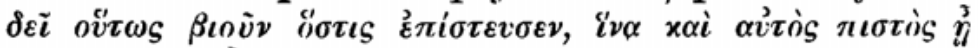

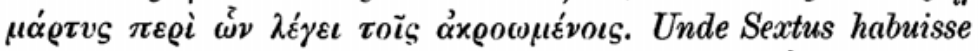

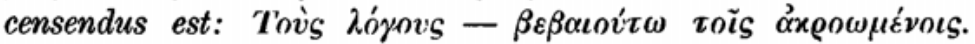

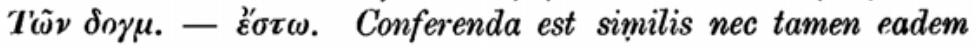
sententia in appendicibus 13 p.29,1 et 9,15), ne te irrideant et detrimentum capiant tuque reprehendaris, quod tua causa multi laesi sint.

178. II 17, 6: Quod fieri non debet ne cogites quidem facere. I 4, 15: Quod igitur fieri non decet, neque facere neque cogitare oportet; cave ne occasionem des, ut vel in suspitionem venias te id fecisse. Prior interpretatio, quae etiam Pythagorae Syri est, respondet lectioni v́rovóєı, quam praebet Arsenius Viol. p. 420. 'Yлоvоoṽ, cum medium in usu non sit, passivum

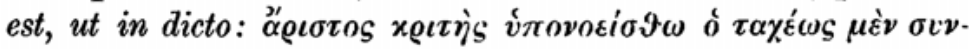

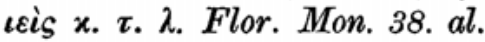

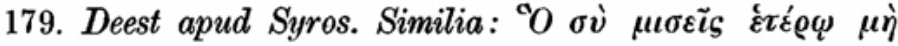

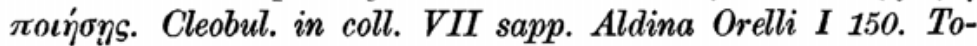
bit 4, $\left.15\left({ }^{2}\right) . \lambda \omega\right)$. Quodeunque tibi odiosum est, tu alteri facere noli. Menander syriacus apud Land Anecd. syr. 169

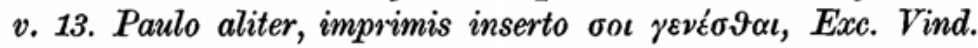


180 (170) Quae tibi facere turpe est, haec et alii inperare

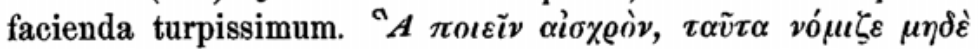

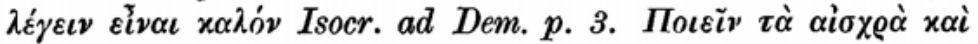

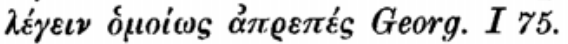

181 (171) Etiam in cogitationibus mundus esto a peccatis.

182 (172) Cum praees hominibus, memento, quia et tibi

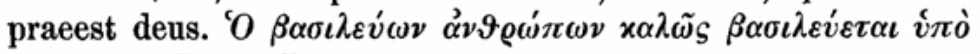
สoṽ $\vartheta \varepsilon \cap \tilde{v}$ Boiss. I 131.

183 (173) Et iudicans homines scito, quia et ipse iudiceris a deo.

$180 \mathrm{Ea}$ quae $\mathbf{w}$ | est turpe $\mathbf{r}$ | alii $\mathbf{B}$ | facienda om. Gc || 178-180 OPw ita interpungunt: Quod - pati non vis. Neque facias - turpe est. haec et - Neque aliter locum legit Pseudo-Isidorus qui ter habet: nec in suspitionem veniat (debet venire $v$. $l$.) fidelis homo ut dicat aut faciat ea quae pati non vult Pius ep. 1, 6 (p. 118) Pont. 2,8 (149) Melch. 1, 5 (244) - W 178 et 179 ita iungit: facias ea. quae \| 181 in om. G || cog. tuis PGer \| 182 quia WPVB: quod OGewr || 183 iudicans WOBGw: vindicans Per: indicans V / et ipse WOVBw: et Pr: praeest tibi deus et $\mathbf{G}:$ tu $\mathbf{e}$ | vindiceris $\mathbf{c}$

1. Constitt. apost. 3, 15, quae utramque formam coniungunt 7, 2.

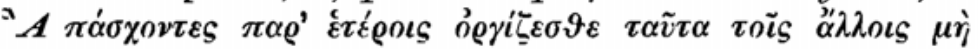

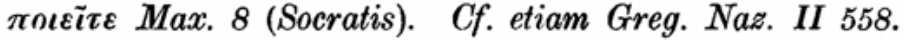

180. II 17, 8: Quod, si quis facit, odiosum est, odiosum etiam est, si quis dicit aut imperat, Inde apparet, interpretes habuisse $\lambda \dot{\varepsilon} \gamma \varepsilon \iota \nu$, cui modo dicendi (Publil. Syr. 320 Wölffl. Quod facere turpe est, dicere ne honestum puta), modo imperandi notionem tribuerint. Redit sententia in prima utriusque libri appendice 15 p. 29, 4: Turpe est imperare, quod ipse non facias, et 9, 17: Persuasus esto bona esse, quae facis et quae ab aliis postulas ut faciant.

181. II 17, 9: Quousque pertinet cogitatio tua, caveas a peccatis.

182. II 17, 10: Quia princeps factus es hominibus, etiam deus princeps tibi factus est. I 4, 17: Et si principatus tibi contingit, ne extollaris neve obliviscaris deum supra te esse. $\downarrow \kappa \alpha \lambda \tilde{\omega}_{S}$ igitur Sextus non habuit.

183. II 17, 11: quia etiam eius, qui hominibus princeps et iudex factus est, iudex deus est. I 4, 18: sed scias et teneas, te ei rationem morum tuorum redditurum esse, quod si tibi 
184 (174) Maius est periculum iudicantis, quam eius qui

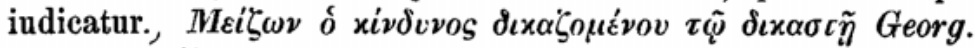

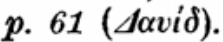

185 (175) Leuius est omne uulnus quam [linguae] uulnus.

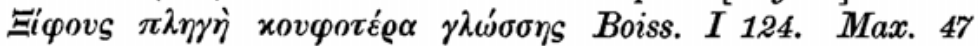
(Pythagorae).

186 (176) Possibile est uerbo fallere hominem, non tamen

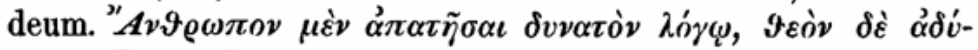
vatov Boiss. I 131.

$187(177) *$ Non putes malum, si cum ueritatem scias uincaris in uerbo.

$188(178) *$ *Male sentire de fide amor iactantiae facit.

184 Pseudo-Isid. maius peccatum est iud. etc. Calist. ep. 2, 20 (p. 143), sed Capit. Angilr. 3: maius periculum est || 185 uulnus WB: uulnus addito puncto, quo lectio dubia significari solet $\mathbf{0}$ : animae vulnus e coniectura aperta $\mathbf{w}$ : ulcus (ulc') itidem e coniectura $\mathbf{P}$; supra vocabulum vulnus minoribus litteris scriptum est: quod fit, et supra ulcus: qui nascitur: verbum VGcr. Etiam hoc ex emendatiıne satis facili ortum est. Vetus, quam omnia demonstrant, lectio vulnus apte voce linguae suppletur || 186 verbo] omne verbum G: om. e hominem WOPVBw: homines Ger | deo WOP | Pseudo-Isid. facile est verbo fallere hominem non tamen (v. $l$. sed non) deum Alex. ep. 3, 18 (p. 105). Zeph. 1, 9 (133). Ant. 8 (157). Melch. 1, 5 (244). Corn. 2, 6 (174) \| 187 si cum WPVBw: idem voluit 0 sicut: $\operatorname{sed} \mathbf{G}$ : si tu cum er | veritate OV | vincaris Be: vindicaris WOPVGwr \| 188 facit] est Ge

vere persuasum est, secundum voluntatem dei in principatu tuo bene agis.

184. II 17, 12: Magnum igitur periculum est iudicis, qui est ... Deesse aliquid videtur.

185. II 17, 13: Tu autem numquam hominem affligas aut ei noceas vel verbo vel re.

186. II 17, 14: quia hominem fallere potes, deum autem fallere non potes.

187. 188. His respondent apud Syr. II 17, 15: Quicunque in fide vera versatur et vanam hominum laudem amat, baud multo inferior est eo, qui in operibus malis versari amat; at vero vere fidelis non odit sapientem, qui cum causam cognoscat, pacis causa se submittit et vinci se patitur; exosa enim est vana laudatio sapienti, qua perhibetur rebus inutilibus laudari velle et vanam laudem amare. Solam sent. 188 reddit 
189 (179) *Fidelis esse magis quam uideri stude. $c f .{ }^{\prime} A \gamma \alpha-$

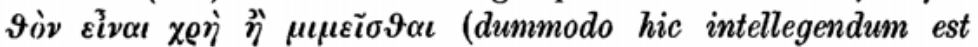
$\mu \tilde{\alpha} \lambda \lambda o v)$ Democrat. Sent. 5. Cf. 64.

190 (180) Cole sapientem uirum sicut imaginem dei ui-

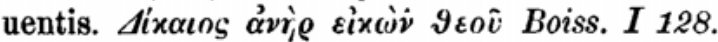

191 (181) Sapiens vir, etiamsi nudus sit, sapiens habeatur apud te.

192 (182) Neminem propterea honores, quia habet multas

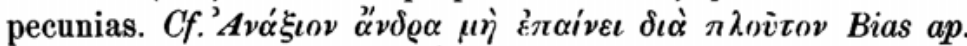

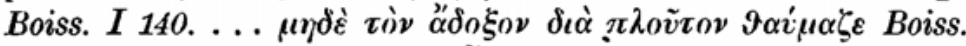

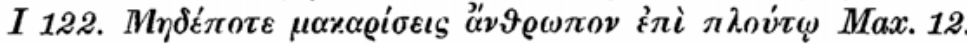

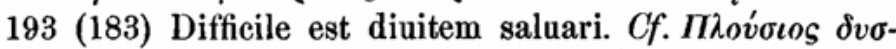

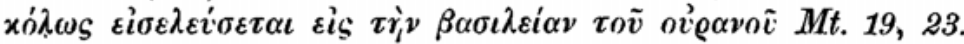

194 (184) Derogare uirum sapientem et deum aequale

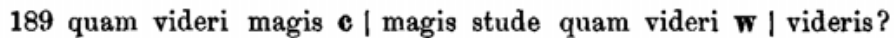
OP || 190 sapientem virum] sapienter viventem V || 191 habeatur apud te WOPw: apud te habeatur VBGr: sit apud te $\mathrm{\| l} 192$ propt. q. hab. m. divitias, honores $\mathbf{G} \mid$ quod multas habet pec. er, sed habeat $\mathbf{r}$ | habet] hic (sic, ht?) P \| $193 \mathbf{B}$ habet in margine \| 194 viro sapienti et deo Vwr | et deum om. $\mathbf{G}$

I 9, 26: Hominem a fide sua abducit vanae laudis amor; in omni enim re homini nocet is, praeter maledictionem ( $\lambda \circ \iota \delta o-$ eiav; haec sana esse non possunt).

189. II 17, 20: Desidera, ut vere fidelis sis.

190. II 17, 21: Verum sapientem tanquam magnam dei vivi imaginem honora. Diogenes ap. Laert. VI, 51 voìs àya-

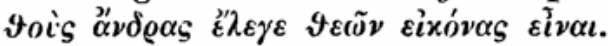

191. II 17, 22: Ne despicias sapientem, etiamsi in vita pauper sit. I 4, 20: Sapiens vir, etiamsi nudus sit, sapiens a te habeatur.

191². Addit II 17, 23: Nam sapientis sapientia divitias eius efficit.

192. II 17, 23: neve stultum honora propter opum copiam. I 4, 21: neve rursus propter divitias aut propter imperium honores aliquem externam respiciens speciem.

193. II 17, 24: Nam diviti valde difficile est vitam intrare $(\sigma \omega \vartheta \tilde{r}, \nu \alpha \iota)$.

194. II 17, 25: Si quis deum culpat aut virum perfectum: utriusque rei vis aequalis est. 


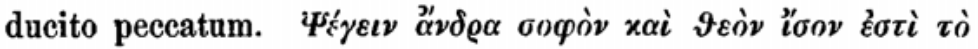

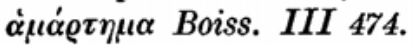

195 (185) Uerbum de deo loquens depositum te putato accepisse a deo animas auditorum.

196 (189) Ne pates bene uiuere, qui non integre credit.

197 (186) Quod bonum est, hoc solum te dicere puta.

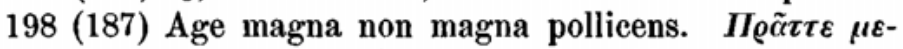

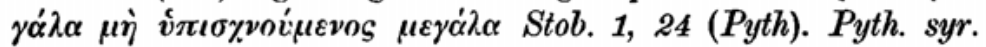
65. Demoph. 37.

199 (188) Numquam eris sapiens, si te putaueris sapientem, antequam sis. $=333$.

200 (190) In tribulationibus magnis qui sit fidelis ostenditur.

195 a deo WVBGw: addeo 0: a deo ad P: om er \| 196 eum bene $\mathrm{w} \mid$ Non potest bene er, qui sententiam post 199 ponunt | PreudoIsid. Non bene vivit, qui non recte credit Calist. ep. 1, 3 (p. 136) bis\| 197 dicere omnes, nullus cum culgata decere $\mid$ te $\mid$ recte te $\mathbf{S} \mid$ dicere putato debere $\mathbf{w}$ | putato er: om. J || 198 quae magna polliceris $\mathbf{S}$ | non magis pollicere e || 199 Numquam] Tunc J: Tu non er | non put. J: reputaveris $\mathbf{r} \mid$ putas sapientem esse $\mathbf{G U} \mid$ antequam sis om. er $\| 200$ magnis om. er | quis $\mathbf{S}$ : quid $\mathbf{U}$ : quidem sit fid. quis $\mathbf{S} \mid$ ostenditur] agnoscitur Jer

195. II 17, 26: Quando verbum dei loqueris, scias depositum (utitur Graeco vocabulo $\pi \alpha \rho \alpha \vartheta \eta^{\prime} \ltimes \eta$ ) tibi datum esse a deo, ut consulatur vitae animi aliorum.

196. II 17, 27: Nemo enim vivere potest, nisi firmam per caritatem fidem nanciscatur. I 4, 22: Nemo enim probe vivere potest, nisi recte credat, nec vere credere potest, nisi optime vivat; fides enim dux est ad bona opera, haec autem opera cognata sunt fidei.

197. II 17, 28: et haec ipsa a te putetur bonum perfectum, nam verum bonum constituit ea, quae deo placet, (fides). Syrus igitur ad intellegenda vel emendanda Rufini verba nil confert.

198. II 17, 29: Age magna, non promittens te magna acturum.

199. II 17, 29: Ne enim putes te sapientem esse antequam sapiens sis. I 9, 28: Non potes sapiens esse, si te ipsum sapientem putas, nam tunc fraudatus es, si non es sapiens.

200. II 18, 1: Tentationes homines fideles constituunt. 
201 (191) Finem uitae aestima uiuere secundum deum.

202 (192) Nihil putes malum quod non sit et turpe. $K \alpha$ -

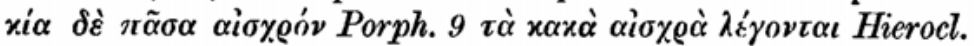
in carm. aur. 10 fin. p. 63 Needh.

203 (193) Mali finis iniuria, iniuriae antem perditio.

204 (194) Non ascendit passio in cor hominis fidelis.

205 (195) Omnis passio animi rationi eius inimica est.

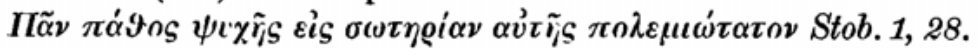
Pyth. syr. 2. Porph. 9:

206 (196) Quicquid feceris, dum in passione est anima, poenitebis.

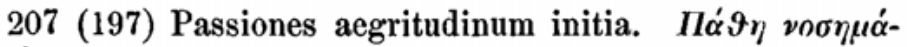

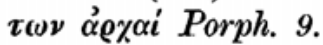

208 (198. 199) Malitia aegritudo est animae, animae autem

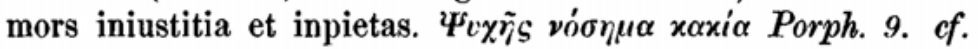

201 aestimato V: existima er \| 202 turpe a prima manu $\mathbf{V}$, sed nunc est Et turpis mali etc. 203: et turpem mali etc. $203 \mathrm{~W}$ : et turpe quod non sit GU | et om. er \| 204 absconditur S | hominis om. r $\|$ 205 animae $\mathbf{S}$ | rationis $\mathbf{c}$ | an. poss. eius rat. $\mathbf{w}$ | est inimica er || 206 perturbatione $\mathbf{w} \mid \mathrm{es}$, anima(-amJ) poenitebit Je | Ab hac sententia lacuna codicis $\mathbf{V}$ incipit $\| 207$ in. sunt aegr. S: aegritudinis vulnera sunt GU || 208 malitia WBGwer: mali 0: malum PS | est aegritudo cr | autem om. $\mathbf{S}$ | impietates $\mathbf{G}$

201. II 18, 1: Tu autem age secundum dei, non secundum tuam ipsius voluntatem.

202. Deest.

203. II 18, 2: Finis saturitatis (xí@ov legit homo pro $x \alpha-$ $x o \overline{\text { ) }}$ dedecus, dedecoris finis perditio (cadem verba sunt 146. 73). 204. II 18, 3: Non occupat libido cor iusti.

205. II 18, 4: Omnes animi affectus inimici sunt verbo veritatis. I 9, 30: Omnes animi affectus inimici sunt virtuti

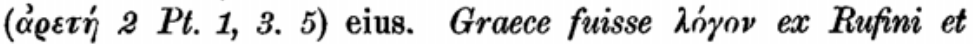
Syri II interpretatione efficitur.

206. II 18, 4: Quidquid facis, dum in angustia es, tandem ad poenitendum aget te (angustia). I 4, 25: Omnis, quod facis dum in cupiditate es, poenitebit te.

207. I 4, 27: affectus enim causa sunt aegritudinum.

208. II 18, 5: Improbitas morbus est animi, quin malitia 


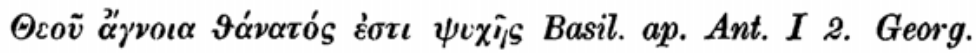
p. 46.

209 (200) Non te putato fidelem, cum passionibus animae carueris.

210 (201) Omnibus hominibus ita utere quasi communis prouisor omnium post deum.

211 (202) Qui hominibus male utitur, se ipso male utitur.

212 (203) Nihil mali uult, qui fidelis est.

213 (204) Opta, ut bene possis facere inimicis.

214 (206) Malis hominibus ineptus uidetur uir sapiens.

$215(205)$ *Sine deo non potes deo viuere.

209 Non - cum WOPB : non - nisi w: non nisi cum S: Tune - cum JGUer. Prior lectio sola fidem habet; quam cum non intelligerent reliqui, etiam Syri, e coniectura emendare voluerunt $\mid$ putato te $\mathbf{G U} \mid$ passiones (sic) $G$ || 210 omn. post. d. provisor SGUr | omnium praecursor e || 211 Nam qui J | quibus hom. G| ipsum WP || 212 Qui nihil mali vult fidelis est er|Pseudo-Isid. nihil (semel nec quicquam) mali vult qui fidelis est. Alex. ep. 3, 18 (p. 105) Calsst ep. 1, 3 (136) Pont. 2, 6 (148) Corn. 2, 6 (174) Melch. 1, 5 (244) || 213 bene facere possis JGU: possis bene facere e \| 214 hominibus WOBGUw: om. PJSer | videtur esse $\mathbf{P}|| 215$ deo vivere AGUewr: vivere deo WOPBJS

animi mors est. I 4, 27: Improbitas morbus est animi et iniuria tibi quasi mors est.

209. II 18, 7: Quoties cupiditate animi te abdicas, persuasum habeas, animum tuum esse fidelem. I 4, 28: Tunc te puta iustum, quando omnes animi affectus vincis; nam vis sapientiae divinae per talem victoriam inclarescit.

210. II 18, 8: Ita utere hominibus, ut vir fidelis, cuius aequales omnes homines sunt. Loco sent. 211, quae cum 219 coniuncta est, sequitur sent. 89 , iam supra exhibita.

212. II 18, 10: Homo sapiens et benignus neminem laedit, etiamsi in altero studium improbitatis incitatum est.

213. II 18, 11: Tu autem precare, ut rursus etiam inimi$\cos$ tuos ames et adiuves.

214. II 18, 12: Hominibus pravis non est aptus doctor bonus et sapiens.

214 . Addit II 18, 13: quia bonus malo inimicus est. Cf.

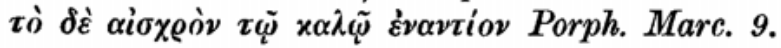

215. II 18, 13: Sine dei consilio bene vivere non potes. 
216 (207) Omnia suffer pro eo, ut secundum deum uiuas.

217 (208) Orationem non exaudit deus hominis, qui egenum non exaudit. $C f .378$.

218 (209) Sapiens sapienti donum a deo.

219 (210) Honorans sapientem honorabis te ipsum.

220 (211) Fidelem te esse nosce.

221 (212) Cum filium te dei quis dicit, memento cuius te filium dicat. $C f$. 58 .

222 (213) Deum patrem invocans in actibus tuis hoc memorare. $=59$.

223 (214) Uerba tua pietate semper plena sint.

224 (215) In actibus tuis ante oculos pone deum.

216 sufferto P: suffert OS \| 217 deus JSGUewr, sed etiam Syrus: dominus WOPB | deus non ex. Gewr: eius non ex. $\mathbf{S}$ | hominis om. SG / non eg. ex. r: eg. non audit c \| 218 Sapientia sapienti $\mathbf{r} \|$ 219 honora te ipsum $\mathbf{S}$ : te ipsum hon. er \| 220 Sententiam om Je agnosce S || 221 te dei quis WPB: ,te quis dei OSr: dei te aliquis GU: dei te quis $\mathbf{J w}$ : | filium te $\mathbf{G w} \mid$ dicat] dicit e $\| 222$ tuis om. $\mathbf{w} \|$ 223 Verba tua et opera $\mathbf{G}$ | semper om. S || 224 oculos tuos ewr

216. II 18, 14: Propter vitam, quae a deo est, suffer omnia quae tibi accidunt.

217. II 18, 15: Omnium, qui homines quando ab eis petunt non exaudiunt, preces nec deus exaudit. III 31, 7: Nam non exaudit preces eius, qui hominem sui generis a se petentem non exaudit.

218. II 18, 16: quia frater fratri donum est a deo.

218 ${ }^{\mathrm{a}}$. Addit II 18, 17: Alter enim per alterum ad deum appropinquamus.

219. II 18, 18: Quicunque alium honorat, se ipsum honorat; 211. et qui alium ignominia afficit, se ipsum ignominia afficit.

220. II 18, 19: Si fidelis es, tanquam dei filius haberis.

221. II 18, 19: et quando deo filius aut frater appellaris, scias et videas in te, cui appelleris filius et frater.

222. Il 18, 21: et quando deum appellas tibi patrem, seias quid te facere oporteat.

223. II 18, 22: Omnibus fidei tuae praeceptis obediatur sincere.

224. II 18, 22: Et quidquid facias, deus ante oculos tuos versetur. 
225 (216) Nefas est deum patrem inuocare et inhonestum

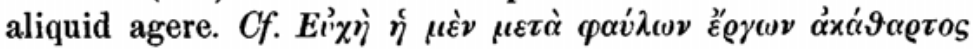
Porph. 24.

226 (217) Qui non diligit sapientem nec se ipsum.

227 (218) Nulla propria possessio putetur philosophi.

228 (219) Quorum communis est deus idemque pater, horum nisi et possessio communis est, inpii sunt.

229 (220) Deo ingratus est qui non magni ducit philosophum.

230 (221) Coniugium tibi refutare concessum est, idcirco ut uiuas indesinenter adhaerens deo. nubere et filios procreare pessimum scias utrumque; sin autem tamquam proelium sciens esse pessimum, tamen pugnare non uis, et uxorem nube et filios procrea.

225 inh. ag. al. G: al. inh. ag. Jer | aliquid om. S || 226 sapientiam SU | In fine diligit add. Uer || 227 putatur Je | phil. putetur GU I put. pr. ph. poss. S || $228^{*}$ Quorum consessio (confessio U) communis GU | est oin. G: sit JSUer | horum (et U) poss. nisi comm. Ue || 229 magnum e || 230 adh. deo om. S | nubere - procrea om. GU | tanquam om. $\mathbf{B}$ | sc. esse iniquum et ideo pugn. $\mathbf{S}$ | esse pessimum om. $\mathbf{c r}$ | tamen] tanquam $\mathbf{P}$ | non vis WOPBJSw: vis er | nube WOPBJ: duc

225. II 18, 23: Culpa enim magna est, aliquem appellari filium dei et facere opera mala, quae deo displicent.

226. II 18, 25: Quicunque iustum non amat, nec semet ipsum amat. I 10, 1: Qui verum sapientem non amat nec se ipsum amat.

227. II 18, 26: Ne credas aliam possessionem meliorem esse vera sapientia. I 4, 30: Nec ullam [huius mundi] possessionem suam putare sapienti licet. Quae uncis inclusi, desunt in duobus codicibus eisque non antiquissimis et in cod. 17178 ap. Wright. Catal. II 856.

228. I 5, 1: Hominum enim, quorum deus unus est, possessiones non communes esse non decet.

229. II 18, 26: Ingratus erga deum est quicunque fratribus non studet.

230. II 18, $27:$ Si renuncias coningio, familiaris es dei; sin autem in te perferendi vis non est, ducas uxorem et fiant tibi filii. Media quae Syrus non agnoscit verba addidisse potest Rufinus, cum contextum turbent. 
231 (222) Adulter etiam propriae uxoris omnis inpudicus.

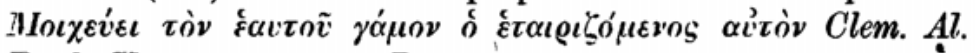
Pacd. Il 10, 99 p. 229 Pott.

232 (223) Nihil propter solam libidinem facias.

233 (224) Scito te adulterum esse etiam si cogitasti de adulterio. sed et de omni peccato eadem tibi sit ratio.

234 (225) Fidelem te professus spopondisti pariter non peccare deo.

235 (226) Fideli mulieri ornatui ducatur pudicitia.

cr: ducito $\mathbf{S w}$ | procreato $\mathbf{w} \mid$ tamen sententıcom prorsus turbat; an fuit

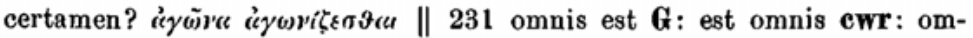
nis qui est $\mathbf{U}$ | omn. imp. ad. est et. pr. ux. S | Addunt er: vel amator ardentior, quae sumpta sunt sine dubio ab ipsis editoribus ex Hieronymo, qui locum bis affert, adv. Iov. I ante Rufinum: adulter est in suam uxorem amator ardentior, et in comm. in Ezech. 6,18 post editum a Rufino librum: ad. est uxoris propriae amator ardentior. $C f$. $\mathbf{P u}$ blıl. Syr. spur. 9 Wolffl.: adulter est uxoris amator acrior, quae sententia ex Hieronymo originem duxit || 232 solam om. PS | solum propter G | facies WO || 233 cogitasti WOPJSUGw: $\operatorname{cogitas}$ B : cogites er | adulterium $\mathbf{J}$ | sed cet. om $\mathbf{S}$ | sit tibi GUer | tibi ratio sit $\mathbf{w}|| 234$ te esse $\mathbf{r}$ | et sic pariter $\mathbf{J} \mid$ deo om. $\mathbf{G}||$ 235. 236 om. GU | 235 ornatui Pcr: ornatum WOS: ornatu $B$ ornatus Jw

231. II 18, 29: Et scias omnem, qui corpus suum iuste non domat, adulterum esse uxoris suae.

232. II 18, 30: Propterea decet fideles corpus coercere in omni re (huc magis, quam ad s. 239 referendum). Confe-

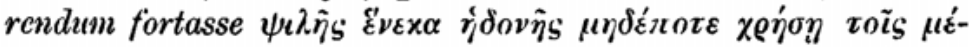

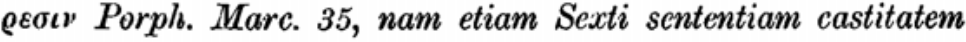
spectare locus inter vicinas ei tributus indicat.

233. I 10, 2: Adulterium a te putetur etiam cogitatio adulterii. Cf. Mt. 5, 28. De II vide ad s. $283^{\mathrm{a}}$.

Deinde in sententiarum ordine apud Syrum II confusio quaedam est: sequuntur 240-43. 253. 254. 256. 234. 240. 24352. 255. 257, unde apparet bis positas esse 240 et 243 .

234. II 19, 9: $\mathrm{Si}$ deo te secrevisti (Sמג) solemne de monachorum votis vocabulum), de te ipso testatus es te amplius non peccaturum.

$234^{\mathrm{a}}$. II 19, 10: nam vir sapiens peccatum fugit.

Desunt 235-239, id quod eandem cum transmutato ordine causam habuisse videtur. Sententia tamen 236 in appendice 
236 (227) Uir, qui uxorem dimittit, profitetur se nec mulierem regere.

237 (228) Mulier pudica gloria viri est.

238 (229) Reverentiam habens uxori habes eam reverentem.

239 (230) Fidelium coniugium certamen habeat continentiae.

240 (231) Prout continueris ventrem, ita et uenerios motus.

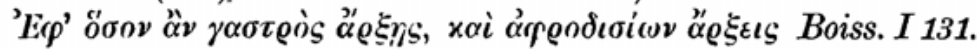

241 (232) Deuita infidelium laudes.

242 (233) Quae gratis accipis a deo, praesta gratis.

243 (234) Multitudinem fidelium non inuenies, rarum enim est omne, quod bonum est.

244 (235) Sapientem honora post deum. Cf. 319.

245 Cum argueris, ut sapiens fias, habe gratiam arguentibus.

236 Omnes praebent gerere, quod cum alienum sit Syro duce cum regere mutandum est \| 237 viri est gloria $\mathbf{( H}$ : est v. gl. U || 238 habes PBJSGe: habens WU: habet 0 : habebis wr || 239 Fidele $B$ | habet SU: habebat $\boldsymbol{G} \mid$ In media hac sententia denuo incipit $\mathbf{V}|| 240$ venerios W: venerius OP: veneris Sw: venereos rell. $\| 241.242$ om. U|i 241 In $\mathbf{P}$ super devita scriptum est $\cdot \mathrm{i} \cdot$ fuge $\| 242$ accipiens puncto critico sub n posito $\mathbf{V}$ | quod gr. accepisti $\mathrm{S}$ | et praesta $\mathrm{V} \| \mid 243$ enim om. SGU | est enim er | omne om. J || 244-7 om. GU || 245 r prae

I 8, 30 servata est: Et si dimittis uxorem tuam, indicas te ne uxorem quidem regere posse.

240. II 19, 1: Sicut coerces ventrem tuum, sic coerce etiam libidinem tuam, et mox 19, 10: Pro ratione, qua libidinem ventri tui coerces, vince etiam libidinem corporis tui.

241. II 19, 2: Propterea cave a iactantia eorum, qui fide carent, qui se iactant malis; multi enim se iactarunt et perierunt. I 5, 2: Fili mi, contemne laudem a parte veracium, ut modestus esse cognoscaris, et fer contumeliam a parte mendacium, ut fortis appareas.

242. II 19, 4: Sed sicut donum est, quod a deo accepisti,

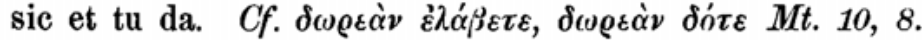

243. II 19, 5: Et scias multos fideles non facile inveniri et mox plene 19, 11: Non enim multi inveniuntur viri fideles, quia exigua est pars boni in hoc mundo.

244. II 19, 13: Post deum honora virum sapientem.

245. II 19, 13: Si quis te arguit, ut sapiens fias, habe 
246 (237) Qui sapienti non obtemperat nec deo obtemperat.

247 (238) Fidelis uolens esse praecipue quidem nitere, ne pecces; quod etsi forte acciderit, saltim ne iteretur id ipsum.

248 (239) Doctrinam, quae non est deo digna, ne discas.

249 (240) Multa uelle scire curiositas animi putanda est.

250 (241) Qui cognoseit, quae deo digna sunt, ille sapiens.

251 (242) Doctrinam, ex qua proficere potes in amore dei, illam specialiter et necessario expete.

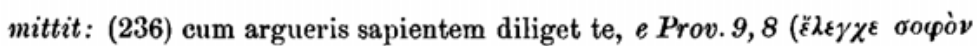

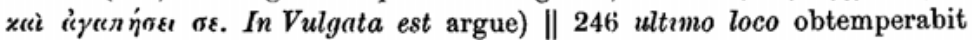
Vr || 247 quidem om. JS | hoc nitere PVGr | nitaris $\mathbf{w}$ | nitere ve] intra te non c | etiamsi Jr: enim si Abst: | Post saltim inserunt cave $\mathbf{r}$ (et $\mathbf{V}$ ?): rogo Je | quodsi peccaveris ne iteres. S || 248 non deo digna est G| discas PJSGU cum Syro: dicas WOVBewr $\| 250$ de deo (sic) $\mathbf{G}$ | sapiens WOPw: sapiens est VBSUe: est sapiens Jr: sapiens ille est G\| $251 \mathrm{om}$. U | speciatio $\mathbf{W} \mid$ specialiter et on. $\mathbf{G} \mid$ et necessario om. $\mathbf{c}$

ei gratiam, quod te arguerit. I 5, 3: Et habe gratiam eis, qui te arguunt, ut sapiens inveniaris.

246. II 19, 14: Quicunque iusti disciplinam non fert, etiam bono (rebus secundis) appropinquare non potest. Utraque forma et Latina et Syriaca referri potest ad sententiam ${ }^{\circ} \mathrm{O} v$ ov́

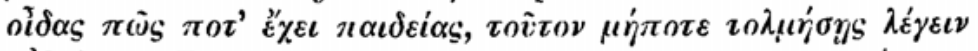

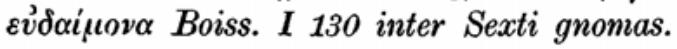

247. II 19, 15: Si sapiens appellari vis, cave tibi ne pec-

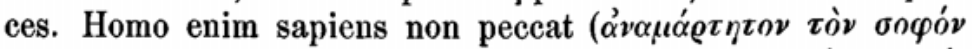

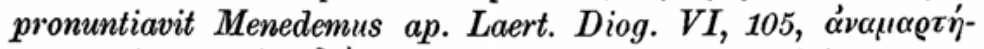
tors sois onipoìs siva Zeno, ibid. 7, 122). Age igitur, quae agis, respiciens ne altera vice labores.

248. II 19, 18: Doctrinam, quae deo non digna est, nunquam disce.

249. II 19, 19: Doctrina enim multa ad veritatem inutilis aberratio mentis est. I 5, 5: Multitudo autem doctrinae a te putetur scrutatio vana.

250. II 19, 20: Qui doctrinam deo dignam discit, is sapiens est. I 5, 6: Is enim sapiens est, qui seit, quid deo conveniens sit, et studet ut faciat.

251. II 19, 20: Nam sine doctrina timoris dei non potes dei amans fieri; hane doctrinam attende diligenter. I 10, 3: Doctrinam, sine qua dei amans non fis, acquire eique firmiter adhaere. 
252 (243) Sapiens uir parcit ne perdat tempus.

253 (244) Fiduciam cum verecundia habeto. Cf. $\varphi v \lambda \alpha \dot{\alpha}$ -

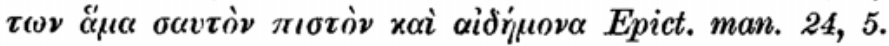

254 (245) Excrucient te liberi male uiuentes magis quam morientes.

255 (248) Uiuere quidem non est in nobis, recte autem uiuere in nobis est.

256 (246) Filii infideles nee filii.

257 (247) Fidelis uir non ingrate fert abiectionem libe-

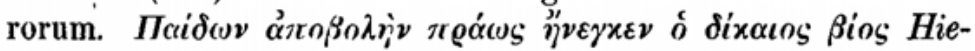
rocl. in carm. aur. 17-20 p. 85 Needh.

258 (249) Non iudices esse philosophum, eui non de om-

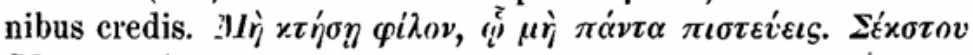
Max. 6. Ant. 1, 25.

252 parcet JGU || 253 reverentia GU | habe $\mathbf{S} \| 254$ om. U | 255 om. GU | quidem om. S | est cum dei auxilio in nobis $\mathbf{S} \| 256$ om. $\mathbf{S}$ | ne fili $\mathbf{G}$ : ne filhi quidem sunt $\mathbf{w}$ | nee filii fidelis. Uir etc. 257 WVUB(-les) || $257 \mathrm{om}$. S | abi. non ingr. fert lib. G || $258 \mathrm{om}$. GU

252. II 19, 22: Vir sapiens diebus suis pareit, ne eos frustra absumat. I 5, 7: Vir enim sapiens tempus suum non absumit frustra atque denuo 10, 4: iisdem prorsus verbis.

253. II 19, 6: Homo sapiens etiam gradus suos cum verecundia facit.

254. II, 19, 7: Sine filiis vivere melius tibi est, quam pravos habere filios.

255. II 19, 23: Corpore vivere nostrum non est, at mente

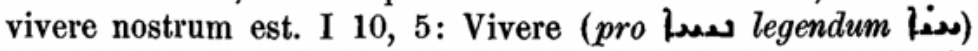
enim potestatis nostrae non est, probe autem agere potestatis nostrae est.

256. II post 254 habet 19, 8: Quia filii, in quibus vera fides non est, filii non sunt. Eodem loco collocat vulgaris editio Latina contra omnes meos testes.

257. Deest.

258. II 19, 24: Neminem, cui credi non potest in omnibus,

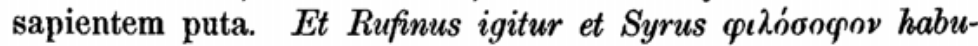
erunt pro piגov, ex quo illud depravatum censendum est.

258 . Addit II 19, 25: $\mathrm{Si}$ antem eum vere sapientem scis, omuia, quae tibi dicit, ab eo accipe. 
259 (251) Criminationes adversus philosophum noli recipere.

260 (250) Stude communiter omni homini bene facere.

261 (252) Execrabile sit tibi etiam iuste aliquid punire.

262 (253) $\mathrm{Si}$ uis cum laetitia animi uiuere, noli multa agere; in multis enim actibus noceris. Tòv $\varepsilon \dot{\jmath} 9 \iota \mu \dot{\varepsilon} \varepsilon \sigma \vartheta \alpha \iota \mu \dot{z} \lambda$ -

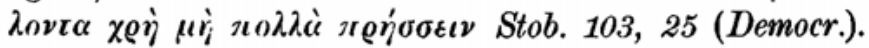

263 (254) Quod non posuisti, non tollas, sed sufficiant

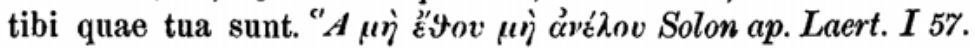
$264(255)$ Derelinquens quae possides sequere uerbum dei; liber enim eris ab omnibus, cum deo servis.

$259 \mathrm{om} . \mathrm{U}$ | recipere WOPVBJSw: admittere Ger|Pseudo-Isid. Criminationes adversus doctorem nemo recipiat Sixt. III (p. 562) suscipsat Alex. ep. 1. 5 (97) Cal. ep. 1, 3 (136 ubi contra) Steph. 2, 13 (186). Accusationes adversus doctorem nemo suscipiat Capit. Angilr. $12^{\text {bis }}$.\| 260 Omni honini] omnibus er || 261 sit tibi WOPJS: tibi sit rell.| aliquem aliquid iuste $\boldsymbol{\theta}$ || 262 actionibus er | moneris WPB: moueris $\mathbf{O S w}$ : et caute premoneris $\mathbf{V}$ : et comptus bene non eris $\mathbf{G U}$ : minor eris er Haec omnia ferr non posse apparet; proposu Syrum secutus noceris; non prorsus alienum esset: et cautus noceris \|| 263 Quae U | ne tollas $\mathbf{O P w}$ | sufficient $\mathbf{0 P}$ : sufficiunt $\mathbf{G} \| 264$ ea quae $\mathbf{w} \mid$ enim om. $\mathbf{S}$ | ab omnibus eris G | servieris Jr e?

259. II 19, 26: Calumniam adversus sapientem ne admittas.

260. II 19, 26: sed ita te geras, ut omnium hominum adiutor sis.

261. II 19, 27: Recusa hominem punire, etiamsi iuste eum punias. 260. 261 coniungit I 5, 7: Si cum hominibus benigne agere tibi in animo est, precare, ut etiam iuste nemini supplicium irroges.

262. II 19, 28: Si recte vivere vis, ne cupias principatum et dominium huius mundi, qui enim in multa se coniicit, multa congerit peccata. I 5, 9: Si vitam laetitiae vivere vis, non coniice te in multa; si enim multa sunt negotia (pro corrupto , lego Sequitur apud. I sent. 75, quam v. supra p. 11.

263. II 19, 30: Nulla re, quae tua non est, utere; sin autem, tanquam avarus ea uteris.

264. II 20,2 : Relinque omnem possessionem tuam et sequere verbum dei; liberum reddis te, cum dei servus es. I 10, 6: Ab omnibus libera te, si dei servus es. 


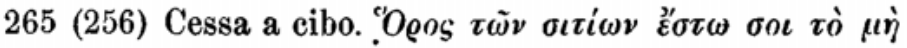
$\pi \varepsilon \iota \nu \tilde{\nu}$ Boiss. 1132.

266 (258) Omni homini inperti.

267 (259) Pro reficiendo paupere etiam ieiunare bonum est.

268 (260) Omne poculum suaue tibi sit.

269 (261) Temulentiam quasi insaniam fuge. $C f$. $\grave{\eta} \mu \varepsilon \dot{\vartheta} \eta$

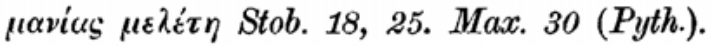

270 (262) *Homo qui a uentre uincitur similis est beluae.

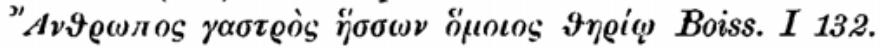

265. 266 inperti WOPVU: imparti $\mathbf{w}$ : impertire B: impertire stude $\mathbf{S}$ : impertito $\mathbf{J}$ : impartito $\mathbf{r}$ | Cesse a cibo omni homini impartiri G: Cessa ab omni cibo bonis impartito e || $2680 \mathrm{mni}$ poculo W0w| tibi suave sit $\mathbf{r}(\mathbf{O P}$ ?): tibi sit suave $\mathbf{S}$ | In fine quod sitim extinguit addunt er || 269 Temulentiam] ebrietatem er || 270 a om. $\mathbf{G}$ | similis est beluae A: belua similis est WOPVBJSGUw: belluae fidelis est $\mathbf{r}$ : belluo fidelis est $\mathbf{c}$

264. Addit II 20, 3: Uno enim dei timore te multis timoribus levabis.

265. II 20, 4: Desine a cibo, quamdiu esuris, neve edas multa avide. II 5, 13: Recede a cibo, dum adhuc esuris, ut corpus tuum vegetum sit et animus vigilans. Syri confirmarc videntur, recte supra collata esse Gracca verba, quae Rufinus, nullo tamen sententiae damno, ita in angustum cogere potuit. Quae Latinus textus vulgatus addit: (257) Ede citra satietatem, explicandi studio deberi videntur, nec est quod antiquioris lectionis vestigia inesse suspiceris.

266. II 20, 5: et participes fac tecum egenos cibi tui. Recte cibi, de quo etiam Rufinus intellegendus est, mentionem facit.

267. II 20, 6: Melior enim is est, qui esurientes satiat, eo qui ieiunat et preces fundit. I 5, 14: et quo te ipsum fraudas, id des homini indigenti, ut eo tibi merces sit.

268. Deest: at eius loco II praebet

$268^{\mathrm{a}}$. 20, 7: Ne multum cibum et potum appetas. Apud

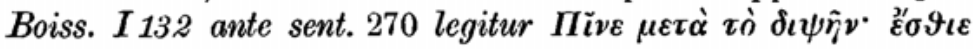
$\mu \varepsilon \tau \grave{\alpha}$ iò $\pi \varepsilon \imath \nu \tilde{\eta} \nu, q u o d$ ab illis verbis haud nimis alienum est.

269. Il 20, 8: et cave ab ebrietate tanquam ab insania.

270. II 20, 8: Quicunque homo a ventris cupiditate vincitur, animalium sensum habet, quibus addit $270^{\mathrm{a}}$. I prae- 
271 (263) Ex carne nil oritur bonum.

- 272 (264) Turpissimae libidinis ea quidem, quae suauia sunt, cito transeunt, probra vero perpetua manent.

273 (265) Solent homines abscidere aliqua membrorum suorum pro sanitate reliquorum; quanto id praestantius pro pudicitia fiet. 'Av9

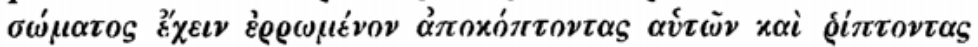

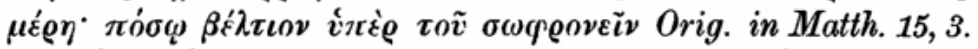

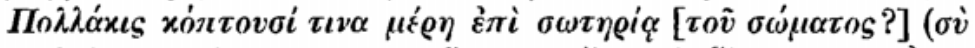

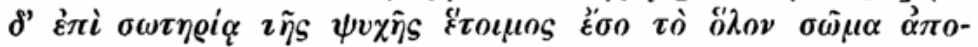

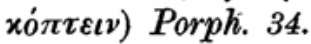

271 boni Sw || 272 lib. suavia cito S | perpetua WOPVB: perpetuo JSUwr: in aeternum $\mathbf{G} \mid$ Ultima vocabula seorsum ita ponit c: Proba verba perpetuo manent || 273 hom. membr. suor. absc. G | aliquod S | quanto magis hoc fit praest. pro pud. S

mittit, quae numero $270^{\text {b }}$ insignimus, et pergit 5, 16: qui enim ventris cupiditati succumbit, animalia is aequat.

$270^{\mathrm{a}}$. II 20, 9: quia animali nil (cordi) est, quam ut, si esuriat, edat.

$270^{\text {b }}$. I 5, 15: Magnam sapientiam puta, hominem corpus

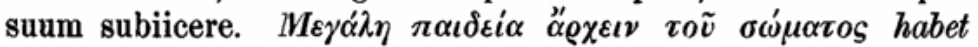
Porph. Marc. 34 coniunctum cum aliis e Sexto petitis, cui haec eo certius tribui possunt, cum etiam Syr. II ea legerit cf. 274.

271. II 20, 10: Ex omnibus enim, quae seminas in ventrem, nil boni oritur, sed corruptio, quae verba sunt Pauli Gal.

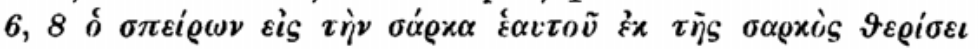
$\varphi \vartheta o \varrho \alpha \dot{\nu}$, sed non e Simplici petita.

272. II 20, 11: $\mathrm{Si}$ autem cupiditatem tuam vincere vis, animum a cibis multis coerce, quia opprobrium sunt eorum qui iis utuntur. I 5, 17: Quia expletio cupiditatis celeriter finem habet et dedecus eius semper manet.

272 ${ }^{\mathrm{a}}$. Addit II 20, 12: Cupiditas enim ciborum multorum ad scortationem te trahit et ducit. Est sententia a Georgide servata, in qua casus locum male mutarunt, p. 21: $\gamma \alpha \sigma \tau \varrho \iota \mu \alpha-$

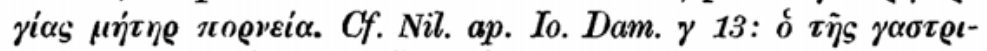

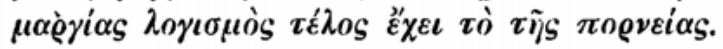

$272^{\mathrm{b}}$, Pergit II 20, 13: Haec enim est curatio immundae cupiditatis, si ab ea prohibes corporis voluptates.

273. II 20, 13: Potius quam a cupiditate tua vincaris et 
274 (266) Grandem poenam putato cum desideriis optinueris, numquam enim compescit desiderium possessio desideratorum.

275 (267) Non est sapiens factum, in quo libertas aufertur. 276 Libidinem necessariam tamquam necessariam ducito.

277 (268) Bona quidem habere omnes optant, optinent autem hi qui semetipsos exintro uerbo dei manciparunt.

274 desideriis W0Bw: desideria PJS: quid ex desideriis corporalibus $\mathbf{V}$ (sed quid ex supra scriptum est): desiderans carnalia $\mathbf{G U}$ : in desideriis or | enim om. GU | compescit VBGer: concupiscit WOPS: quietat $\mathbf{w}$ | poss. des.] desiderans multa (sic) GU | desideriorum J || 275 sapienter Ger || 276 necessariam WOPVBJSw : non necessariam GUer| dicito S || 277 quidem om. SVGU: quidam, omisso omnes e | habere]

membrum naturale abscidas, cupiditatem corporis tui coerce et membrum tuum loco suo relinque. I 5, 18: Multos aegrotos vidi, qui, ut sanum sit reliquum corpus, abscisa proiecerunt membra sua nocentia, ne usum sanorum inutilitate sua turbarent. Quanto magis quis consuetudini hominum profanorum et levium se subtrahere debet, ne etiam animae suae partes sanas moribus eorum laedat.

274. II 20, 16: Nam magna sapientia a te putetur, si corpus tuum regis eique imperas atque dominus et iudex es (Haec priori parti sententiae 274 non respondent, sed Porphy-

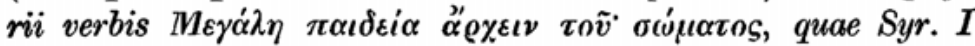
iam $270^{\mathrm{b}}$ exhibuit). Si igitur omne mundi aurum et argentum das, ignem cupiditatis tuae nec vincere nec exstinguere potes.

275. II 20, 19: Homo autem sapiens per libertatem suam cupidinem vincit et domat. I 5, 22: Oritur tibi praevalens di-

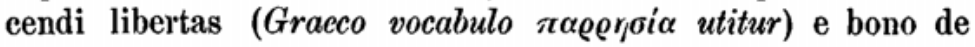
puritate cordis tui testimonio, hoc est, cum ei admixta est gravis memoriae dei verecundia propter veram mentis tuae sibi consciae humilitatem.

$275^{\mathrm{a}}$. Addit II 20, 20: Nihil enim est, quod hominis libertatem vincat.

276. II 20,21 : Licet autem tibi distinctio inter cupiditatem tibi honestam et cupiditatem tibi turpem; est enim cupiditas vitae et cupiditas mortis: 'E Epicuri intellegendae sunt. Laert. D. 10, 149.

277. II 20, 23: Bonum quivis amat in verbis, in operibus 
278 (269) Philosophus et honestus esto et non obtrectator.

279 (270) Rara sit obtrectatio tua et opportuna.

$280(271) *$ Nimius risus indicium est animae neglegentis; non ergo tibi ipsi indulgeas plus diffundi quam subridere.

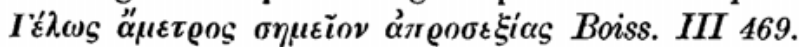

$281 *$ Alacritate magis utere, quam resolutione.

facere $\mathbf{S}$ | omnes] homines $\mathbf{G}$ : homines omnes $\mathbf{w} \mid$ hi om. Ur: ii $\mathbf{w} \mid$ met-

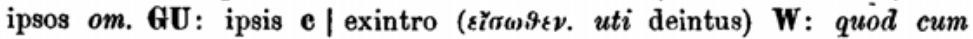
prorsus singulare esset, emendare sibi visi sunt ex integro OPBJSGUer: integro V: ex intimo $\mathbf{w}$ : | verbum W |'ंdei om $\mathbf{S}$ | mancipant $\mathbf{S}$ || 278. 79 om. GU || 279 sit WPJpr: sit satis OBSw: satis sit V| tua om. w || 280. 281 ipsi om. S | indulgeas tibi ipsi G|plus s.lus A que utrobique pro quam A | Vocabula plus et alacritate magis utere in co-

vero penes quos inveniatur pauci sunt, ei quibus familiaritas

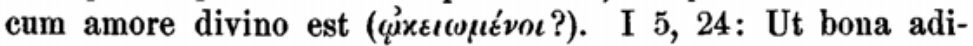
piscatur quivis preces fundit, adipiscuntur autem operibus ei, qui vere ad vim (?) sapientiae divinae se applicant.

$277^{\star}$. Novam sententiam inducit I 5, 26: Suaves sint tibi aerumnae quae propter deum sunt, quae tibi etiam utiles sunt, nam sine iis fieri non potest, ut, si fidelis es, constantia tua exploretur.

278. 279. II 20, 25: Si sapiens es, sis integrae mentis

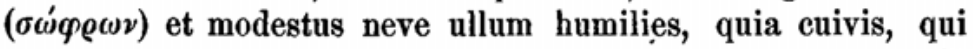
linguam non coercet, lingua contumeliam affert. I 5, 28: Si

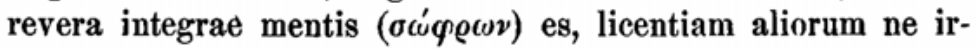
rideas neve illudas (leg. 2 ( 2$)$, sed dolore propter eos afficiaris et fleas sicut mater de unico suo filio dolet. Et quando rursus eum qui deliquit vituperare oportet, benigne admone, ut eum dolore afficias et animus eius e verbo tuo fructum capiat, neve acriter eum accuses, ne eum perdas et damnum efficias. Conferri potest Flor. Mon. 33.

280. II 20,26 : $\mathrm{Si}$ autem ridere et oblectari vis verbis, quae homines non afficiunt et in quibus amor dei inest, talibus oblectare et laetare (279?), nunquam autem risui turbulento animum tuum des, sed hilaris tantum sis exemplo ( $\pi \alpha \rho \alpha \delta \varepsilon \varepsilon \gamma \mu \alpha$ cf. Lagarde Anal. p. 173, 27) illo, quod spiritus sanctus per os prophetae pronuntiavit. (Respicere videtur Eccles. 11, 9).

281. Vocis alacritate vestigium Syrus servavit in vocabulo hilaris. Resolutio risum dissolutum immoderatum significat, de 
282 (272) Castorum uita sit tibi ad honestatis exemplum.

283 (273) Optimum quidem est non peccare, peccantem vero agnoscere, quam ignorare melius est. Pyth. syr. 63 (Graeca desunt).

dice illo ex quo ceteri omnes manarunt exciderant, unde hi reliqua dua vocabula cum praecedentibus coniungere pro viribus conati sunt. Post diffundi igrtur praebent quam subridere quam resolutione WOP: tam subridere quam resolvi Vr: quam subridere cum resolutione B: quam subridere sine resolutione $\mathbf{S}$ : quoniam subridere quam dissolutionem ferri honestius $\mathbf{w}$ : in minima (nimiam $\mathbf{U}$ ) oris risus resolutione(-nem $\mathbf{U}) \mathbf{( H U}$ : omnia haec om. Je || 282 ab honestis \& || 283 quidem om. S | est bis om. G | agnoscere PVSUr: ignoscere WOB: innotescere Jc: agnosce te $\mathbf{w}$ | quam] quoniam $\mathbf{w}$ | multo melius $\mathbf{U}$ | vero non cognoscere multo melius $\theta$

quo Tertullianus ad nat. 1, 19 utitur verbo resolutius cachin-

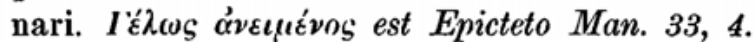

282. II 20, 30: Omne autem huius mundi tempus certamen tibi sit propter mundum illum castum qui non transit. I 10, 7: Per totam tuam vitam certamen tibi sit propter res

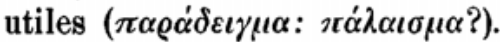

283. II 21, 2: Primum autem hominem oportet cavere ne peccet, si autem labitur et peccat, necessarium est, ut peccatum suum confiteatur et per lacrimas et preces et dei amorem sanetur. Sed idem iam antea inter 10 et 11 sententiam ita exhibuerat: Prima autem virtus est hominem non peccare, si autem labatur et peccet, magis decet hominem peccatum suum patefacere, quam celare. Cognata, sed non eadem sunt: Kuגòv

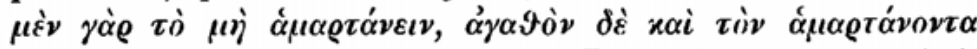

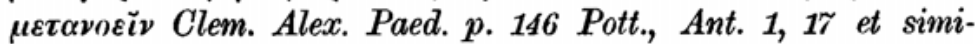

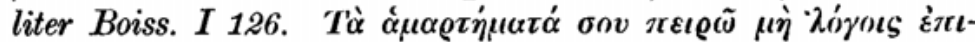

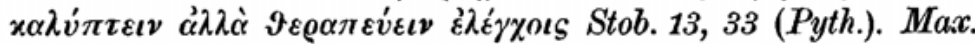

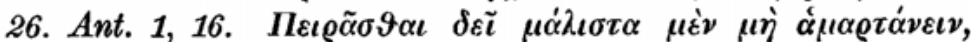

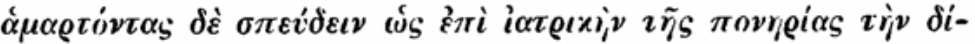
xๆv Hierocl. in carm. aur. 27-29 p. 125 Needh.

283a. Addit II 11, 5: Et scias et videas peccatum esse, si quis etiam in mente tantum peccare cogitet, nam omne quod cogitas et cui mens tua consentit, iam dudum in animo tuo fecisti. $C f . M t$. 5, 28. Haec fortasse respondent sent. 233, quam suo loco non habet Syr. II. 
284 (274) Iactans non est philosophus.

285 (275) Magnam scito esse sapientiam, per quam ferre

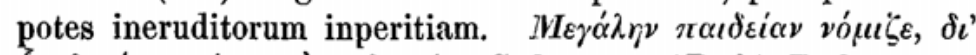

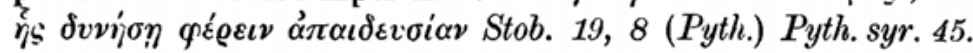
Demoph. 28. Ant. 2, 89.

286 (276) Turpe ducito proprio ore laudari.

287 (277) Sapientum animae insatiabiles in amore dei.

288 (278) Exordium a deo sume in agendo, quae agis.

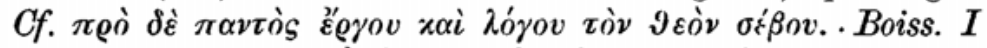

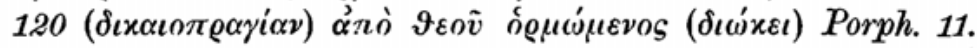
289 (279) Ore prius deum habeto in mente quam respiras.

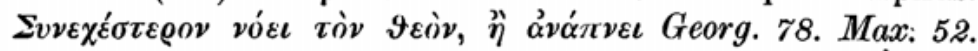
(Epict.) Flor. Mon. 2.

285 esse om. $\mathbf{J} \mid$ per quam om. $\mathbf{O} \mid$ potest $\mathbf{O G} \mid$ ferri potest in. imperitia $\mathbf{U}$ | iner. insipientiam er: imperitorum ignorantiam $\mathbf{S}$ || 286 dicito p. l. o. S || 287 Sapientium JSUewr | sunt in dei amore GU|| 288 sume a deo $\mathbf{B}^{2} \mathbf{G} \| \mathbf{2 8 9}$ Ora prius deum. Habeto in mente cum

284. II 21, 4: Homo iactans suique laudator non est sapiens. I 6, 2: Qui iactans est, sapiens non est.

$284^{2}$. Addit I 6, 3: Sapientia enim vera possessores hic docet humilitatem: se eos, si hic humiles sint, super omnes alios exaltaturam, neque eos. rursus humiliatum iri. Spectasse videtur Mt. 23, 12. Luc. 14, 11. Similia Nil. 128 Dìzє vìv

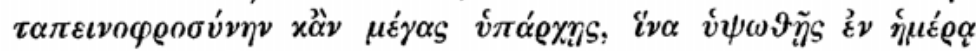
x

285. II 21, 5: Sapientia autem magna tibi putanda est, si perferre potes imperitiam ( $\alpha \gamma v o \iota \alpha v)$ eorum, qui sine disci-

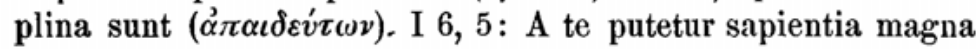
esse, propter quam sine murmure ferre potes stultorum mentis defectum.

286. II 21, 6: Pudori tibi magno est, si laudari vis ob decus corporis et pulchram speciem.

287. II 21, 7: Iustorum animi nunquam satiantur timore dei. I 6, 8 (post 289): Animo fidelium in sinceritate sua non est satietas timoris dei.

288. II 21, 8: Enixe igitur in corde tuo semper memoria dei teneatur.

289. II 21, 9: Neve desinat memoria dei in corde tuo, 
$290(280) \mathrm{Ea}$, quae oportet discere et ita facere, ne coneris facere, antequam discas.

291 (281) Carnem noli amare:

292 (282) Animam bonam dilige post deum.

293 (283) Domesticorum indignationes ferre sapientis est.

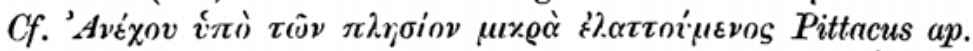
Boiss. I 139 s. Thales ap. Stob. 3, 79.

294 (284) *Sapientium diuitiae continentia.

295 (285) Si quid proprium alii tradideris, at ipse non

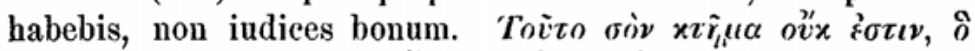

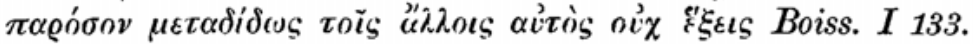
cf. Pyth. syr. 30.

296 (286) Nihil bonum, quod non potest esse commune.

respiras B: Prius deum habeto in ore et in. mente quam respiras G: Prius habeto deum ore et mente q. r. U | Ore WOPJSw: ore autem Vr | in mente quam WOPVBw: et mente qnam er: quam mente $\mathbf{S} \mid$ respires JSUer || 288. 289 Qui agis ore e. Codd. offenderunt in vocabulo ore ad respiras trahendo et emendare voluerunt || 290 dicere $\mathbf{G}$ | facere ant. discas] dicere antequam discas GU | anteaquam w || 292 post deum dilige er || 293 indignationem JU | sapiens G || 294 Sapientiz A : sapientum VB: sapientium rell. \| 295 at] et B \| 295. 6 habis. Ne indices bonum quod non $\mathbf{w} \| 296$ communiter $\mathbf{U}$

sicut non desinit spiritus in naribus tuis. I 6,7: Magis quam respiratio tua sit firma in te memoria dei.

290. II 21, 10: Quod te discere oportet, usquedum a vero magistro didiceris, ne facias.

291. II 21, 11: Ne concupiscas corporis speciem, sed animi boni pulchritudinem. Bis habuit vel vertit animam bonam s. 292.

292. 'II 21, 12: Et post dei amorem ama hominem bonum.

293. II 21, 13: Vir sapiens sustinet et tolerat iram domesticorum.

294. II 21, 14: Divitiae sapientis coercitio corporis. I 10, 8: Divitiae sapientis sunt: cavere a cupiditatibus.

295. II 21, 14: Omne donum, quod das ex opera non tua, tibi non imputatur in iustitiam. Sequitur 21, 15 eadem sententia aliter reddita: Omne donum, quod aliis das et quod e tuo labore non est, non est a deo. I 6, 9: Quod cum aliis das totum penes te non manet, non inter bona a te referatur. 296. II 2k, 16: Bonis tuis fructus non est, nisi cum eis 
297 (287) Non ducas aliud alio peccatum leuius. 'A $A \alpha$ á-

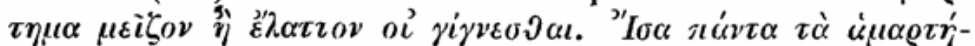
$\mu$ на $\alpha$ Stoici ap. Stob. Ecl. II 220. 218 Heeren.

298 (288) Sicut in bonis actibus laudari uis, ita in delictis patienter accipe, si culperis.

299 (289) Quorum-laudes contemnis, nec derogationes

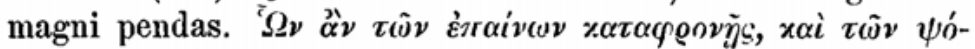

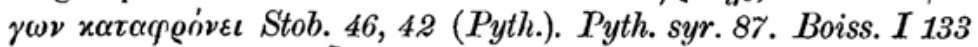

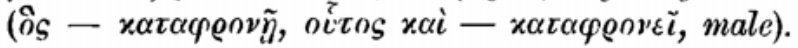

300 (290) Thesaurum defodere quidem inlumanum est, inuentum autem auferre non est philosophi.

301 (291) Quantum laboras pro corpore, si tantum pro

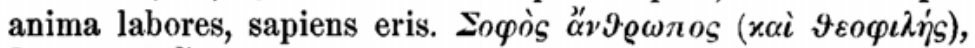

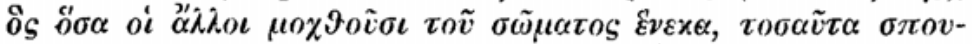

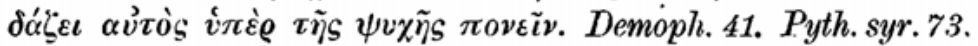

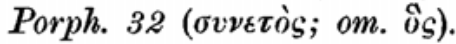

$297 \mathrm{Ne} \mathbf{w}$ | dictas $\mathbf{G}$ : dicas Ser | alio] odio w | peccato BSer\| 298 Sicut enim $\mathbf{U} \mid \mathrm{Si}$ in - ita et $\mathbf{G} \mid$ factibus $\mathbf{O P} \mid$ delitiis $\mathbf{O P}$ : deliciis W | si culperis] sicut petis $\mathbf{W}$ : si corriperis U || 299 neque Oer || 300 defodere quidem WPVBJer: effodere quidem Sw: quidem defodere $\mathbf{0}$ : defudere QU | autem WVBJSUew: om. OPGr | est om J || 301 Quantum autem er | laboraes P: laborares $\mathbf{U}$ : laboras $\mathbf{e}$ | pro an. lab. WPBJw: lab. pro an. OVSGUer | esses U

qui tecum sunt communicas. I 6, 10: Nilil enim est, quod servatum nec ad alios translatum bonum sit (dele $\circ$ ante $\rightarrow \sigma o \Delta s)$.

297. II 21, 17: Peccatum magnum et peccatum parvum ex eadem mali natura sunt.

298. II 21, 18: Sicut in re quam instituis laudari cupis, ita etiam, quando de stultitia tua corriperis aut culparis, sustine neve conquerere.

299. II 21, 20: Et sicut laudatus laetaris sic eulpatus perfer. I 6, 11: Hominum, quorum laus a te contemnitur, etiam vituperatio despiciatur.

300. II 21, 21: Thesaurum in terra condere non est humanitatis. I 6, 12: Thesaurum reservare non est virorum humanorum, neque eum effodere fidelium.

301. II 21, 22: Omnes labores, quos corporis causa perfers, si animi causa perfers, tunc iustus appellaris. I 10, 9 : Quoties laboras corporis causa, vesanus es, sin autem animi causa, sapiens eris. 
302 (292) *Sapiens non est qui nocet.

303 (293) Omnia quae agis, deum inuoca testem. Móor

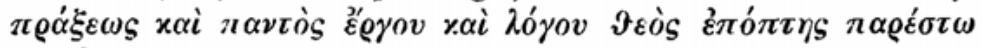

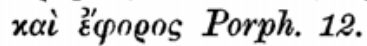

304 (294) Deus bonos actus hominum confirmat. $\Theta \varepsilon o ̀ s$

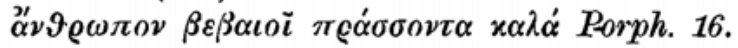

305 (295) Malorum actuum malus daemon dux est. Kaxĩv

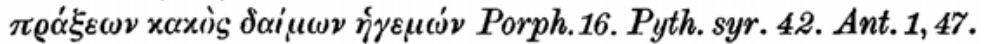

306 Non poterit sapiens compelli facere quod non uult, sicut nec deus.

307 (296) Sapiens uir deum hominibus commendat.

308 (297) Deus inter opera sua omnia plus super sapientem gloriatur.

309 (298) Nihil tale uerum post deum, sicut sapiens post uerum.

302 S. est qui non nocet G: S. non est qui non docet S | PseudoIsid. Sapiens est qui (v. l. omnis qui) non nocet Alex. ep. 3,20 (p. 105). Corn. 2, 6 (174). Luc. 6 (178). Melch. 1, 5 (244) \| 303 Omnium VB $^{2}$ : ad omnia er: in omne $\mathbf{S} \| \mathbf{3 0 4}$ hominum actus $\mathbf{S}$ : hominis actus $\mathbf{A} \| 306$ ut faciat $\mathbf{w}$ | quae SU | videt $\mathbf{e}$ | sic nec deus $\mathbf{P}$ : sicut deus $\mathbf{c}$ : perinde atque nec deus $\mathbf{W} \| \mid 308$ super omnia opera sua?? P: inter omnia opera sua SG: sine sua $\mathbf{J}$ : omnia inter opera $\mathbf{e}$ | sapiente $\mathbf{B}$ | glorificatur $\mathbf{J}||$ rum post deum WOPBSw: quam verum est post deum $\mathbf{V}$ : verum est post deum GU: post deum verum Jer | post verum $\mathbf{J}$ : post virum Wo PBSGUw : post virum, correctum in post verum $\mathbf{V}$ : om. er

302. II 21, 24: Quia sapienti nihil est quod ei noceat.

303. II 21, 24: Quidquid agis, deum invoca socium.

304. II 21, 25: quia deus bona opera in fidelibus confirmat. 305 . II 21, 26: sicut etiam malorum operum malus daemon dux est.

306. II 21, 27: Non autem est necessitas, quae iustum a voluntate dei avertere possit, sicut etiam deum homo compellere non potest.

307. II 21, 28: Homo vero sapiens effieit, ut deus hominibus appropinquet.

308. II 21, 29: Deus etiam magis quam omnibus operibus suis homine bono et iusto delectatus est eumque sibi propinquum reddidit.

309. II 21, 30: Nihil enim laudabilius est post deum quam homo iustus. Latina corrupta sunt neque expediunt verba Porph. 


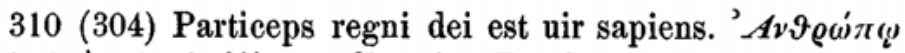

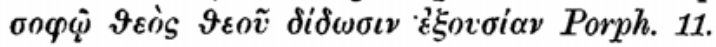

311 (299) Quaecunque deus possidet, haec et sapiens.

312 (300) Malus uir non uult esse prouidentiam. (

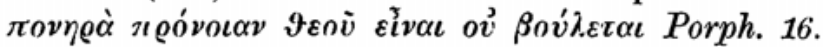

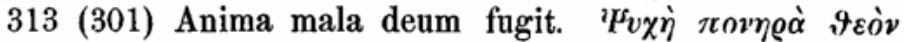

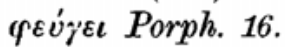

314 (302) Omne, quod malum est, deo inimicum est.

315 (303) Quod sapit in te, hoc ducito esse hominem.

310 om. GU: post 311 collocat $\mathbf{W}$ : post $312 \mathrm{~J}:$ post 315 ponunt Scr | regni dei WOPVBJSw: dei er || 311 Quem deus possidet, hoc et c| possidet] habet GU || 312 vir om. S: homo U | putat non esse V: non putat esse $\mathbf{r}$ | esse om. $\mathbf{G} \mid$ providentiam corr. in providens $\mathbf{B}$ : providens e || $315 \mathrm{om}$. S | Qui - hunc er | huuc? P| B om. hoc - 316 in te

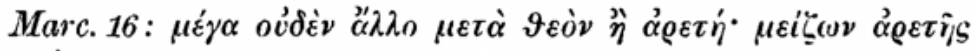
$\vartheta \varepsilon o_{s}$, quae cum ibi sententiis 304. 305. 313.312 iuncta legantur, huc trahenda videri possunt. Quod dicere voluit, fere hoc est: Nihil tam altum quam verum etc.

310. II 22, 2: ( post 311, sed vel propter et coniunctionem alias minus idoneam huc trahendum): et deus etiam amat virum iustum et sapientem. E Graecis conferendum esset Pittaci illud

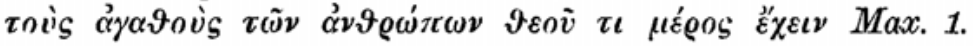
Arsen. p. 420, si statui posset, vocem regni, qua Syrus caret, Rufino postea adsutam veramque lectionem a testibus minoris fidei $\mathbf{c}$ et $\mathbf{r}$ hic servatam esse.

311. II 22, 1: Quidquid deus odit et fastidit, odit et fastidit etiam iustus. Discrimen inter utrumque interpretem non e mu-

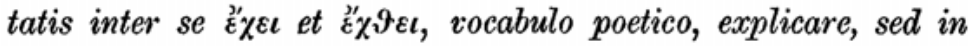
Latina sententia satis absurda fastidit reponere malim.

312. II 22, 3: Homo autem malus secundum voluntatem dei se gerere non vult.

313. II 22, 4: Anima enim mala deúm fugit.

314. II 22, 5: et quidquid facit, deo adversata facit.

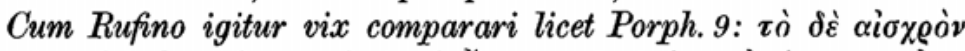

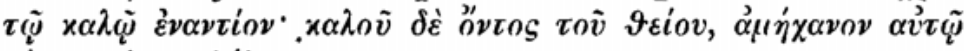

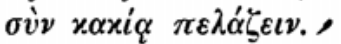

315. II 22, 5: Scias igitur illum quemcunque sensum, qui in te est, qui cognoseit et intellegit, hominem esse. 
316 (305) Ubi est quod sapit in te, ibi est et bonum tuum.

317 (306) Bonum in carne non quaeras.

318 (307) Quod animae non nocet, nec homini.

319 (308) Philosophum hominem tamquam dei ministrum

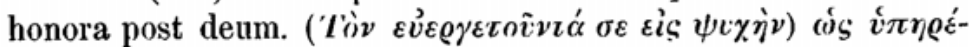

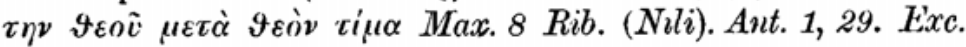
Vind. 8. Pyth. syr. 82. Cf. 244.

320 (309) Tabernaculum corporis grauiter quidem ferre superbum est, deponcre autem posse cum oportuerit in pace beatum est.

321 (310) Mortis quidem ipse tibi causa non fias; si quis autem te exuere unlt corpore, ne indigneris.

322 (311) Sapientem de corpore iniuste si quis extrudat, in iniquitate sua beneficium ei praestat, absoluitur enim tanquam de uinculis.

316 id quod w | est alterum om. BS || 317 ne Vw || 318 id quod w | nec] non S || 319 hominem om. S || 320 Tab. quidem corp. cr: tals. q. f. gr. $\mathbf{J} \mid$ quidem om. $\mathbf{S} \mid$ spfferre $\mathbf{U} \mid$ superbum est sufferre graviter quidem $\mathbf{G}$ | beatum] bonum J(XUe || 321 causa om. G: auctor $\mathbf{U} \mid$ ne fias $\mathbf{w} \mid$ te vult corp. ex. c: vult te corp. ex. $\mathbf{r}$ : ex. to vult corp. JU | te exuerit corpore libenter suscipe $\mathbf{S} \| 322 \mathrm{Si}$ quis de corp. $\mathbf{w} \mid$

316. II 22, 6: Et ubicunque intellectus tuts est, ibi etiam bonum tuum est.

317. II 22, 7: In corpore autem ne quaeras bonum, sed in mente.

318. II 22, 8: Quodeunque animo non nocet etiam homini interno non nocet. Quod cum absurdum sit, legendum propono lsa, homini universo, etsi hic eius verbi usus addubitari possit.

319. II 22, 9: Propterea post deum hominem dei honora tanquam dei ministrum.

320. II 22, 10: Non decet animam, graves sibi esse res exiguas corporis; precare autem, ut cito aerumnas corporis effugias; haec est precatio animi beati.

321. II 22, 12: Tu autem homo tua ipsius voluntate ne fias causa mortis; quando autem tibi mors supervenit, ut te corpore exuat, deum de ea re lauda. I 6, 13: Causa mortis tibi ipsi ne fias, si quis autem te interficere studet, ne ei succenseas.

322. II 22, 14: Quicunque autem iustum per vim corpore 
323 (312) Hominem metus mortis contristat pro inperitia animae.

324 (313) Ferrum, quo homines interimuntur, optimum quidem fuerat non fieri, factum tamen apud te non sit factum.

$325(314) *$ Nulla simulatio multo tempore latebit et ma-

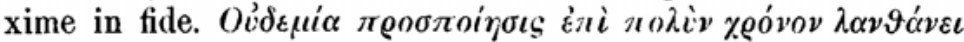

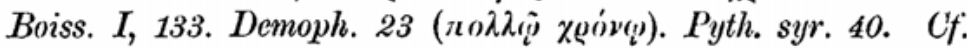
Menander Mon. 5.7\%.

326 (315) Prout sunt mores tui, talis sit et uita tua; mores enim religiosi faciunt uitam beatam. Oiov $\tau i \eta^{3} \vartheta o s \underline{\varepsilon} \times \alpha^{\prime}-$

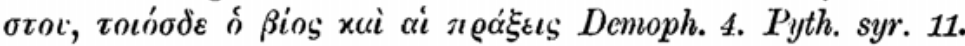
Fere eadem Democrat. 26.

327 (316) Qui cogitat aduersum alium mala, praeueniens

iniuste extrudat Ur: iniuste excludat $\mathbf{c}$ : vi extrudat $\mathbf{S}$ | in om. OBJSUw| sua om. ${ }^{-} \mathbf{G} \mid$ tanquam om. $\mathbf{w} \mid$ a vinculis $\mathbf{G} \mid \mathbf{S}$ hanc et priorem sent. turbat || 323 mortis metus $\mathbf{w}$ : mortis om. Je | propter imperitiam (GU| animae om. $\mathbf{w}|| 324$ quol quidem quo $\mathbf{c}:$ quidem in quo $\mathbf{r}$ : in quo JSU | interimuntur et occiduntur $\mathbf{G} \mid$ melius $\mathbf{S} \mid$ quidem om. PS | factum in fine om JUer $\| 325$ diu $\mathbf{S} \mid$ in fide $\mathbf{A}$ : in finem $\mathbf{J}$ : in fine rell. $\|$ 326 sit om. JSer | bonam vitam $G|| 327$ adversum WPVGU: adversus

exuit, scelus suo sceleri addit: iustus autem, si corpore exuitur, duris vinculis solvitur. I 6, 14: Qui autem iustum temere interficit, per suam malitiam ei bene facit, quia iustus tanquam compedibus solvitur et mercedem oppressorum accipit; ille autem ad poenam eorum, qui iustos occiderunt, asservatur.

323. II 22, 16: Mors autem non affligit nisi animum, qui legem dei non agnoscit. I 6, 17: Metus mortis afflictat virum vilem, qui autem in se ipso bonum testimonium possidet, eam sibi optat, ut vitam habeat.

324. Huius loco habet II 22, 17 scnt. 387 , quam infra confer.

325. Deest; pro ea legitur sent. 334 .

326. II 22, 20: Quales facis corpori tuo consuetudines, tales etiam patefacies consuetudines; consuetudines vero timoris dei hominibus in hac vita prosunt. I 6, 19: Quales sunt mores tui, talis et vita tua; boni enim mores vitam reddunt beatitudinis plenam.

327. II 22, 22: Quicunque alii malum infert, super eum venit multoties. 


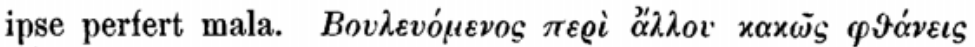

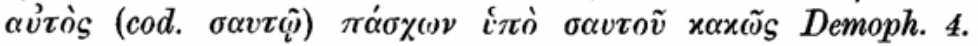
Pyth. syr. 11.

$328(317) *$ Non te inpediat a bene faciendo homo ingratus. Graeca habuit etiam Pyth. syr. 81.

329 Nihil eorum quod petitur maioris pretii dignum ducas pro eo, qui accipit.

330 (318) Optime utitur facultatibus is, qui indigentibus libenter tribuit.

331 (319) Fratrem uolentem a fide discedere persuade, ne faciat, et si insanabilis est, mìgis conserua.

332 (320) In fide omnes homines conare uincere.

333 (321) Intellectum non prius habebis, quam intellexeris te non habere $=199$.

334 (322) Sufficientiam seruare stude.

OBJSewr | praeveniens ipse W0VBGUw: praeveniens J : ipsa praeveniens c. ipsa praeveniens ipse $\mathbf{P r} \mid$ perficit malum $\mathbf{U}$ | praev. - mala om. $\mathbf{S} \|$ $328 \mathrm{Ne}$ te $\mathbf{O P}$ ? | impediat te $\mathbf{W}$ | a $\mathrm{om} . \mathbf{G} \| \mathbf{| |} 329 \mathrm{om}$. GU | petitus $\mathbf{W} \mathbf{w}$ : petitus dederis $\mathbf{V}$ | que pot'is maioris tê pr. $\mathbf{S} \mid$ quam] ab $\mathbf{S} \mid$ Nihil rerum maioris pretii ducas, quam petit is qui accipit Jer. Legendum erit tuorum || 330 facult. ut.? $\mathbf{O}$ | is om. SU | tribuit libenter V || 331 recedere Ser | persuadere $\mathbf{B}$ | sit $\mathbf{O G} \| \mathbf{| |} 333$ intellegas $\mathbf{S}$ | posterius non om. er || 334. $335 \mathrm{om}$. GU || 334 servare] habere w

328. II 22, 23: Ne vel ingratis beneficia dare cesses neve te a beneficiis homo malus impediat. I 6, 20: Ne te eo redigat vir ingratus, ut benefaciendo abstineas; omnis enim boni, quod ne per gratiarum quidem actionem refertur, merces tota apud deum asservatur.

329. II 22, 24: Si donum ab aliquo accepisti, stude, ut referas ei beneficium, quod tibi praestitit.

330. II 22, 26: Thesauros pretiosos possides, cum indigentibus bono animo das.

331. II 22, 27: Cuivis autem fratri, cui non persuasum est, persuade tu, ut ei persuadeatur amor dei, et eum qui nolit

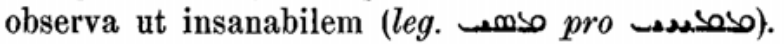

332. II 22, 28: Quia virtuti semper cum omni re pugnandum est eaque in omni vincit.

333. II 22, 30: Intellectum vitae possidere non potes nisi deum amas, et de unoquoque consilio valet hoc verbum.

334. Hic deest, sed respondere videtur, quod pro 325 pracbet 
335 (323) Membra corporis sarcina sunt his, qui eis non utuntur.

336 (324) Ministrare aliis melius est, quam ministrari ab aliis.

$337(325) *$ Quem deus non emittit ex corpore, non grauiter ferat.

338 (326) *Sententiam, quae misericordiam uetat, non solum tenere, sed audire refugite.

339 (327) Qui dat aliquid et inputat, contumeliam magis

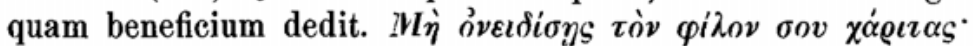

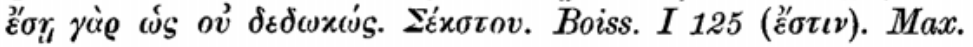
8 Rib. Ant. 1, 29. Exc. Vind. 45.

335 iis qui ewr | eis om. w || 336 Ministrare te aliis GU | ministrari tibi ab aliis $\mathbf{G U}$ : ab aliis ministrari er $\mid \mathbf{S}$ nil nisi: melius est non ministrare || 337. $338 \mathrm{om}$. GU || 337 e corpore $\mathbf{r}$ : a corpore $\mathbf{e}$ | in corpore retinet $\mathbf{S}$ || 338 tenere AWOPVBJSW: non tenere er | sed et WVBJw: sed etiam $\mathbf{S}$ | fugire ortum $e$ refugite $\mathbf{A}$ : refuge rell. | PseudoIsid. Sent. q. m. v. non solum tenere sed ( $v . l$ sed et) audire refugite. Calist. ep. 2, 20 (p. 143) \| 339 dat $\mathbf{S}$

II 22, 19: Ne cures multa, sed ut viro fideli sufficiant tibi pauca, fortasse etiam, quod post 344 legitur 23, 14: Modus omnibus tuis actionibus sit.

335. II 23, 1: Omne membrum, quod vitiosum est in corpore tuo et quo non uteris, corpori tuo onus est; ita omnes actiones, quae sine amore dei sunt, onus sunt animo. I, postquam sent. 398 . 399 praemisit 6 , 25: Manus, quae non laborant, onus sunt.

336. II $23,3: \mathrm{Tu}$ autem humilitatem ama; magis ama, ut aliis ministres, quam ut alii tibi ministrent. I 6, 26: et propterea melius est, homines sibi ipsi quam alios eis ministrare.

337. II 23, 4: Quicunque fidelis dei est, etiamsi corpore imperfectus sit, tibi gravis non sit.

338. II 23, 5: Ullum donum (inepte; f. l. . os scientia, quo reddi potuit $\gamma \nu\left({ }^{\prime} \mu \mu\right)$ ), quod benevolentiae et amoris dei non particeps est, non solum non possideas sed ne velis quidem audire; sin minus, peccatum tibi est.

339. II 23, 8: Qui alii cum exprobratione dat, haud inferior est eo, qui contumeliam facit. I 6, 27: $\mathrm{Si}$ donum das 
$340(328) *$ Qui tuetur pupillos, erit multorum filiorum secundum deum pater.

341 (329) Quicquid egeris causa gloriae, haec erit merces facti tui.

342 (330) Si quid dederis ita ut hominibus innotescat, non homini, sed propriae libidini praestitisti.

343 (331) Iracundiam multitudinis ne prouoces in te.

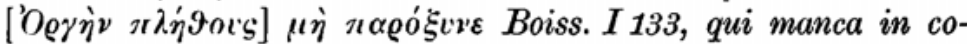
dice, verba bene supplevit.

344 (332) Disce, quod oportet fieri, ut beatus fias. (Cf. 56).

340 pusillos $\mathbf{U}$ | filiorum om. GU | secundum deum om. e || $\mathbf{3 4 1}$ om GU | haec WOVBJSw: hoc Per | facti tui om. S || 342 ita om. GU | innotescas? V || 343 non Sw | in te om. S || 344 bonus $\mathbf{B}^{2}$

cum exprobratione, contumeliam das. Supra exhibenda erat sententia Graeca, qualis discrte Sexto tribuitur. Magis tamen cum Rufino et Syro conveniunt, quae Libanius I 177 (allata

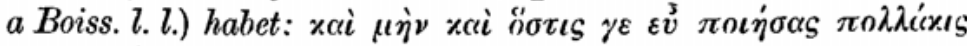

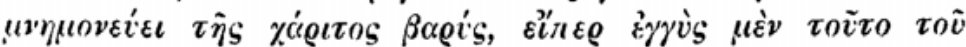

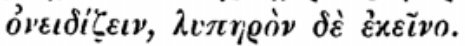

340. II 23, 9: Quicunque orborum saluti consulit, dux est multis filiis, eis qui deum amant. I 10, 10: Cum orbi tibi curae sunt, pater eris multorum et a deo propter opera tua bona diligeris.

341. II 23, 10: Quidquid homini vanae gloriae causa das, aut ut te remuncret aut ut tibi satisfaciat, penes deum nibili tibi est; si autem propter deum facis, a deo remuneraberis. I 6, 28: Et si beneficium tribuis laudis causa, tanquam mercenarius hoc facis.

, 342, I 6, 29: Et quidquid alicui das ut innotescas, non homini das, sed libidini tuae.

343. II 23, 13: Ne ira utaris immoderate.

344. II 23, 13: sed disce, quod te facere decet tanquam deum timentem. I 6, 30: sed disce, quod facere oportet eum, qui beatus esse vult, et quomodo facere oportet.

Inserit hic II sententiam 334 de qua vide quae supra dicta sunt, aliam autem $\mathrm{I}$ :

$344^{2}$. 7, 1: Da donum tuum occulte, ita ut uni tantum innotescas (aut innotescat), cum Mt. 6, 4 convenientem. 
$345(333)$ *Melius est fame mori, quam per incontinen-

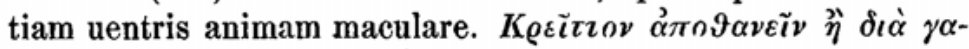

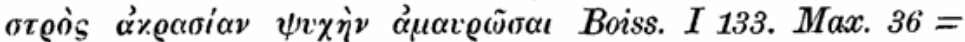

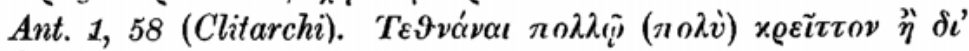

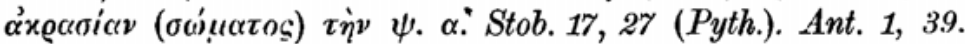
Flor. Mon. 21. Demoplb. 39. Porph. 35. Pyth. syr. 80.

346 (334) *Uestimentum putato esse animae corpus tuum, mundum igitur id serua. $C f .449$.

$347(335) * Q u a l i a$ gesserit studia anima corpus inhabitans, tales habebit testes in iudicio.

$348(336)$ *Inmundam animam inmundi daemones sibi uindicant.

349 (337) *Fidelem animam et bonam in uia dei mali daemones non inpediunt.

$350(338) *$ Uerbum de deo non omni homini committas.

345 fame om. $\mathbf{w}$ ? | perire pro mori solus $\mathbf{W}$ | incontinentiâ $\mathbf{G U}$ | veneris w || 346 conserva er \| 347 gesserit (gessit J) anima studia JUewr || 348 sibi daemones immundi er | sibi - 349 non om GU| 349 Fidels WOw | et bona in via $\mathbf{B}$ | in uidia dei $\mathbf{A} \|$ 349. 50 Fidelis anima et bona verbum de deo non omni homini committit(-ttas J)Je $\|$ 350 homini omni $\mathbf{G}$

345. II 23, 14: Homini multo melius est fame mori, quam mole libidinum corpus (leg. animum) obscurare I 7, 2: Melius est prae fame mori, quam per eibum multum animum voracitate obscurare $(v . l$. quam per voracitatem multam animum obscurare). I I cor @ós inter Graecos sola collectio Boissonadii habet, qua re eius cum Sexti cognatio proditur; an etiam fame, quod omnes tres interpretes legerunt, in ea servatum fuerit dici non potest, cum verba in codice Parisino ab initio usque ad syllabam - $\varepsilon \imath v$ manca sint.

346. II 23, 16: Scias corpus tuum vestimentum esse animi, propterea caute id conserva pecatorum expers.

347. II 23, 17: Quae animus agit in corpore, ea eum prosequuntur testimonia in indicium. Similia Agapet. c. 69.

348. II 23, 18: Animo immundo daemones immundi utuntur.

349. II 23, 19: Animo bono, qui deo fidem habet, daemones mali nequaquam nocent.

350. I 7, 3: Verbum de deo non coram quolibet loquere. 
351 (339) *Non est tutum audire de deo homines uanae

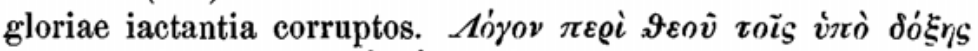

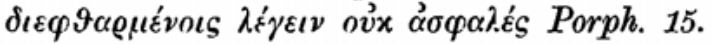

$352(340) *$ De deo etiam quae uera sunt dicere periculum

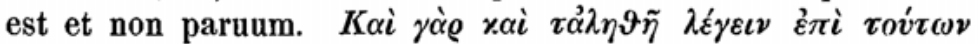

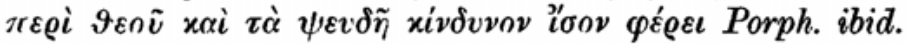

353 (341) *De deo nibil dicas, quod non didiceris a deo.

$354(341) * \mathrm{Ei}$, qui non credit esse deum, de deo nihil loquaris.

355 (342 Uerbum uerum ut deum honora.

356 (343) Si inmunis non es a flagitiosis operibus, de

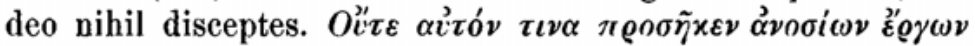

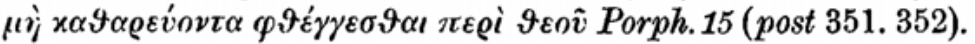

351 tunc Ue | de deo audire GU | iactantia corruptos] deditos G: deditos et iactantia corruptos U || 352 quae et sunt om. S | loqui Per: non loqui $\mathbf{J}$ : non dicere $\mathbf{S}$ | et om. JSUGe \| 353 De deo quod non audieris (didiceris $\mathbf{U}$ ) nihil dicas ab eo GU | a domino WJ || $354 \mathrm{Ei}$ AVS: Et WOPBJGUw: Vel ei qui er | non om. $\mathbf{P}$ | credit $\mathbf{J}$ : credis GUw | deum om. J | loquatur $\mathbf{B}|| 356$ dicas $\mathbf{S}$

351. I 7, 4: Non enim sine periculo est, homines, quorum mens corrupta est, narrationem de deo audire.

352-355. Desunt. Sed 355 in app. p. 28, 15 ita redditur: verbum verum deo simile est.

$355^{\mathrm{a}}$. Ante 356 II inserit 23, 30: Quandocunque enim de deo loqueris, ita loquere, ut de divinitate ineffabili.

356. II 23, 21: Ei autem, qui non mundus est a malis operibus, nihil de deo loquaris. I 7, 5: Cum mundus non es a malis facinoribus, de deo ne loquaris.

Sequntur apud II quatuor sententiae novae:

$356^{\mathrm{a}}$. 23, 22: In corde mundo habitat deus idque decet loqui de divinitate.

$356^{\text {b. }}$. II 23, 23: Quod eloqui os impotens est, id intellectus purus cognoscere potest, et quod intellectus tuus per spiritus revelationem assequitúr, auribus fidelium committas et praecipue eorum, qui deo digni sunt.

$356^{\mathrm{c}}$. III 23, 25: Concredita tibi sunt arcana maiestatis; fias dispensator (alludit ad 1 Cor. 4, 1) fidelis, qui thesauros domini custodit.

$356^{\text {d. }}$ II 23, 26: Qui autem arcanum maiestatis adversariis regis prodit, sibi periculum mortis affert. 
357 (344) Sermo uerus de deo sermo dei est.

358 (345) Si scis, quia acceptum habent de te quod diligas deum hi qui te audiunt, tunc eis loquere de deo.

359 (346) Opera caritatis dei praecedant abs te et tunc

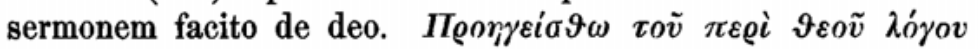
$\tau \grave{\alpha} \vartheta \varepsilon \circ \varphi \iota \lambda \tilde{\eta}$ हैe $\gamma \alpha$ Porph. 15.

360 (347) In multitudine dicere de deo non audeas. $\Sigma$ -

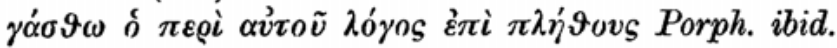

361 (348) Uerbum de deo parcius proferto magis quam de anima.

362 (348) Melius est animam perdere, quam uerbum uanum de deo proferre. Graece habuit Pyth. syr. 91.

363 (349) Uiri amantis deum corporis potestatem habet leo et tyrannus similiter.

357 de deo om. SGU | est dei VGU || 358 quia] quod w: qui W0 | certum PS | diligis $\mathbf{J}$ | ii qui $\mathbf{w}$ : qui Je || 359 opere $\mathbf{B}$ | praecedant WOPS (et $\mathbf{r}$ ?): procedant rell. | dei om. $\mathbf{A} \mid$ abs om. $\mathbf{S}$ | et om. $\mathbf{w} \|$ 360 om. GU | de deo loqui $\mathbf{S} \mid$ audias e || $\begin{array}{lll} & 361 & \text { om } \\ \mathbf{U} & \text { magis om. } \mathbf{J} \mid\end{array}$ magis - an. om. S| quam anima e $\| 362$ prodere WS: prodire $\mathbf{J} \|$ 363 pot. quidem hab.V : pot. tamen hab. J|corp. tantum, non autem animae pot. potest habere l. vel t. S | et om. $\mathbf{w} \mid$ et (voluit ut) leo similiter et tyrannus V I potestatem quidem habebis, non dominaberis vero animae; corporis quidem (habet $\mathbf{U}$ ) potestatem ut leo similiter et tyrannus $\mathbf{G U}$

357. II 26, 15: Verbum verum, quod dicit (melius fortasse |is lil? quod dicitur) de deo, ut verbum dei honora, quae conflata sunt e sent. 355 et 357. I 7, 6: Verum enim de deo effatum sicut effatum dei est.

358. I 7, 7: Dilige ergo deum et tunc loquaris de deo.

359. II 26, 16: Omnia opera tua bona, quae secundum deum sunt, praecedant verba tua. I 7, 8: Et praecedant mores tui a deo probati tua de deo verba.

360. I 7, 9: Verba, nec tamen apte, verti quidem possunt: Et cave valde ab eo, quod in animo tuo (est) per verbum dei, vel etiam aliter, sed aperte mutila sunt et fortasse pro

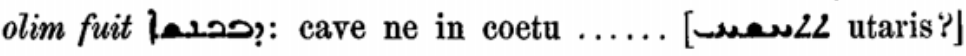
verbo de deo. Minus probabile est, verbar pertincre ad 361: quam de anima.

361-363. Desunt. 
364 (350) Cum tibi minatur tyrannus, cuius sis tunc maxime memor esto.

365 Uerbum de deo qui loquitur his, quibus non licet, proditor dei putandus est.

366 (351) Uerbum de deo reticere praestat magis quam

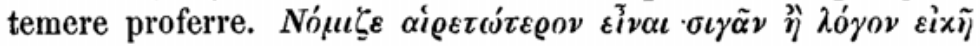

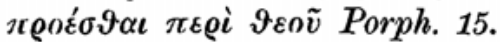

367 (352) Qui dicit de deo ea, quae non sunt, contra deum falsum loquitur.

368 Homo, qui nibil habet quod dicat de deo, uere desertus est a deo.

369 (353) Deum.non cognouit qui non colit.

370 (354) Non est uerum, quod deum colat, qui hominem laedit.

364 tibi om. GU | tibi tyr. min. B | tunc sis $\mathbf{G} \mid$ memor maxime? P. maxime om. C | cum max. c. sis memento $\mathbf{S} \| \mid 365$ om. VB (?) | qui loquitur de deo GU | iis er | his - 367 de deo om. w | est om. $\mathbf{S}$ || 366 de deo] dei $\mathbf{A} \mid$ magis om. $\mathbf{G} \mid$ plus praestat quam $\mathbf{U} \| 367$ de deo] contra deum GU | ea om. PQ | deum WOVGUw: eum PBSr | falsa U | Qui dicit de deo ea: quae non sunt contra eum; falsum non loyutur c| sunt. falsum de eo testimonium loquitur $\mathbf{S} \| 368$ quid OP | ab eo S || 369 coluit c

364. II 26, 17: Quando tibi vir tyrannus iratus est, maxime nitere in deo.

365. II 26, 18: Quicunque verbum, quod non decet, de deo loquitur, tanquam proditor habeatur. I 7, 9: Qui enim verbum dei ei cui non decet loquitur, tanquam proditor domini sui a te habeatur.

366. II 26, 19: Melius homini est tacere, quam temere de deo aliquid loqui.

367. Deest.

368. I 7, 11: Vir, qui nihil habet, quod de deo dicat, revera dei expers est.

369. I 7, 12: Non enim sine timore dei deum cognoscere licet.

370. II 26, 20: Nemo enim, qui hominibus nocet eosque affligit, deuin cognoscere potest. I 7, 12: neque deum quis timere potest sine misericordia erga dolores (leg.رla pro (متر) animo afflictorum. 
371 (355) Fundamentum et inițium est cultus dei, amare

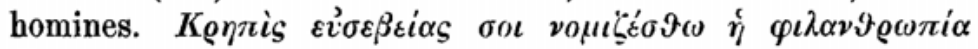
Porph. 35. Pyth. syr. 44.

372 (356) Qui hominum curam gerit et orat deum pro eis, iste uere a deo esse putandus est.

373 (357) Dei proprium est saluare quos dignos iudicat.

374 (358) Cultoris autem dei est orare deum pro salute hominum.

375 (359) Cum oranti tibi praestitum fuerit, quod poposcisti a deo, tunc tibi potestatem permissam a deo intellege.

376 (360) Dignus deo homo deus est in hominibus. " $A \xi \iota \circ$

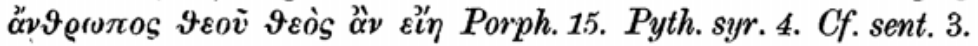

377 (361) Melius est non habere, quam multa habentem nemini inpertiri.

371 est et initium $\mathbf{G}$ | dei amare dei homines $\mathbf{r}$ || 372 vere] vero WB | a om. G| esse om. Uew || 373 est om. $\mathbf{S}$ | eos quos $\mathbf{w}$ | dignos om. U || 374 Ultoris $\mathbf{P}$ | autem om. S | deum om. GUe || 375 id quod W | poposceris S: poposei e | a deo in fin. om. GUe | datam S || 375 tunc -376 deo om. $\mathbf{w} \| 376$ et in $0 \mathbf{r} \mid$ in omnibus $\mathbf{S}$ || 377 non] nihil VGUer $\mid$ habendo $\mathbf{S} \mid$ impertire JU: impartire $\mathbf{w}$ : dare $\mathbf{S}$

371. II 26, 21: Quia initium timoris dei amor erga homines est.

372. II 26, 22: Quicunque enim homo continuo hominum curam gerit et pro eis precatur, in veritate dei (sed leg. oم:ije revera divinus) exsistit $I$ 7, 13: Qui hominum curam gerit et pro omnibus ut resipiscant precatur, is revera a te divinus putetur.

373. II 26, 23: Deus potestatem habet salvos reddendi quos vult.

374. II 26, 24: Hominis autem, qui deum timet, est deum precari, ut omnes homines salvos reddat.

375. II 26, 25: Quandocunque precatio, quam feceris, coram deo accepta est, scias et videas te donum a deo accepisse.

376. II 26, 27: Quicunque enim deo dignus est, deus est inter homines. Addit: Deus enim et filius dei eodem loco habentur atque spiritus sanctus, quo ad offensionem effugicndam significet, nominis divini de homine in his sententiis usurpationem nil indicare, nisi hominem spiritu divino imbutum esse.

377. II 26, 29: Melius est hominem nihil possidere, quam possidere aliquid, quod non cum multis communicet. 
$378(362)$ *Si non das egentilus cum possis, non accipis

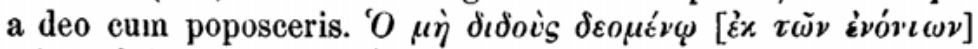

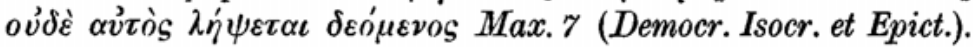

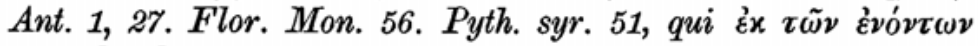
in verbis habent, quae praemittunt. Cf. 217.

$379(363)$ *Qui ex animo dat cibum indigenti, parum quidem est quod dat, sed magna fiet ei bonae uoluntatis retributio.

380 (364) *Deum qui putat esse et nihil ab eo curari, nihil differt ab eo, qui non crediderit esse deum.

381 (365) *Optime honorat deum ille qui mentem suam,

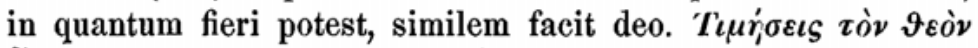

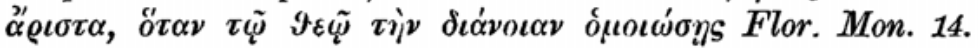
Anton. 1, 7. Porph. 16. Hierocl. ad c. aur. 1. p. 24 Needh. Pyth. syr. 79. Cf. 48.

$382(366){ }^{*}$ Deus quidem nequaquam indiget, laetatur autem

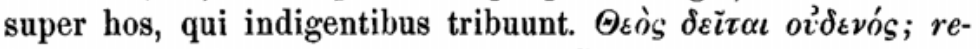
liqua Graece habuit Pyth. syr. 51. Cf. sent. 49.

378 egentibus] hominibus GU: egenti er | poscit r | accipies WJSUw quod $\mathbf{S}$ | poposceris Acr: poscis $G$ : petieris WPBVJSw : peteris 0 : non poteris U || 379 parum] pauperum A | fiet ei $\mathbf{A 0 c r}$ : ei fit $\mathbf{G}$ : fiet et $\mathbf{P}$ : fit et WB: sit et $\mathbf{w}$ : fiet $\mathbf{J}$ : fit $\mathbf{S}$ : fiet eius $\mathbf{U} \| 380 \mathrm{om}$. $\mathbf{G U}$ | creari $\mathbf{c}$ defert A : differri OP | ab om. WOB ! ab eo differt $\mathbf{e} \mid$ credederit $\mathbf{A}$ : credit rell. I| 381 honora A | ille om. BJUe: deum ille $\mathbf{A} \mid$ quantum PJ fieri om. GU | in q. praevalet $\mathbf{S}$ | s. deo facit SGer: facit deo s. $\mathbf{U}|| 382$ eget? $\mathbf{V}$ / hos A: iis $\mathbf{w}$ : his rell.

378. II 26, 30: Qui autem multis dare potest nec dat, imprimis indigentibus, neque accipit quod a deo petit.

$378^{\mathrm{a}}$. Addit II 27, 1: quia deus dator datoribus dona dat.

379. II 27, 2: Qui autem cibum pauperibus ex animo dat, eius donum inter homines exiguum est, voluntas autem a deo magni habetur.

380. 381: Desunt, nam quae eorum loco apud II leguntur, aliena putanda sunt:

$381^{\mathrm{a}}$. 27, 4: Deus enim non eius est qui verba solum loquitur, sed eius qui facit, quod lingua loquitur.

382. II 27, 5: Deus enim neminis indiget, laetatur autem eis qui indigentibus dant. Ex hac et $s .49$ conflata sunt, quae habet Agapetus c. 63, male apud Max. 9. Anton. 2, 1 Philoni ascripta: 
383 (367) Fidelium pauca sint uerba, opera autem multa. 384 (368) *Fidelis, qui libenter habet doceri, operarius efficitur veritatis.

385 (369) Praepara et apta te ad tribulationes et laetus

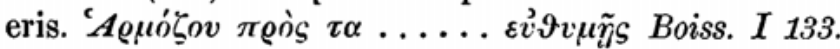

386 (370) *Neminem laedens nullum timebis.

387 (371) Tyrannus beatitudinem non auferet.

383 De vera lectione collato Syro dubium esse nequit. paucas (vel paueas) inter uerba W: pauea sint uerba $\mathbf{P}$ : paucas inter uerba $\mathbf{0}$ : paucas (vel paueas) int' uerba $\mathbf{V}$ : int' verba paucas $\mathbf{S}$ : Inter fidelium verba paveas operare autem multa $\mathbf{w}$ : pauca sunt verba,BGe: autem (at J) sunt verba JU: pauca sint verba $\mathbf{r}$ / operae autem multa B: $\mathbf{0}$. a. plurima $\mathbf{O U}$ : autem om. $\mathbf{S}$ | Fidelis ex initio sequentis sententiae huic adiungunt JSe || 384 libenter habet doceri A: libenter doceri 0: libenter docetur P: vult doceri V: libenter docet WBJGUew: hbenter vult doceri $\mathbf{r}$ | operarios AG: operius $\mathbf{0}$ : operosius $\mathbf{P}$ : operator $\mathbf{S}$ | efficietur VBer | veritas P || 385 lenis e: securus et laetus S || 386 tenebis $\mathbf{G} \|$ 387 aufert JGUewr

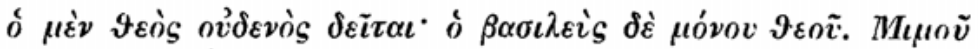

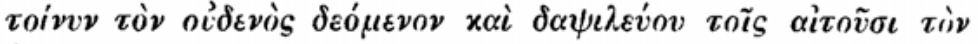

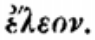

383. II 27, 6: A fidelibus autem hoc requiritur, ut verba eorum sint pauca et opera multa.

384 . II 27, 8: Sapiens vero, qui doctrinam amat, operarius fidelis deo est.

385. Graecam sententiam in codice mutilatam huc trahere non dubito; $\tau \alpha$... cum accentu careat, non $\tau \dot{\alpha} s$, sed fortasse $\tau \alpha-$ $\lambda \alpha \iota \pi \omega \rho i \alpha \nu$ vult; reliqua ni fallor erant ö $\pi \omega \varsigma$ iv $\alpha \dot{v} i \tilde{y}$ vel similia. II 27, 9: Certamen ini contra haec (vocabulum haec non habet quo referatur) omnia, ut fias fidelis et apud deum honoratus. Propius accedit II 25, 11: Quicunque animus subactus non est calamitatibus, per calamitates demissus fit.

386. II 27, 10: Quod homini noxium est nunquam facias, et a nemine timebis.

387. II 27,11 : Quia si omnia, quae possides, abs te aufert mundus, timorem dei a te auferre non potest. Facile forct Syrum cum Rufino concordem reddere, si pro is mundus

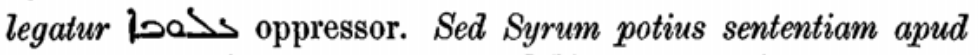
Boiss. p. 133 inter 385 et 399 exhibitam expressisse puto: $\pi \varepsilon-$

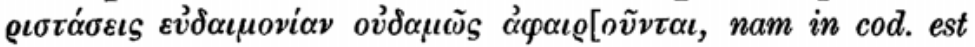
lacuna] et Rufinum aliud quid legisse. 
388 (372) Quod fieri necesse est, uoluntarie facito.

389 (373) Quod non oportet fieri, nullo modo facias.

390 (374) Omnem magis causam refer ad deum.

391 (375) Nemo sapiens uir est, qui deorsum respicit in terram et mensas.

$392(376){ }^{*}$ Philosophi libertas non sit in nomine, sed in anima.

- 393. (377) Mentiri in uita decipere est et decipi.

394 (378) Quid sit deus agnosce et quid in te quod agnoscit deum.

388 facito] sacrificato $\mathbf{r} \| 389$ n. m. facito $\mathbf{U}$ : non facias $\mathbf{S} \| 390$ causam magis $\mathbf{w}|| 391.392 \mathrm{om}$. GU | 391 et in mensas B: in mensas P: Immensa Jer, qui cum sequente sententia 392 iungunt, quam er mutato nomine in homine, vesane legunt: Immensa philosophi libertas non sit in homine sed in anima || 393 in vita om. S || 394 Quid -

388. II 27, 12: Quodeunque scis fieri debere, voluntarie facias. I 7, 15: Quod igitur agi oportet, cum bona voluntate fac.

389. II 27, 13: et quod fieri non decet, omni modo operam da ut non facias. I 7, 16: quod autem agi non oportet, nulla ratione agas.

$389^{\mathrm{a}}$. Addit II 27, 14: In omni re confitere hominibus, te exiguum et debilem esse, cum amore dei plenus es.

390. II 27, 15: Quidquid boni facis, scias et videas, causam huius boni quod facis deum solum esse, retributorem. Sic: sed ultimum vocabulum apparet male additum esse. Magis, $\mu \hat{\alpha} \lambda \lambda_{o \nu}$, apud Rufinum explicari quidem potest, sed num apte dubito.

391. II 27, 17: Quicunque sapiens est, non semper respicit quae in terra sunt et quae ad mensas (pluralem praebet optimus cod. $H$ ) solum pertinent, sed res spiritales et ea, quae ad mundum futurum pertinent, respicit. I 7, 16: Non est sapiens, cuius mens sollicita est de terra et de cibis et (leg. nec) mentem sinceram et cibum perfectorum assequi potest.

392. II 27, 19: Sapiens autem non e verbis suis cognoscitur sapiens esse, sed ex operibus.

393. II 27, 20: Quantum potes te a mendacio custodi, ne tu decipiaris aliosque tecum decipias.

394. II 27, 21: Cognosce, quis sit deus, et disce quis in te dei intellegentiam habeat. 
395 (379) Dei opus bonum homo bonus.

396 (380) Sine deo sunt hi, pro quibus uerbum dei maledicitur.

397 (381) Animam mors non perdit, sed mala uita. $\Psi v$ -

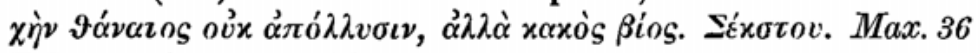
Rib. 53. Ant. 1, 58 (Philist.).

398 (382) Si scis, a quo factus es, et temetipsum agnoscis.

399 (383) Non est secundum deum uiuere nisi pudice et

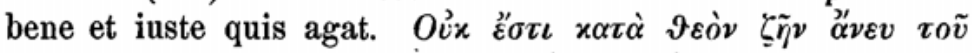

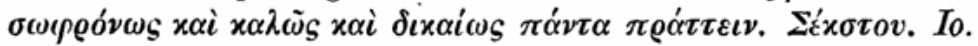

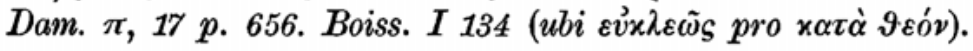

et om. S | quod agn. deus SG | Signum interrogationis addit $\mathbf{W}$, cui respondetur verbis Dei opus bonum \| 395 homo bonns VGUr cum Syro: om. WOPBJSew | 394. 395 Je et $\mathbf{w}$ ita habent: Mentiri in vita decipere est: et mentiri (decipi w) quid sit deus agnoscit (agnoscat w). Et quid est in te quod agnoscit deum dei opus bonum || 396 ii w | hi qui verbum dei maledicunt GU \| 397 vita mala WOVBJSU | tollit e"|

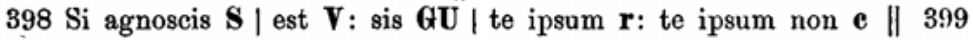
et bene om. OS: et om. W/ quispiam $\mathbf{W}$ : si quis Je

395. II 27, 22: Dei opus optimum est homo bonus, et boni hominis opus (est) quod deo placet.

396. II 27, 23: Daemones (من ita antiquissimus codex; reliqui '̈o! miseri quod si vera Syri lectio est explicanda videtur e mendo codicis Graeci $\alpha^{\prime} \vartheta \lambda \iota n \iota$ pro $\alpha^{\alpha} \vartheta \varepsilon o \iota$ praebentis) autem sunt omnes, propter quos nomini dei maledicitur.

397. II 27, 24: Animum mors non interficit, sed interficiunt eum opera mala, quae facit; et vivit et punitur. Sed eandem sententiam iam loco sent. 324 ita exhibuerat 22, 17: Mors vero corporalis corpus interficit et scelus atque peccata animum interficiunt; non enim ulla est necessitas, quae mentem fidelis tentet.

398. II 27, 26: Prout veri cognitionem adipisceris, te ipsum cognoscere potes, si vis. I (cum sequente inter 328 et 335) 6, 22: Ut scias ad quod creatus es, nosce te ipsum et stude ut omnes homines superes sinceritate mentis tuae. ( $C f$. app. II, 2 p. 30, 7.)

399. II 27, 27: Nemo autem coram deo vivere et eius vo-

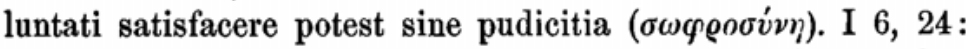
Nam deo placere non potes sine pudicitia et probitate et bonis operibus humanitatis. 
400 (384) Hominum infidelium uita obprobrium est. 'H $H$ ov

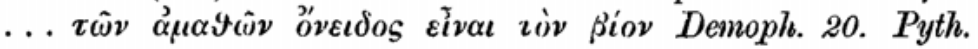
syr. 33.

$401 \mathrm{Ne}$ te praetereat et malo ingenio uerba dei committas.

402 (385) *Animam de terra fides eleuat ad deum. IVóvi;

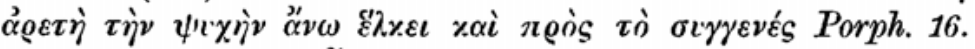
Flor. Mon. 14 (om. $\left.{ }_{\alpha}^{\prime \prime} \nu \omega\right)$. Ant. 1, \%. Pyth. syr. 79.

403 (386) Animae sapientis magnitudinem non reperies, sicut nec dei quidem.

404 (387) *Quaecunque dat mundus, nemo firmiter tenet.

$405(388)$ *Quaecunque dat deus, nullus auferre potest.

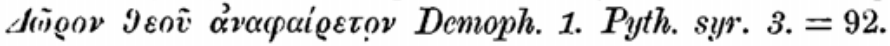

406 (389) Diuina sapientia est scientia.

401 om 0? SGU: Ne to praetereat et om Je | et reliqui omnes WPBrw et $\mathbf{V}$, in quo punctis infra positis improbatur atque supra scriptum est ut | ne committas er || 402 fidelis $\mathbf{W}$ | allevat $\mathbf{G}$ || $403 \mathrm{om}$. GU | ne dei WBW | quidem om. Je || $404 \mathrm{om}$. SU | dat deus haec homo G || 405 nemo Ger | auferet J: aufert e || 406 om. (GU | scientia] sapientia B | vere (vera $\mathbf{J}$ ) est scientia Jer

400. II 27, 28: Opera auten eorum, qui non sunt fideles, opprobrium sunt doctorum eorum. Ultimam vocem e sent. 174 male ascivisse videtur.

401. II 27, 29: Nunquam verbum dei liominem fallaciter doceas. Latinis verbis medelam non habco.

402. II 27, 30: Animum fidelem fides elevat ad deum. I 7, 18: Veri enim cognitio animum de terra tollit et trahit (legendum est l quam vox lu trahit in lins corpus, ut antiquissimi duo codices praebent, corrupta est, posteriores librarii ineptam sententian emendare voluerunt; alius igitur scripsit et e corpore super coelum statuit, alii et evolat autem iungi possunt diversarum. lectionum partes lis i) مكمعثا.

403. II 28, 1: Magnitudinem animi fidelis assequi non potes, sicut nee magnitudinem dei assequi potes.

404. Deest. 405. II 28, 2: Quidquid deus tibi dat, homo auferre non potest.

406. II 28, 3: Sapientia enim dei est scientia quae de deo $(\pi \varrho \dot{s} \vartheta \varepsilon \dot{\nu} \nu)$ est. Latina manca aut transposita videntur; 
407 (390) Inmundae animae ne audeas loqui experimentum de deo. $=451$.

408 (391) Uiri periculum in operibus primo et sic in

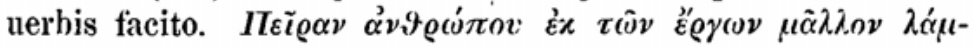

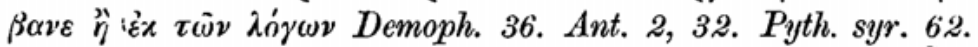
409 (392) Aures tuas non omnibus committas. T'á $\omega^{3} \tau \dot{\alpha}$

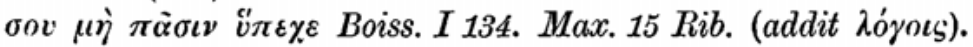
Ant. $1,48$.

410 (393) Opinari quidem de deo facile ab omnibus est, dicere autem ueritatem de deo soli iusto permittendum est.

411 (394) Non eruciet anima tua corpns tuum neque animam tuam crticiet libido corperis.

412 (395) Insuesce te ipsum corpori quidem praebere, quae sua sunt, caste, et animae, quae sua sunt, pie.

407 Immunda anima WOBSw $\mid$ experimentum om. $\mathbf{0}$ | a deo $\mathbf{S}$ : non audes loqui de verbo dei $\boldsymbol{G}$ : non audeas loqui deo $\mathbf{U}$ || 408-12 om. GU || 408 Supra periculnm in $\mathbf{P}$ scriptum est $\cdot \mathrm{i} \cdot$ probationem, in $\mathbf{S}$ sententiae assutum | primo om. $\mathbf{c}$ | et sic] sicut $\mathbf{r}$ || 410 Operari omnes, sed $\mathbf{P}$ optime emendavit superscripto in et $\mathbf{S}$ praebet opinari $\mid \mathrm{ab}$ omnibus WOPVBJw: omnibus Ser | est om. $\mathbf{w}$ | veritatem om. Ver | permittendum| donatum $\mathbf{S} \| 411$ tua om. $\mathbf{S}$ | tuam om. $\mathbf{S}$ | secundum cruciet om. PSer | c. tui J \| 412 quidem om. PS: quidem corpori ewr| prius sua om. $\mathbf{B} \mid$ animae quoque $\mathbf{w}$

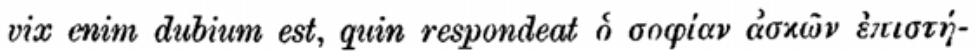

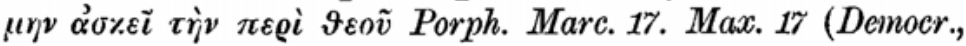
Isocr. et Epict. sec. Ribitt.) Pyth. syr. 72.

\section{Deest.}

408. II 28, 4: Tenta primum opera hominis et tune verbis eius fidem habeas. I 7, 20: Ante verba hominis ex operibus eius tentamen sume.

409. II 28,4 : Ne auris tua cuique sermoni fidem habeat. I 7, 21: Ne cuique confidas aurem tuam.

410. II 28, 5: Aliquem autem de deo sciscitari facile est; vere autem loqui de deo solius prophetae et iusti est. I 7, 21: Veritatem (dele in, ab optimis testrbus reprobatum) dicere iusti tantum est.

411. II $28,7:$ Ne crucies corpus tuum libidine anini neve animum crucies libidinibus corporis.

412. II 28, 8: Omne quod corporis est, da corpori caste 
$413(396)$ *Pasce animam tuam uerbo dei, corpus uero simplicibus cibis.

$414(397) *$ In illis insuesce gaudere animam tuam, in quibus recte gaudet.

$415(397)$ *Anima quae in rebus nullis gaudet indigna est apud deum.

$416(398)$ *Sapientis anima deo aptatur a deo. '

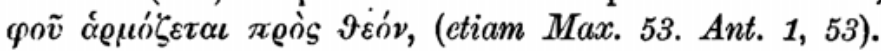

413 de verbo $\boldsymbol{G}$ | et corpus Jer | simplicioribus SG || 414 gandere animam tuam AWVJSw: animam tuam gaudere OBGU: gaudens animam tuam $\mathbf{P}$ : animam tuam gaudens $\mathbf{r}$ : animam tuam $\mathbf{c}$ gaudet deus $\mathbf{A}$ : gaudeat Jer $\| 415$ in rebus nullis $\mathbf{A}$ : in illis rebus WOPB, sed $\mathbf{P}$ supra scripto vel ul: in nullis rebus saeculi $\mathbf{V}$ : nullis rebus $\mathbf{G U}$ : iniquis rebus Jer: in vanis rebus $\mathbf{S}$ : in praesentibus rebus $\mathbf{w}$ / digna $\mathbf{V}$ : immunda S || 416. 417 om. Se, 417 J, 416 post 417 ponunt omnes praeter A, quem confirmat Porphyrius || 416 anima deo aptatur a deo AW0PB : anima aptatur deo $\mathbf{V}$ : anima deo aptatur $\mathbf{J}$ : anima aptatur a deo $\mathbf{w r}$ : anima coaptatur (a $\mathbf{G}$ ) deo $\mathbf{G} \mathbf{U}$

et verum dei timorem da animo. I 7, 22: Assuesce corpori caste quod ei convenit tribuere et animo rursus fideliter quod ei debetur.

413. II 23, 28: Pasce animum tuum verbis divinis et corpus tuum simplicibus cibis. I 7, 23: Animum vero tuum pasce verbo dei et corpus quoque tuum simplicibus cibis. Confer "

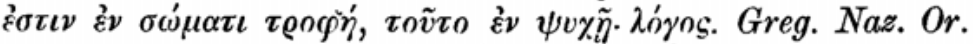
XVII p. 266. Georg. p. 68. 'Verbum dei' habes in sententia

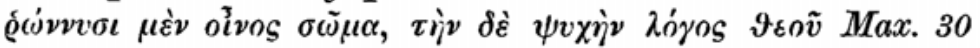
(Evagrii). Nil. 17. Io. Damasc. o, 6. Longius absunt, quae Porphyrius c. 25 ait, mentem animae quasi corpori suo e lege divina alimoniam supportare.

414. II 23, 29: Vive moderate, sicut deum timentem decet. I 7, 24: Consuefac animum tuum gaudere de quibus gaudere licet, et dolere de quibus merito doleas.

415. II 23, 30: Animus, cui paucum aliquid sufficit, a deo honoratus est. I 7, 26: Animus enim, qui de minimis gaudet et vilibus affligitur, a deo contemnitur.

416. II 24, 1: Animus iusti desponsatus est deo. I 7, 27 : Animus iusti ante deum semper obversatur. Apud Rufinum, si veterum codicum in tractando vocum exitu -um morem respi- 
$417(398) *$ Sapientis anima semper intuetur deum. $\dot{\alpha} \varepsilon \grave{\imath}$ $\vartheta \varepsilon \grave{\nu} \nu$ o@ư,

418 (398) *Sapientis anima semper est cum deo. $\sigma \dot{v} \nu \varepsilon \sigma \tau \iota \nu$

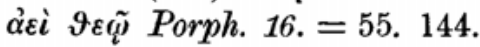

419 (399) Cor diligentis deum in manu dei stabilitum est.

420 (400) Animae ascensus ad deum per uerbum dei est.

421 (401) *Sapiens sequitur deum et deus animam sapientis.

422 (402) *Gaudet rex super hos quos regit, gaudet ergo

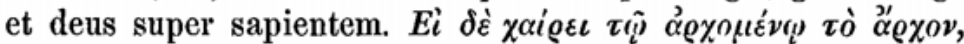

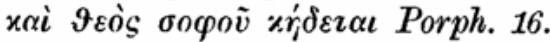

$423(402)$ *Inseparabilis est ab his, quos regit, ille qui regit, ita ergo et deus ab anima sapientis, quem tuctur et regit.

424 (403) *Dispensatur a deo uir sapiens et ideirco be-

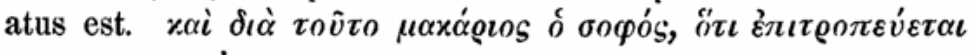

417 intuetur A: audit rell. omnes || 418 est om. B || 419 diligens GU || 420 dei verbum Gewr | est om. S || 421 continet in se $\mathbf{S}$ | deum] verbum $\boldsymbol{G} \| \mathbf{\|} 22$ hos A : is $\mathbf{W}$ : his rell. | ergo om. SU | et dens AWOVBSGUw: deus PJer | sapientem AWOPVJSGewr: sapiente BU|| 423 est AWSUwr: om. Je: est et (?) OPVBG | quem AWOBJw: quam PVGer | ita - regit om. SU || 424 est om. e

cis, facile restitues ad deum; postquam a deo scriptum erat, addendum videbatur deo.

417. II 24, 1: Animus iusti continenter videt deum.

417ª Addit II 24, 2: Animus iusti perpetuo paratus est voluntatem dei facere.

418. II 24, 2: Animus iusti semper cum deo habitat. I 7, 27: et est apud deum perseveranter.

419. II 24, 3: Animus eius, qui deum amat, in dei manu positus est.

420. II 24, 4: Via ascensus animi ad deum per verbum dei est.

421. II 24, 5: Iustus semper deo adhaeret eoque gaudet. Ultimam vocem ascitam esse apparet e sent. 422 quae interiit.

423. I 7, 28: Et sicut moderator ab operariis animum non avertit, sic etiam deus moderatur iustum et curat, quae eius sunt.

424. I 7, 29: et propterea beatus est, quia deus eius curam gerit. 


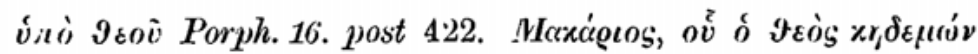
èotıे Boiss. I 134.

425 (404) *Anima sapientis probatur a deo per corpus.

$426(404) *$ Non lingua sapientis probabilis est apud deum,

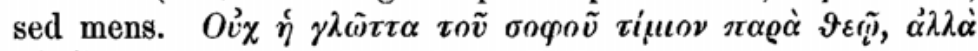

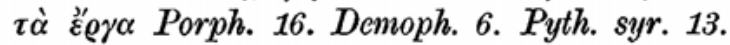

$427(405)$ *Sapiens uir etiam cum tacet honorat deum.

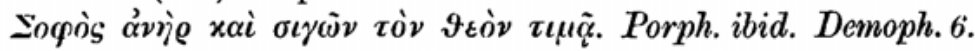
Sexto ascribunt Max. 20 Rib. Ant.1,73. Io. Dam. $\gamma 14$ p. 424

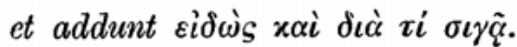

428 (406) *Uentrem et ea, quae sub aluo sunt, qui non continet non est fidelis.

429 (406) *Homo incontinens polluit deum.

425. 426 om. GU. Apud WOPVBJS ita sonant: Anima sapientis probabilis est apud deum sed et mens (eius addit $\mathbf{J}$ ). Eadem, sed apud deum est praebent cr, $\mathbf{W}$ autem etiam sed et mens om. \| 427 vir om. S | etiam om. GU: et Ser \| 428 Venerem $\mathbf{r}$ : ventrem et gulam $\mathbf{S}$ | non continens ewr | nec est fidelis e: nec fidelis $\mathbf{r}$

425. II 24, 6: Animus iusti tentatur a deo per corpus, ut praestans fiat. I 7, 30: Animus iusti per corpus suum a deo exploratur, non ut innotescat ei, sed ut nobis se manifestet.

426. II 24, 6: Non lingua sapientis a deo magni aestimatur, sed eius intellectus. I 8, 1: Non sermo sapientis deo acceptus est, sed proba mens.

427. II 24, 7: quia homo sapiens quanquam tacens a deo honoratur. I 8, 2: Vir enim sapiens quanquam silens deum honorat.

428. II 24,.8: Quicunque animum suum a cupiditate ventris non coercet, non est perfectus. I 8, 3: Qui libidines corporis non vincit, revera fidelis non est.

429. II 24, 9: Quicunque non coercet animi impetum, animum sibi a deo datum immundum reddit. Respondere puto Porphyrii verba sententiae 427 proxime iuncta Marc. 16: ${ }^{\prime \prime} \nu$ -

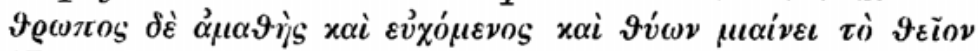
(Demoph. 7. Pyth. syr. 14); in Sexto Graeco male exciderant

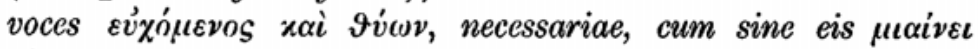

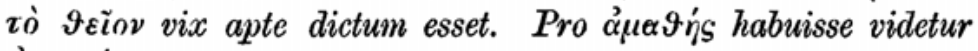

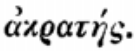


$430(407) *$ Hominem scientia dei paucis uerbis uti facit.

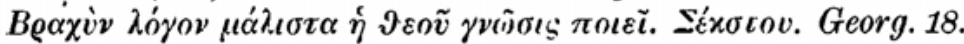
Porph. 20 (om. $\mu \alpha \dot{\lambda} \iota \sigma \tau \alpha)$ ).

$431(408) *$ Multis uerbis uti de deo ignorantia dei facit.

432 (409) Homo qui deum scit non multa ambitione utitur.

433 (410) Qui electus dei est, facit quidem omnia secundum deum, esse autem se ipse non iactat electum.

434 (411) *Fidelis homo semper in metu est, usquequo eat ad deum.

435 (412) *Homo, qui secundo satiatur cibo nec dormit nocte, concubitum non effugit, sed ne apud deum quidem dignus est.

430 om. GU | uti (ut e) facit paucis verbis Je \| 431 dei om. J dei facit] est e || 432 dei cognitionem habet? P || 433 ipsum OVJewr: om. U || 434 Fidelis autem h. GU || 435-7 om. GU || 435 sccumdo] in hoc saeculo $\mathbf{S} \mid$ nec dormit $\mathbf{A V}$ : non dormit rell. | nocte $\mathbf{A J}$ : noctu rell. | concubitum non $\mathbf{A}$ : nec concubitum Vr: nec cubitum BJS: nec cubitum non $\mathbf{O P}$ (hic tamen ita ut non supra scriptum sit): nec cubitu non W: nec cubito nec $\mathbf{w}$ : nec cibum $\mathbf{e}$ / sed ne Aw: sed nec rell.| dignus est apud deum Jer

430. II 24, 11: Omnis homo, in quo cognitio divina est, eo cognoscitur, quod non multa loquitur, sed multa quae co-

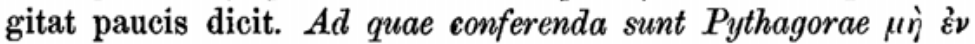

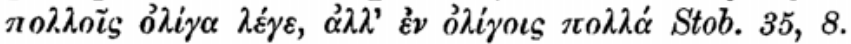

431. II 24, 13: Hoc enim homo cognitionem non habere cognoscitur: e multis verbis.

432. II, 24 14: Quicunque enim deum cognoscit, non edit plura verba quam opera. De I vid. 433.

432. Addit II 24, 15: Animum superbum humiliat deus, animum humilem elevat deus. Argumentum in libris sacris frequens nusquam tamen eisdem verbis expressum. Cf. etiam $284^{\mathrm{a}}$.

433. II 24, 16: Electus dei quidquid facit mensura et pondere facit secundum voluntatem dei nec animum suum elevat, se electum esse professus. Apud I sententiae 132 et 433 propter lacunam conflatae esse videntur 8,4 : Nam qui deum cognovit .... omnia secundum dei voluntatem agit.

434. II 24, 17: Apud omnem fidelem deum timentem vere manet timor dei et probe agit, usque dum diebus suis completis abeat ad deum.

435. II 24, 20: Quicunque bis die edit et satiatur, is vero, 
436 (415) *Sapientem fatum non facit; gratia enim dei fato non subiacet; alioquin et deus.

437 (413) *Grauiter accipit libidines corporis uir fidelis.

438 (414) *Fidelis uir continentia paseitur.

439 (416) Agnosce, qui sunt filii dei in creaturis eius, et honora unumquemque pro merito post deum.

440 (417) Nihil proprium dei ducas quod malum est.

441 (418) Fidelis anima casta et sapiens propheta ueritatis dei est.

436 fatuum $\mathbf{\Lambda}$ | Ut supra factum est, interpungit A; verba alioquin et deus cum sent. 437 coniungunt reliqui, unde viri fidelis scripsit V, vir fidelis omiserunt WOPBJSewr | accepit S || 438 Sed praemittit S | homo U || 439 om. GU | sint $\mathbf{w}$ | un. pro mer. hon. P || 440 ducas WPBJSw: deducas 0: dicas VGUer || 441 et casta PV | virtutis c | etiamsi solus dormiat, vexationis et pugnae expers esse nequit, sed nec dignus est apud deum. Latina vix sana sunt atque imprimis offendit negatio verbo dormiendi adiecta, quam neque

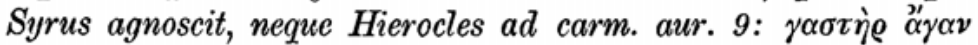

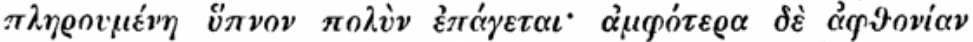

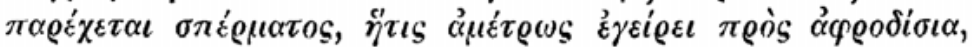
quae ex eodem atque Sexti sententiam fonte fluxisse probabile est.

436. II 24, 22: Vir fidelis non observat sortem et nativitatem. Haec e Sexti qualia Rufinus exhibet verbis effici po-

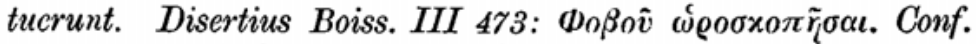

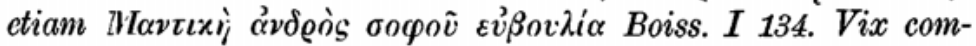

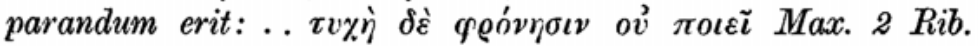

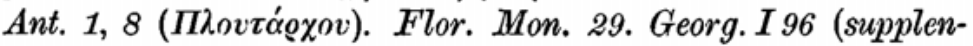
dus e reliquis).

437. II 24, 22: Virum sapientem si impugnant cupiditates corporis, facile eas exstinguit.

438. II 24, 23: Vir fidelis semper coercendo corpori operam dat.

439. II 24, 24: Decet te opus et creationem dei nosse et unumquemque post deum pro merito honorare.

440. II 24, 25: Numquam in cogitatione tua admittas mala homini a deo esse, sed aut a peccatis aut a cupiditatibus homo tentatur. In eis quae addidit respexit Iac. 1, 14:

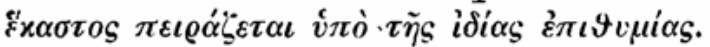

441. II 24, 27: Mundus et sapiens animus propheta est veritatis dei et semper verum loquitur. 
442 (419) Non amabis deum, si non habueris in te aliquid simile dei.

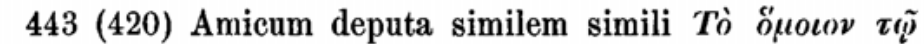

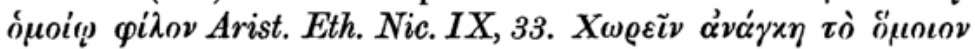

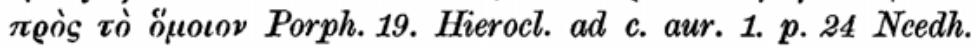
Pyth. syr. 19. deum.

444 (421) Tantummodo non diligis deum, non ibis ad

445 (422) Consuesce te ipsum semper respicere ad deum.

446 (423) Intuendo deum uidebis eum.

447 (424) *Uidens deum facies mentem tuam talem, qualis est deus.

$448(425)$ *Excole, quod intra te est, nec ei ex libidine corporis contumeliam facias.

dei est om. GU \|| 442 deum GU: dominum deum WOPVSrw: dominum deum tuum BJe sed dominum nullo modo ad hunc scriptorem pertinet| nisi Jer | in te om. Je \| 443 In primo vocabulo desinit 0 | animam male V || 444 Sic cum WP scribendum videtur. Cum tantummodo, quod est dummodo, difficultatem crearet, in alia abierunt reliqui: si tantummodo $\mathbf{V}$ : in quantum $\mathbf{G U}$ : quoad $\mathbf{w}$ : vel cum praecedenti sententia iunxerunt: ... simili tantummodo. $\mathrm{Si}$ non diligis $\mathrm{Br}$ : simili tantummodo (tamen modo e). Non diligis deum, si non ibis Je | In quantum non diligis deum (deum om. $\mathbf{G}$ ), in tantum non ibis ad ipsum (eum U) GU || 445 C. t. ipsum. semper respice $\mathbf{W} \mid$ ad deum om. G i| 446 eum WVBS: deum PJGer || 447 fac GU | tuam om. w | talem om. PVS || $448 \mathrm{om}$.

442. II 24, 29: Deum diligere non potes, nisi in te aliquid simile dei est.

443. II 24, 30: Quodeunque enim ei simile est, ex eo est eumque imitatur et diligit. Sententiam Syriace accurate redditam invenies in Euseb. Theoph. III, 39 (p. 2, 16 Lee). Ceterum nihil obstat, quominus etiam apud Latinos olin simile fuisse censeatur.

444. II 25, 1: Si deum non amas, ad deum ire non potes.

445. II 25, 2: Propterea assuefac te ipsum semper ad deum respicere et ad eum conversus sit oculus mentis tuae (leg. $e$ cod. $H$ بم (ب)

446. II $25,4: \mathrm{Si}$ enim mentem ad deum convertis, per ipsam mentem tuam videbis deum.

447. Dèst.

448. II 25, 6: Cohibe quod in mente tua habitat nec ei contumeliam affer per cupiditatem corporis. 
449 ( +26$)$ Incontaminatum custodi corpus tuum, tanquam si indumentum id acceperis a deo, sicut et uestimentum corporis tui inmaculatum seruare studes. Cf. 346 .

450 (427) *Sapientis mens speculum est dei.

$451 *$ Non mundae autem animae nihil audeas dicere de deo. $=407$.

(4U | que intra te est $\mathbf{A}$ | te om. WJW | nec ei] nec te $\mathbf{A} \mid$ ex om. $\mathbf{P S} \mid$ 449 indumentum id $\mathbf{A W V B G U W}$ : mundum PS : indumentum Jer | sicut et AWPSGU: sicut VB: et sicut $\mathbf{J r}$ : et sic $\mathbf{c}$ : sic et $\mathbf{w} \mid$ corporis tui om. BJe | studes AWPBSGU: stude VJewr || 45̆1 Non mundae A: Immundae WPVBJSGUewr | autem om. $\mathbf{S} \mid$ animae om. $\mathbf{G} \mid$ de deo dicere $\mathbf{J G U e r} \mid$ nihil dicas de deo $\mathbf{S}$

449. II 25, 6: Custodi mi fili corpus tuum sine maculis, ne (codd. omnes ut, sed negatio saltem deesse non potest, nisi plura mutanda sint) cupiditate accendatur (f. l. $V_{j}>\mathbf{S} \Delta$ se damnum faciat) mens in te habitans, quia corpus tuum vestimentum animi a deo habetur; si igitur vestes tuas, quae sunt vestimentum corporis, studes ut. sine squalore custodias, eodem modo decet te custodire vestimentum animi.

450. II 25, 10: Nam in sapientis cogitatione deus habitat. 451. II 25, 10: Et multa cura est iusto de honore eius, qui in eo habitat. 